\title{
PALEOCLIMA Y PAISAJE DEL FINAL DEL CUATERNARIO EN CANTABRIA: LOS PEQUEÑOS MAMÍFEROS DE LA CUEVA DEL MIRÓN (RAMALES DE LA VICTORIA)
}

\author{
Gloria CUENCA-BESCÓS ${ }^{1-2}$, Lawrence G. \\ STRAUS $S^{2-3}$, Manuel R. GONZÁLEZ MORALES $S^{3} y$ \\ Juan C. GARCÍA PIMIENTA ${ }^{1}$ \\ ${ }^{1}$ Area de Paleontología, Departamento de Ciencias de la Tierra, Universidad \\ de Zaragoza, 50009 Zaragoza, España \\ ${ }^{2}$ Department of Anthropology, MSCO1-1040, University of New Mexico, Al- \\ buquerque, NM 87131-0001, USA \\ ${ }^{3}$ Instituto Internacional de Investigaciones Prehistóricas, Universidad de Can- \\ tabria, Avda. de los Castros, 39005 Santander, España
}

Cuenca-Bescós, G., Strauss, L. G., González Morales, M. R. \& García Pimienta, J. C. 2008. Paleoclima y paisaje del final del cuaternario en Cantabria: Los Pequeños mamíferos de la cueva del Mirón (Ramales de la Victoria). [Paleoclimate and landscape at the late quaternary in cantabria: the small mammals from El Mirón cave (Ramales de la Victoria).] Revista Española de Paleontología, 23 (1), 91-126. ISSN 0213-6937.

\begin{abstract}
The great diversity of small mammals in the Upper Pleistocene and Holocene deposits of El Mirón Cave, with a total of 26 species belonging to 6 mammalian orders (Erinaceomorpha, Soricomorpha, Chiroptera, Carnivora, Rodentia and Lagomorpha), makes this an important sequence for the study of the development of small mammal associations during the Pleistocene-Holocene transition; what it allows us to know the evolution of the climate and the landscape in the Cantabrian Region. At the end of the Quaternary, the last extinction of Pleistocene microfauna is registered, like the one of the vole Pliomys lenki, related to present day Dinaromys, the Balkan Snow (or Martino's vole). Also local extinction are documented like the disappearance from Spain of cold-climate mammals characteristic of the steppe-tundra ecozones of Northern Europe and Siberia namely Microtus oeconomus and M. gregalis. The extinctions can be explained by the climatic changes that occurred at the end of the Quaternary, without discarding the competition with species inmigrants, of similar ecology. Late in the Holocene, human activity -especially deforestation and cereal agriculture- is reflected at El Mirón in a decline in species diversity among the small mammals.
\end{abstract}

Key Words: El Mirón cave, Biostratigraphy, Paleoclimate, small mammals, Quaternary, Cantabrian Region, Spain.

\section{RESUMEN}

La gran diversidad en pequeños mamíferos del Pleistoceno superior y Holoceno de la Cueva del Mirón, con un total de 26 especies pertenecientes a seis órdenes de mamíferos (Erinaceomorpha, Soricomorpha, Chiroptera, Carnivora, Rodentia y Lagomorpha) hace de la secuencia del Mirón un importante documento sobre la distribución de las asociaciones de pequeños mamíferos durante la transición Pleistoceno-Holoceno; lo que nos permite conocer la evolución del clima y del paisaje en la Región Cantábrica. Al final del Cuaternario se registra la última extinción de microfauna Pleistocena, como la del topillo Pliomys lenki, relacionado con el actual Dinaromys, el topillo nival de los Balcanes o de Martino. También se documentan extinciones locales, como la desaparición del territorio español de los mamíferos característicos de las estepas del Norte de Europa y Siberia, como Microtus oeconomus y M. gregalis. Estas extinciones se pueden explicar por los cambios climáticos ocurridos al final del Cuaternario, sin descartar la competencia con especies inmigrantes, de ecología similar. El final del Holoceno, la actividad humana, sobre todo la deforestación y la cultura cerealística, se refleja también en la disminución de la diversidad específica de los pequeños mamíferos.

Palabras clave: Cueva del Mirón, Bioestratigrafía, Paleoclima, pequeños mamíferos, Cuaternario, Cornisa Cantábrica, España. 


\section{LOS PEQUEÑOS MAMÍFEROS DEL PLEISTOCENO SUPERIOR Y HOLOCENO DE ESPAÑA}

El estudio sistemático de las faunas de pequeños mamíferos de yacimientos arqueo-paleontológicos del Pleistoceno superior español comenzó con los trabajos de Altuna $(1970,1972,1981,1986)$ seguidos en la década de los 80 y hasta mediados de los 90 por los trabajos de Alcalde Gurt (1982), Alcalde \& Brunet (1985), Gil \& Sesé (1985), Pemán $(1985,1987,1988,1990 a, b)$, Alcalde $(1986,1988)$, Agustí et al. (1987), Gil \& Lanchares (1988), Álvarez et al. (1992), Guillem (1995a, b, 1999), y ya en la última década, son algo más numerosos los trabajos sobre pequeños mamíferos con el objeto de reconstruir la evolución de los ecosistemas terrestres del Pleistoceno superior y los cambios ambientales de esta reciente etapa de la historia terrestre (Pokines, 1998, 2000; Guillén, 2001; Sesé, 2005; López-García, 2006; Zubeldia Garmendia, 2006; LópezGarcía \& Morales Hidalgo, 2007). Sin embargo, los estudios sobre los pequeños mamíferos son escasos en los yacimientos arqueológicos de edad Holocena y ni siquiera son mencionados como componentes de los niveles excavados, ya que pasan desapercibidos. Como una excepción podemos mencionar los trabajos de Morales Muñíz (1986), Pemán (1987, 1988, 1990 a, b), Laplana Conesa \& Cuenca-Bescós (1995), Morales Muñiz et al. (1997), Morales \& Rodríguez (1997), Riquelme Cantal \& Morales Muñiz (1997) y Altuna et al. (2004).

En general los pequeños mamíferos del Pleistoceno español han sido analizados por su interés en bioestratigrafía (Cuenca-Bescós et al., 1995, 1997, 1999; Oms et al., 2000; Ruiz Bustos, 2004). Recientemente, el refinamiento e incremento de técnicas de datación radiométrica, hace que los pequeños mamíferos sean útiles además por su valor como indicadores paleoecológicos y paleoclimáticos (Sesé \& Sevilla, 1996; López Antoñanzas \& Cuenca-Bescós, 2002; Cuenca-Bescós et al., 2005; Sesé, 2005).

Los pequeños mamíferos son parte elemental de los ecosistemas terrestres: forman parte de la dieta de numerosos predadores como mamíferos carnívoros (hurones, martas, comadrejas, zorros, lobos), aves de presa (búhos, lechuzas, mochuelos, ratoneros, halcones) e incluso de otros pequeños animales no especializados en la caza de vertebrados como el lirón careto, ratas, córvidos, alcaudones (Chaline, 1972; Ruiz \& Camacho, 1973; Nores, 1979; Moreno \& Rey, 1980; Arrizabalaga i Blanch et al., 1986; Hernández et al., 1987; Andrews, 1990; Vargas \& Palomo, 1990; Gosálbez, 1993; Eastham, 1995; Pokines, 1998; Frafjord, 2003; Carvalho \& Gomes, 2004; Hernández, 2005; observaciones personales). Los pequeños mamíferos son los herbívoros (roedores y lagomorfos) y predadores (insectívoros, murciélagos, pequeños carnívoros) más pequeños en la cadena trófica de los vertebrados. Su pequeño tamaño los excluye como componentes de la dieta huma- na (al menos durante el Pleistoceno superior y Holoceno inicial) por lo que su presencia en los yacimientos se debe a los factores ya mencionados de acumulación, como el de la predación. Hay que resaltar que, aunque los casos de comensalismo son raros durante el Pleistoceno y gran parte del Holoceno, Pokines (1998) propone una posible relación entre la presencia del erizo (Erinaceus Linnaeus, 1758), o la de los lirones (gris: Myoxus Brisson, 1762, y careto: Eliomys Wagner, 1840) y las ocupaciones humanas. Así mismo, Eastham (1995) plantea el aprovechamiento de la piel del topo común europeo (Talpa europaea Linnaeus, 1758) por parte de los humanos; para explicar la notable cantidad de restos de este pequeño mamífero en los niveles Magdalenienses de Dufaure (acantilados de Pastou, con el notable conjunto de yacimientos Magdalenienses de Dufaure, Duruthy Les Pastous) en Les Landes, Gascogne, no lejos de la frontera Franco-Española. Al final del Holoceno y sobre todo en la actualidad, se conoce bien la estrecha relación de comensalismo con los humanos, de los ratones y las ratas (Mus Linnaeus, 1758, y Rattus Fischer, 1803; ver Morales \& Rodríguez, 1997). Por otra parte hay especies que se propagan con la expansión del cultivo de cereales o árboles frutales como el ratón espiguero, Micromys minutus (Pallas, 1771) (Morales Muñiz \& Rodríguez, 1997; Palomo \& Gisbert, 2002; Nores, 2003).

Es interesante resaltar que el cultivo o el uso de cereales en el Neolítico del Mirón (Peña-Chocarro et al., 2005) no parece haber influido en la entrada de estas faunas comensales en la Cornisa Cantábrica, ya que lo hacen mucho más tarde, al final del Holoceno; sin haberse encontrado hasta ahora en los niveles estudiados del Mirón. La mayor parte de los restos de pequeños mamíferos acumulados en cuevas como la del Mirón son el resultado de la actividad biológica de las aves de presa, con algún aporte ocasional por parte de mamíferos carnívoros y ocasionales visitantes/habitantes (Andrews, 1990).

En este trabajo se presenta por primera vez un estudio completo de los pequeños mamíferos de la secuencia estratigráfica del Mirón y se analiza la evolución de la fauna durante la transición Pleistoceno-Holoceno, la extinción de fauna Pleistocena y la aparición de la fauna moderna en Cantabria. Este análisis permite conocer la evolución del clima y del paisaje en la Cornisa Cantábrica al final del Cuaternario.

\section{LA CUEVA DEL MIRÓN}

El Mirón se encuentra en las proximidades de Ramales de la Victoria, en el valle del Río Asón, en Cantabria (Figs. 1 y 2). Es una cavidad cuya boca tiene cerca de 20 metros de altura, con un desarrollo total de $130 \mathrm{~m}$. Forma parte del sistema cárstico del Monte Pando, donde se desarrollan otras cuevas como La Cullalvera, La Luz, El Horno, La Haza, y Covalanas, éstas dos últimas bien cono- 


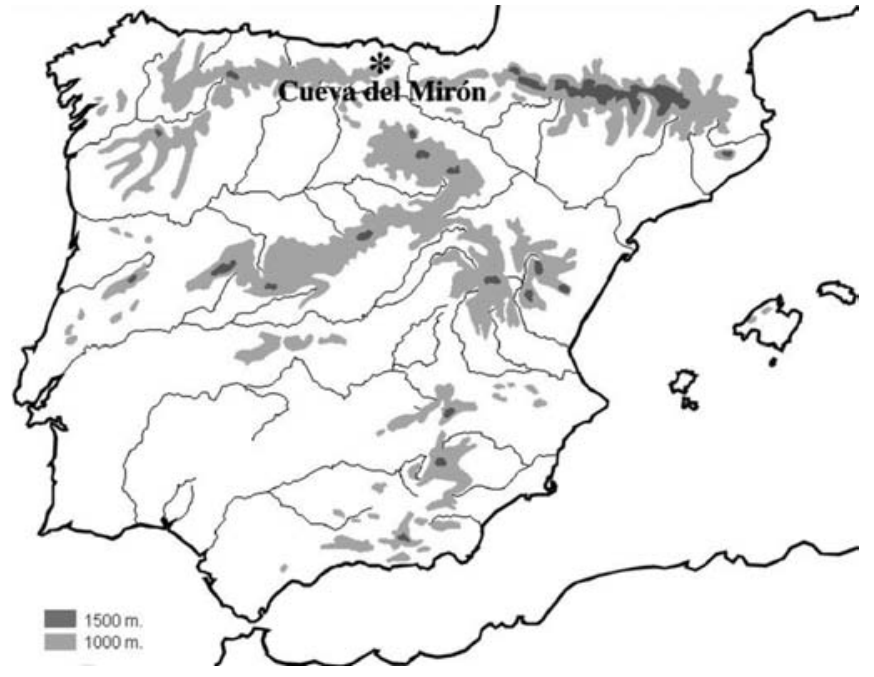

Figura 1. Situación Geográfica del yacimiento Cuaternario de la Cueva del Mirón Geographic situation of the El Mirón Cave Quaternary site.

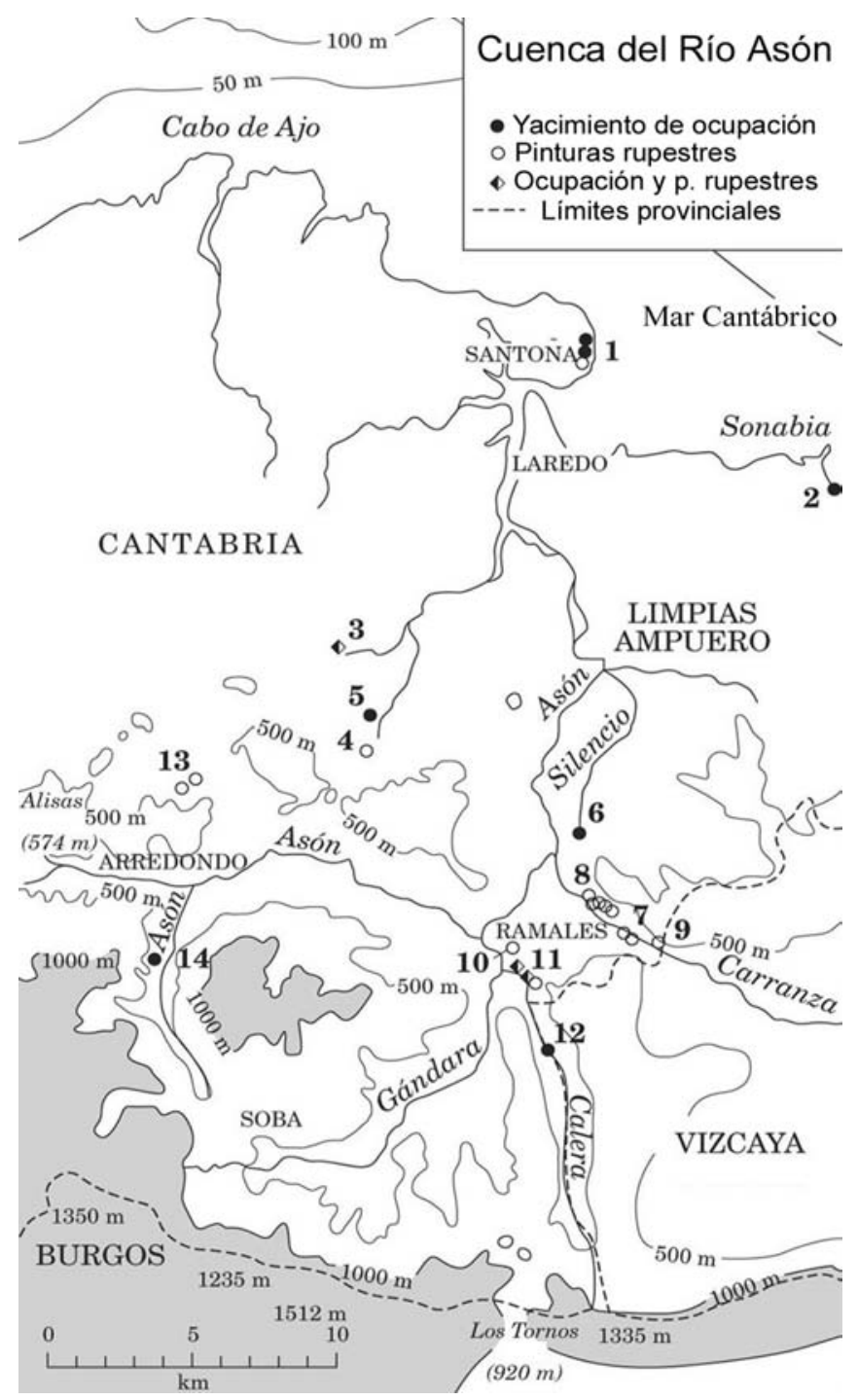

cidas por sus pinturas rupestres de "perfilados con puntos rojos” (León García, 1998; Straus et al., 2006). La Cueva del Mirón se encuentra a $260 \mathrm{~m}$ por encima del actual nivel del mar, a $3^{\circ} 27^{\prime}$ al Oeste de Grenwich y $43^{\circ} 16^{\prime}$ Norte (Figs. 1 y 2). La entrada, estaba orientada hacia poniente y relativamente cerca del litoral (unos $27 \mathrm{~km}$ de la paleolínea de costa) durante el último máximo glacial (LGM: $17 \mathrm{Ka}$ antes del presente, $\mathrm{BP}$ en el resto del texto). Su posición, montana pero cercana al mar, su orientación y su amplitud, pudieron ser las causas de que la cueva del Mirón haya sido utilizada con cierta continuidad por los seres humanos (el hombre de neandertal primero y el hombre moderno después), al menos desde el Musteriense (40 Ka BP) (Straus \& González Morales, 2001a, b, 2003; Altuna et al., 2004; Straus et al., 2006).

La cueva fue descubierta a comienzos del siglo $\mathrm{XX}$, aunque su excavación sistemática comenzó en 1996. Desde entonces, un equipo de unas 15-25 personas excava, durante los dos meses de la campaña de campo, en cuatro zonas distintas (Fig. 3): la Cabaña, la Trinchera, el Corral del gran

Figura 2. La Cuenca Hidrográfica del Río Asón y principales yacimientos Cuaternarios (Paleolíticos y Mesolíticos), así como otros detalles geográficos y políticos. 1: La Fragua, El Perro, San Carlos; 2: La Trecha; 3: El Otero; 4: Cobrantes; 5: La Chora; 6: El Valle; 7: Sotarriza, Covanegra; 8: Morro, Pondra, Arco A, B y C; 9: Venta de la Perra, Polvorín; 10: Cullalvera; 11: Ramales yacimiento de exterior, La Haza, El Mirón, Covalanas, El Horno; 12: Tarrerón; 13: Los Emboscados, Patatal, Cubio Redondo; 14: Cubera. La línea discontínua indica el límite entre las provincias de Burgos, Vizcaya y Cantabria. Este límite marca también el límite geográfico entre la Meseta y la Cordillera Cantábrica, que se comunican por el estrecho paso de Los Tormos, el Camino Real (mapa dibujado por R. Stauber, del original de L.G. Straus).

River Asón Drainage Basin and main Quaternary (Paleolithic and Mesolithic) sites, as well as other political and geographic details. 1: La Fragua, El Perro, San Carlos; 2: La Trecha; 3: El Otero; 4: Cobrantes; 5: La Chora; 6: El Valle; 7: Sotarriza, Covanegra; 8: Morro, Pondra, Arco A, B \& C; 9: Venta de la Perra, Polvorín; 10: Cullalvera; 11: Ramales open-air site, La Haza, El Mirón, Covalanas, El Horno; 12: Tarrerón; 13: Los Emboscados, Patatal, Cubio Redondo; 14: Cubera. Legend: Black circles, habitation site; blawhite circless, cave art sitess; black and white losanges, cave art and habitation sites. The striped line in the South marks the limit between Burgos, Vizcaya and Cantabria. This limit is also the geographic boundary between the Upland Spain and the Cantabrian Mountains, that are communicated by the Los Tormos Pass, The Real Road. (drawing of $R$. Stauber, after an original of L.G. Straus). 


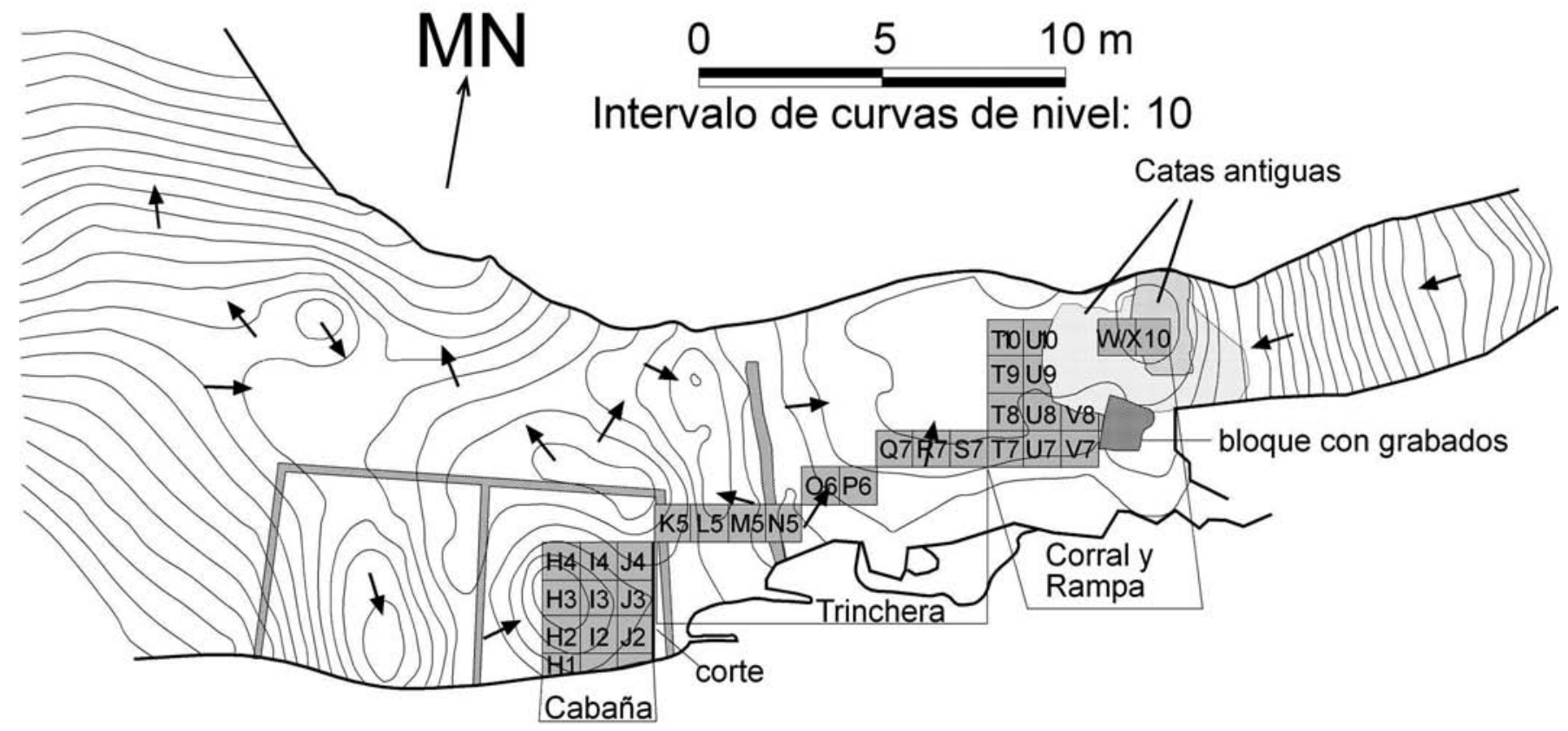

Figura 3. Plano de la Cueva del Mirón. Las zonas de excavación son, de Oeste a Este: Cabaña (Cuadros H-K); Trinchera (Cuadros L-P); Corral (Cuadros Q-V) y el Sondeo de la Rampa (cuadros W-X) que comunica el Vestíbulo de la Cueva del Mirón con la zona hipogea, oscura.

Map of the El Mirón site. The excavation areas are, from West to East: Cabin or Outer Vestibule or Vestibule Front (Squares H-K); Trench or Mid-vestibule Trench (Squares L-P); Vestibule Rear (Squares Q-V), and the Sondage of the Footslope (Squares $W-X)$ that communicates the Vestibule of El Mirón with the dark zone of the Cave.

vestíbulo soleado y la Rampa, una pendiente erosional que sube hacia la parte interior y oscura de la caverna (Straus \& González Morales, 2001a, b, y en este trabajo).

\section{ESTRATIGRAFÍA Y DISTRIBUCIÓN DE LA MICROFAUNA EN LA SECUENCIA DEL MIRÓN}

Courty \& Valverdú (2001) y Straus et al. (2001) describen en detalle ciertos aspectos sedimentológicos y estratigráficos de la Cueva del Mirón que completan la descripción que damos en este trabajo. Se sigue una descripción algo distinta de la utilizada tradicionalmente en geología pues empezamos describiendo los niveles desde el techo hasta la base de la excavación, la cual no coincide con la de la sección; ya que no se ha alcanzado el sustrato rocoso en ninguna de las zonas (Figs. 3 a 7). La prospección geofísica que hizo el Dr. Jaime Clapés nos indica que la base se encuentra a $9 \mathrm{~m}$ de profundidad (a partir de la superficie inicial de la cueva, en el Corral). Hasta ahora se ha exca- vado una profundidad que varía de 3 a $5 \mathrm{~m}$. La potencia de los niveles es variable (Figs. 4 a 7). El número de muestras para el análisis de los micromamíferos tomado en cada nivel responde más a la estrategia de la excavación arqueológica que a un muestreo paleontológico. Por ejemplo, en los niveles en los que los materiales arqueológicos son muy abundantes, hay un número de muestras mayor puesto que la excavación se divide en un número mayor de "tallas" o tramos arqueológicos (spits). Debido a su gran superficie, la excavación, se ha dividido en cuatro zonas (Fig. 3). La distribución estratigráfica de las asociaciones de pequeños mamíferos se muestra en las Tablas 1 y 2. Para facilitar la lectura, la cronología de los Niveles Culturales del final del Cuaternario se sintetiza en la Tabla 3.

Zona de la Cabaña (Outer or Vestibule Front). Cuadros $\mathrm{H}-\mathrm{K} / 1-4$

Descripción de los niveles, 1 a 17, de techo a base (Fig. 4):

Nivel 1: Nivel gris de relleno final de cueva, compuesto por materia orgánica procedente de la cabaña reciente y bloques de la caliza de las paredes y techo de la cueva. Nivel de ocupación actual.

Tabla 1. Listado de los pequeños mamíferos actuales de la Cornisa Cantábrica (izquierda), y del registro fósil del Cuaternario del Mirón (derecha). La columna central es la de los autores de los taxones.

In the first column is the inventory of the extant small mammals of the Cantabrian Region, Spain. In the third column are these in the fossil record of the Quaternary of El Mirón. The central column gives the name of the author of each taxa. 


\begin{tabular}{|c|c|c|}
\hline Cuaternario El Mirón & Autor & Actual Región Cántabra \\
\hline Orden Erinaceomorpha & Gregory, 1910 & \\
\hline Familia Erinaceidae & Fischer von Waldheim, 1817 & \\
\hline Erinaceus europaeus & Linnaeus, 1758 & Erinaceus europaeus \\
\hline Orden Soricomorpha & Gregory, 1910 & \\
\hline Familia Soricidae & Fischer von Waldheim, 1817 & \\
\hline \multirow[t]{2}{*}{ Crocidura russula } & (Hermann, 1780) & Crocidura russula \\
\hline & (Pallas, 1811) & Crocidura suaveolens \\
\hline Neomys fodiens & (Pennant, 1771) & Neomys fodiens \\
\hline Sorex minutus & Linnaeus, 1766 & Sorex minutus \\
\hline \multicolumn{3}{|l|}{ Sorex gr. coronatus-araneus } \\
\hline & Linnaeus, 1758 & Sorex araneus \\
\hline & Millet, 1828 & Sorex coronatus \\
\hline & (Savi, 1822) & Suncus etruscus \\
\hline Familia Talpidae & Fischer von Waldheim, 1817 & \\
\hline Galemys pyrenaicus & (E. geoffroy, 1811) & Galemys pyrenaicus \\
\hline Talpa europaea & Linnaeus, 1758 & Talpa europaea \\
\hline Orden Chiroptera & Blumenbach, 1779 & \\
\hline \multicolumn{3}{|l|}{ Quiroptera indet. } \\
\hline Familia Vespertilionidae & Gray, 1821 & \\
\hline \multirow[t]{13}{*}{ Myotis } & Kaup, 1829 & Myotis \\
\hline & (Borkhausen, 1797) & Myotis myotis \\
\hline & (Kuhl, 1817) & Myotis bechsteinii \\
\hline & (E. Geoffroy, 1806) & Myotis emarginatus \\
\hline & (Tomes, 1857) & Myotis blythii \\
\hline & (Kuhl, 1817) & Myotis nattereri \\
\hline & (Schreber, 1774) & Barbastella barbastellus \\
\hline & (Schreber, 1774) & Eptesicus serotinus \\
\hline & (Kuhl, 1817) & Nyctalus leisleri \\
\hline & (Schreber, 1774) & Nyctalus noctula \\
\hline & (Keyserling y Blasius, 1839) & Pipistrellus nathusii \\
\hline & (Linnaeus, 1758) & Plecotus auritus \\
\hline & (Fischer, 1829) & Plecotus austriacus \\
\hline \multirow[t]{4}{*}{ Familia Rhinolophidae } & Gray, 1825 & \\
\hline & Blasius, 1853 & Rhinolophus euryale \\
\hline & (Schreber, 1774) & Rhinolophus ferrumequinum \\
\hline & (Bechstein, 1800) & Rhinolophus hipposideros \\
\hline \multirow[t]{2}{*}{ Familia Molossidae } & Gervais, 1856 & \\
\hline & (Rafinesque, 1814) & Tadarida teniotis \\
\hline Familia Miniopteridae & Dobson, 1875 & \\
\hline Miniopterus schereibersii & (Kuhl, 1817) & Miniopterus schereibersii \\
\hline Orden Carnivora & Bowdich, 1779 & \\
\hline Familia Mustelidae & Fischer von Waldheim, 1817 & \\
\hline Mustela nivalis & Linnaeus, 1766 & Mustela nivalis \\
\hline Orden Rodentia & Griffith, 1827 & \\
\hline Familia Sciuridae & Hemprich, 1820 & \\
\hline Sciurus vulgaris & Linnaeus, 1758 & Sciurus vulgaris \\
\hline Familia Muridae & Illiger, 1815 & \\
\hline Subfamilia Arvicolinae & Gray, 1821 & \\
\hline Arvicola terrestris & Linnaeus, 1758 & Arvicola terrestris cantabrae \\
\hline Arvicola sapidus & Miller, 1908 & Arvicola sapidus \\
\hline Chionomys nivalis & (Martins, 1842) & Chionomys nivalis \\
\hline Clethrionomys glareolus & (Schreber, 1780) & Clethrionomys glareolus \\
\hline Microtus agrestis & (Linnaeus, 1761) & Microtus agrestis \\
\hline Microtus arvalis & \begin{tabular}{|l} 
(Pallas, 1778) \\
\end{tabular} & Microtus arvalis asturianus \\
\hline Microtus oeconomus & (Pallas, 1776) & \\
\hline \multirow[t]{2}{*}{ Microtus gregalis } & Pallas, 1779 & \\
\hline & & Terricola pyrenaicus-gerbei \\
\hline Terricola lusitanicus & (Gerbe, 1879) & Terricola lusitanicus \\
\hline Pliomys lenki & Heller, 1930 & \\
\hline Subfamilia Murinae & Illiger, 1815 & \\
\hline \multicolumn{3}{|c|}{ Apodemus sylvaticus-flavicollis } \\
\hline & (Melchior, 1834) & Apodemus flavicollis \\
\hline & (Linnaeus, 1758) & Apodemus sylvaticus \\
\hline & (Pallas, 1771) & Micromys minutus \\
\hline & Linnaeus, 1758 & Mus musculus \\
\hline & Lataste, 1883 & Mus spretus \\
\hline & (Berkenhout, 1769) & Rattus norvegicus \\
\hline & (Linnaeus, 1758) & Rattus rattus \\
\hline Familia Myoxidae & Gray, 1821 & \\
\hline Eliomys quercinus & (Linnaeus, 1766) & Eliomys quercinus \\
\hline Myoxus glis & (Linnaeus, 1766) & Myoxus glis \\
\hline Orden Lagomorpha & Brandt, 1855 & \\
\hline \multirow[t]{3}{*}{ Familia Leporidae } & Fischer von Waldheim, 1817 & \\
\hline & Pallas, 1778 & Lepus europaeus \\
\hline & (Linnaeus, 1758) & Oryctolagus cuniculus \\
\hline
\end{tabular}




\begin{tabular}{|c|c|c|c|c|c|c|c|c|c|c|c|c|c|c|c|c|c|c|c|c|c|c|c|c|c|c|c|c|}
\hline 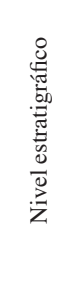 & 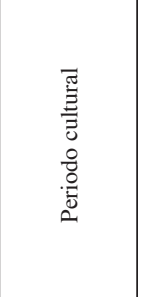 & 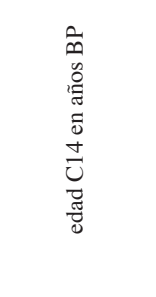 & 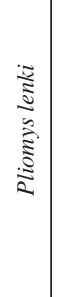 & 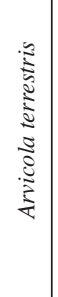 & 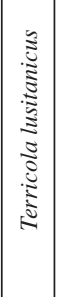 & 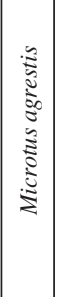 & 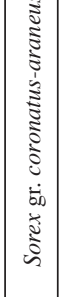 & 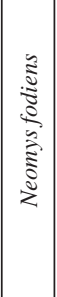 & 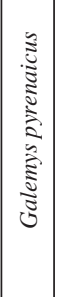 & 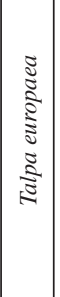 & 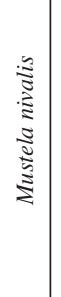 & 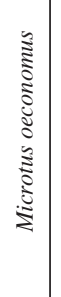 & 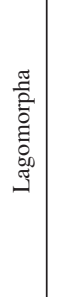 & 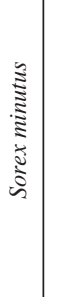 & 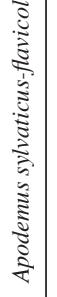 & 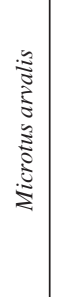 & 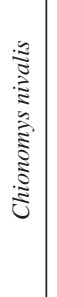 & 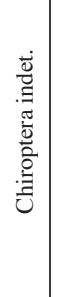 & 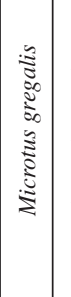 & 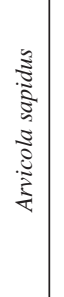 & 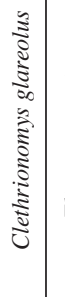 & 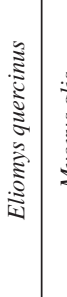 & 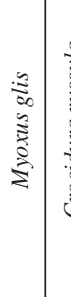 & 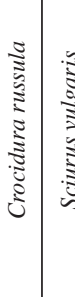 & | & 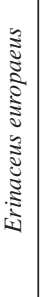 & 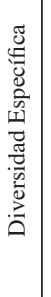 & \\
\hline 1 & \multirow{6}{*}{ 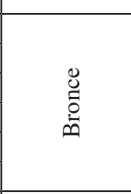 } & $100-1.400$ & & $\mathrm{x}$ & & & & & & $\mathrm{x}$ & & & & & & & & & & & & & & & & & 2 & $\frac{2}{2}$ \\
\hline 2 & & $00-1.401$ & & $\mathrm{x}$ & & & & & & & & & $\mathrm{X}$ & & & & & & & & & & & & & & 2 & \\
\hline $2+3$ & & & & $\mathrm{X}$ & & & & & & $\mathrm{x}$ & & \begin{tabular}{l|l}
$x$ \\
\end{tabular} & & & & & & & & & & & & & & & 3 & $\frac{3}{33}$ \\
\hline 3 & & 3.700 & & $\mathrm{x}$ & $\mathrm{X}$ & $\mathrm{x}$ & $\mathrm{X}$ & $\mathrm{X}$ & & $\mathrm{x}$ & & $\mathrm{X}$ & & & $\mathrm{X}$ & $\mathrm{X}$ & $\mathrm{X}$ & $\mathrm{X}$ & & & $X$ & & \begin{tabular}{l|l}
$\mathrm{X}$ & $\mathrm{x}$ \\
\end{tabular} & $\mathrm{X}$ & & & 14 & $\frac{33}{1}$ \\
\hline$\frac{3.2}{3.3}$ & & & & $\mathrm{x} \mid$ & & & & & & & & & & & $\frac{X}{x}$ & & & & & & & & & & & & $\frac{1}{2}$ & $\frac{1}{3}$ \\
\hline 3.4 & & & & $\begin{array}{l}\mathrm{A} \\
\mathrm{X}\end{array}$ & 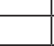 & & & 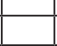 & & $x$ & & - & & & $X$ & & & & & & 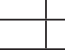 & & & & & & 2 & 2 \\
\hline 3.5 & & & & & & & & & & & & & & & $x$ & & & & & & $x$ & & & & & & \begin{tabular}{l|l}
2 \\
7
\end{tabular} & $\begin{array}{ll}1 \\
19\end{array}$ \\
\hline 4 & & & & $\mathrm{x}$ & & & $\mathrm{X}$ & & & $\mathrm{x}$ & $\mathrm{x}$ & & & & $\mathrm{x}$ & $\mathrm{X}$ & & & & & & & $\frac{X}{x}$ & & & & 7 & $\frac{19}{30}$ \\
\hline 5 & & 3.820 & & $\mathrm{X}$ & & & $\mathrm{X}$ & $\mathrm{X}$ & & $\mathrm{X}$ & $\mathrm{x}$ & $\mathrm{X}$ & $\mathrm{X}$ & & $\mathrm{x}$ & $\mathrm{X}$ & & & & & $\mathrm{X}$ & & $\mathrm{X}$ & & & & 11 & $\frac{30}{7}$ \\
\hline 5.1 & & 4.120 & & $\mathrm{x}$ & $\mathrm{x}$ & $\mathrm{x}$ & & & & & & & & & $\mathrm{X}$ & $\mathrm{x}$ & & & & & & & $\mathrm{x}$ & & & & 6 & \\
\hline 5.2 & & & & & & & & & & & & & & & $\mathrm{X}$ & & & & & & & & \begin{tabular}{l|l}
$x$ \\
$x$
\end{tabular} & & & & $\frac{2}{2}$ & 2 \\
\hline 5.4 & & & & & & & & & & & 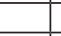 & 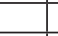 & & & $\mathrm{X}$ & & $\mathrm{X}$ & & & & & & $\mathrm{X}$ & & & & 3 & 5 \\
\hline 6 & $\frac{8}{\pi}$ & 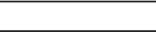 & & $\mathrm{x}$ & 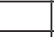 & $\mathrm{x}$ & $\mathrm{X}$ & $\mathrm{X}$ & & $\mathrm{x}$ & & & $\mathrm{X}$ & & $\mathrm{X}$ & & $\mathrm{X}$ & & & & $\mathrm{X}$ & $\mathrm{X}$ & $\Lambda$ & & & & 11 & 29 \\
\hline$\frac{6.1}{7}$ & & 3740 & & & - & & & & & & & & & & \begin{tabular}{l|l}
$x$ \\
\end{tabular} & & & & & & & & $\frac{X}{x}$ & & & & \begin{tabular}{l|l}
2 \\
9
\end{tabular} & $\frac{2}{28}$ \\
\hline 7.1 & & & & & 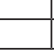 & $x$ & $x$ & $C_{-1}$ & & $x$ & & & & & $\frac{X}{X}$ & - & $X$ & & & & - & $\begin{array}{ll}x & x \\
& y\end{array}$ & $\frac{X}{X}$ & $\frac{\mathrm{X}}{\mathrm{x}}$ & & X & \begin{tabular}{l|l}
$y^{3}$ &
\end{tabular} & $\frac{28}{2}$ \\
\hline 7.2 & & & & & & 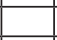 & 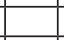 & 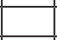 & & $\mathrm{x}$ & & & & & $\mathrm{X}$ & & & & & & & & & & & & 2 & \\
\hline 7.4 & & & & & & & & & & & & & & & & & & & & & & & $\mathrm{X}$ & & & & 1 & 1 \\
\hline 7.5 & & & & & & & & & & $\mathrm{X}$ & & & & & & & & & & & & & & & & & 1 & \\
\hline 8 & & & & $\mathrm{x}$ & $\mathrm{X}$ & $\mathrm{x}$ & & $\mathrm{X}$ & & $\mathrm{X}$ & & & & & $\mathrm{X}$ & $\mathrm{X}$ & $\mathrm{X}$ & $\mathrm{x}$ & & & $\mathrm{X}$ & \begin{tabular}{l|l}
$x$ & $x$ \\
\end{tabular} & \begin{tabular}{l|l}
$x$ & $x$ \\
\end{tabular} & $\mathrm{X}$ & & & 13 & 17 \\
\hline 9 & & $5.170-5.280$ & & $\mathrm{x}$ & $\mathrm{x}$ & $\mathrm{x}$ & $\mathrm{X}$ & & & $\mathrm{X}$ & & & & & $\mathrm{x}$ & & $\mathrm{X}$ & & & & $\mathrm{X}$ & $\mathrm{X}$ & $\mathrm{X}$ & & & & 10 & \\
\hline 9.6 & & 5.250 & & & $\mathrm{X}$ & $\mathrm{x}$ & & 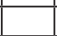 & & $\mathrm{X}$ & & & & & $\mathrm{x}$ & $\mathrm{x}$ & $\mathrm{x}$ & & & & $\mathrm{X}$ & & $\mathrm{x}$ & & & & 8 & 17 \\
\hline 9.7 & 8 & & & $\mathrm{x}$ & $\mathrm{X}$ & $\mathrm{X}$ & 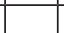 & & & $\mathrm{x}$ & & & & & $\mathrm{x}$ & & & & & & $\mathrm{X}$ & & $\mathrm{X}$ & & & & 7 & 8 \\
\hline 9.8 & & & & & $\mathrm{X}$ & & $x$ & & & $\mathrm{x}$ & & & & & $\mathrm{X}$ & $\mathrm{X}$ & $\mathrm{X}$ & & & & $\mathrm{X}$ & & & & & & 8 & \\
\hline 303 & & 5.500 & & $\mathrm{x}$ & & 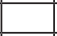 & & & & $\mathrm{X}$ & & $\mathrm{X}$ & & & $\mathrm{X}$ & & & & & & & & $\bar{X}$ & & & & 5 & 5 \\
\hline 303.1 & & 5.520 & & & & & & & & & & & & & $\mathrm{X}$ & & & & & & & & $\mathrm{X}$ & & & & 2 & 2 \\
\hline 10 & Mes & $5.570-5.690$ & & $\mathrm{x}$ & $\mathrm{x}$ & $x$ & $\mathrm{x}$ & $\mathrm{y}$ & & $\mathrm{x}$ & $\mathrm{x}$ & & & $\mathrm{X}$ & $\mathrm{x}$ & $\mathrm{x}$ & $\mathrm{X}$ & $\mathrm{x}$ & & $\mathrm{X}$ & $\mathrm{X}$ & \begin{tabular}{c|c}
$x$ & $x$ \\
\end{tabular} & $\mathrm{X}$ & $\mathrm{X}$ & & & 17 & 31 \\
\hline 10.1 & Miles. & $8.380-9.550$ & & $\mathrm{x}$ & $\mathrm{x}$ & $\mathrm{x}$ & $\mathrm{X}$ & $\mathrm{x}$ & & $\mathrm{x}$ & $\mathrm{X}$ & $\mathrm{X}$ & & $\mathrm{X}$ & $\mathrm{x}$ & & $\mathrm{X}$ & & & & $\mathrm{X}$ & \begin{tabular}{l|l}
$\mathrm{X}$ & $\mathrm{x}$ \\
\end{tabular} & $\mathrm{X}$ & $\mathrm{X}$ & $\mathrm{X}$ & & 16 & 15 \\
\hline 304 & & & & $\mathrm{X}$ & $\mathrm{X}$ & & $\mathrm{X}$ & $\lambda_{1}$ & & $\mathrm{x}$ & & & & & $\mathrm{x}$ & & $\mathrm{X}$ & & & & $\mathrm{X}$ & & \begin{tabular}{l|l}
$x$ & $x$ \\
\end{tabular} & $\mathrm{X}$ & & & 10 & 4 \\
\hline 102.1 & 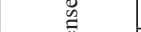 & 11.950 & & $\mathrm{x}$ & $\mathrm{X}$ & $\mathrm{x}$ & $\mathrm{X}$ & & & $\mathrm{X}$ & & & & & $\mathrm{X}$ & $\mathrm{X}$ & & & & & & & & & & & 8 & 5 \\
\hline 102 & 骂 & & & $\mathrm{x}$ & $\mathrm{X}$ & & & $\mathrm{X}$ & & $\mathrm{x}$ & & & & & $\mathrm{x}$ & $\mathrm{x}$ & $X$ & & & & & & $\mathrm{X}$ & & & & 8 & 5 \\
\hline 104 & 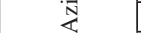 & & & $\mathrm{X}$ & & 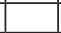 & $\mathrm{X}$ & & & $\mathrm{x}$ & $\mathrm{x}$ & & & & $\mathrm{X}$ & $\mathrm{X}$ & $\mathrm{X}$ & $\mathrm{X}$ & & & & & & & & & 8 & 16 \\
\hline 104.2 & & & & $\mathrm{X}$ & & & & & & & & & & & $\mathrm{X}$ & $\mathrm{x}$ & & $\mathrm{x}$ & & & & & & & & & 4 & 2 \\
\hline 305 & & 10.270 & & $\bar{x}$ & & & & & & $\mathrm{X}$ & & & & & $\mathrm{X}$ & & $\mathrm{X}$ & & & & & $\mathrm{X}$ & $\mathrm{X}$ & & & & 6 & - \\
\hline 306 & & 11.650 & & $\mathrm{X}$ & & $\mathrm{x}$ & $\mathrm{X}$ & & & $\mathrm{X}$ & & & & & $\mathrm{X}$ & $\bar{x}$ & $\bar{X}$ & & & & & & & & & & 7 & 7 \\
\hline 11 & & & & $\mathrm{X}$ & $\mathrm{x}$ & $\mathrm{x}$ & $\mathrm{x}$ & $x$ & & $\mathrm{x}$ & \begin{tabular}{|l|}
$x$ \\
\end{tabular} & & & & $\mathrm{x}$ & & $\underline{x}$ & & & & $x$ & & $\mathrm{X}$ & & & & 11 & 15 \\
\hline 11.1 & & 11.720 & & $\%$ & $\pi$ & $\mathrm{x}$ & $\mathrm{X}$ & 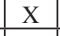 & & $\mathrm{x}$ & & & & & $\mathrm{X}$ & $x$ & & & & & & & & & & & 9 & 8 \\
\hline 11.2 & & & & $\mathrm{X}$ & $\Lambda$ & $\mathrm{x}$ & & & & $\mathrm{X}$ & & & & & $\mathrm{X}$ & $\mathrm{X}$ & & & & & & $\mathrm{X}$ & & & & & 8 & 4 \\
\hline 10 & & 12.460 & $\mathrm{X}$ & $\Lambda$ & $\lambda$ & $\mathrm{x}$ & $\mathrm{x}$ & & & $\lambda$ & & $\mathrm{X}$ & & & $\mathrm{X}$ & & & & & & & & & & & & 10 & 37 \\
\hline 10 & & & & $x$ & $\mathrm{X}$ & $\mathrm{x}$ & $\mathrm{X}$ & & & $\mathrm{X}$ & $\mathrm{x}$ & & & & $\mathrm{X}$ & $x$ & $x$ & $\mathrm{x}$ & & & & & & & & & 11 & 21 \\
\hline 107.1 & & & & $\mathrm{X}$ & & $\mathrm{x}$ & & & & $\mathrm{x}$ & $\mathrm{x}$ & & & & $\mathrm{X}$ & $\Lambda$ & $X$ & & & & & & & & & & 8 & 6 \\
\hline 12 & g & 12.790 & & $\mathrm{x}$ & $\mathrm{X}$ & $\mathrm{x}$ & 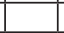 & & & $\mathrm{x}$ & \begin{tabular}{|l|}
$x$ \\
\end{tabular} & $\mathrm{x}$ & & & $\mathrm{x}$ & $\mathrm{X}$ & \begin{tabular}{l|l}
$x$ \\
\end{tabular} & $\mathrm{x}$ & & & & $\mathrm{X}$ & & & & & 11 & 16 \\
\hline 13 & & & & $\mathrm{X}$ & $\mathrm{x}$ & $\mathrm{X}$ & $\mathrm{x}$ & & & $\mathrm{x}$ & & & & & & $\mathrm{X}$ & Y & & & & & & & & & & 8 & 42 \\
\hline 14 & 击 & 14.600 & & $\bar{x}$ & & $\mathrm{X}$ & $\mathrm{x}$ & & & & & & & $\mathrm{x}$ & & & & & & & & & & & & & 9 & \\
\hline 108 & :̊ & $13.660-14.850$ & $\mathrm{x}$ & $\bar{x}$ & & $\bar{x}$ & $\mathrm{x}$ & $x$ & & $\underline{X}$ & & & & & $\mathrm{X}$ & $\underline{x}$ & 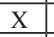 & $\mathrm{X}$ & & & $\mathrm{X}$ & $\mathrm{X}$ & $\mathrm{X}$ & X & & & 17 & 48 \\
\hline 109 & $\sum_{\Sigma}^{\circ}$ & & $\mathrm{x}$ & $\underline{x}$ & $\mathrm{x}$ & $\mathrm{x}$ & & & & $\bar{x}$ & & $\Lambda$ & & $\mathrm{X}$ & $\mathrm{X}$ & & & & & & & & & & & & 10 & 11 \\
\hline 15 & & $15.010-15.220$ & & $x$ & & & $\mathrm{x}$ & & & $\mathrm{x}$ & & & & & & & & & & & & & & & & & 6 & 17 \\
\hline 16 & 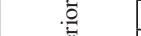 & & & $\mathrm{X}$ & $\mathrm{x}$ & $\mathrm{x}$ & & & & $\mathrm{x}$ & & $x$ & & & & $\mathrm{X}$ & & & & & & & & & & & 7 & 26 \\
\hline 17 & 党 & 15.37 & & $\mathrm{x}$ & $\mathrm{X}$ & & & $\mathrm{X}$ & & $\mathrm{X}$ & $\mathrm{x}$ & & & & & & & & & $\mathrm{X}$ & & & & & & & 6 & 3 \\
\hline 110 & $\Xi$ & 16. & $\mathrm{x}$ & $X$ & $\mathrm{X}$ & $\mathrm{x}$ & $\mathrm{X}$ & $x$ & & $\mathrm{X}$ & $\mathrm{x}$ & $\mathrm{X}$ & & & & $\mathrm{X}$ & $\mathrm{X}$ & $\mathrm{x}$ & & & & & & & & & 12 & 37 \\
\hline 111 & $\tilde{0}$ & $15.530-16.370$ & & $\mathrm{X}$ & $\mathrm{X}$ & $\mathrm{x}$ & $\mathrm{x}$ & & & $\mathrm{x}$ & $\mathrm{x}$ & $\mathrm{X}$ & $\mathrm{X}$ & & $\mathrm{x}$ & $x$ & $\mathrm{X}$ & & & & & & & & & & 11 & 27 \\
\hline 112 & $\cong$ & & & $\mathrm{x}$ & $\mathrm{X}$ & $\mathrm{x}$ & $\mathrm{X}$ & & & $\mathrm{x}$ & & $\mathrm{X}$ & & & \begin{tabular}{|l|}
$x$ \\
\end{tabular} & $\mathrm{X}$ & $\mathrm{X}$ & & & & & & & & & & \begin{tabular}{l|l} 
\\
9
\end{tabular} & 7 \\
\hline 113 & $\frac{\frac{2}{\pi}}{\frac{\pi}{\pi}}$ & & & 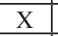 & $\mathrm{X}$ & & & & & $\mathrm{x}$ & $\mathrm{x}$ & $\mathrm{X}$ & & $\mathrm{X}$ & & $\mathrm{X}$ & $\mathrm{X}$ & & & & & & & & & & 9 & 3 \\
\hline 114 & & 16.460 & & $\bar{x}$ & & & $\mathrm{x}$ & & & $\mathrm{X}$ & & & & & & & & & & & & & & & & & 6 & 6 \\
\hline 115 & $\bar{z}$ & & & $\mathrm{X}$ & $x$ & & $\mathrm{X}$ & & & & & & & & & $\Lambda$ & $\mathrm{x}$ & & & & & & & & & & 7 & 4 \\
\hline 11 & & $15.220-17$. & & $\bar{x}$ & & $\mathrm{X}$ & & & & & & & & & & & & & & & & & & & & & 4 & \\
\hline 12 & & & $x$ & $\underline{X}$ & & $\mathrm{x}$ & & & & $\mathrm{x}$ & $x$ & & & $\mathrm{X}$ & & & $\mathrm{x}$ & & & & & & & & & & 8 & \\
\hline 12 & 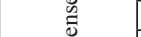 & 18.390 & $\mathrm{x}$ & $x$ & $\mathrm{X}$ & & & & & & $\mathrm{x}$ & & & & & & $\mathrm{X}$ & & & & & & & & & & 6 & 1 \\
\hline 12 & & & & $\mathrm{x}$ & $\mathrm{x}$ & $\mathrm{x}$ & & & & & & & & & & $\mathrm{X}$ & & & & & & & & & & & 5 & 1 \\
\hline 12. & $\overline{0}$ & & & & & & & & & $\mathrm{x}$ & & $\mathrm{x}$ & & & & $x$ & & & & & & & & & & & 4 & 1 \\
\hline 124 & & & $\mathrm{x}$ & $\mathrm{X}$ & & & & $\mathrm{X}$ & & $\mathrm{x}$ & $\mathrm{x}$ & $\mathrm{x}$ & & & & $\mathrm{X}$ & & $\mathrm{X}$ & & & & & & & & & 8 & 2 \\
\hline 125 & & 18.980 & & $y_{1}$ & & \begin{tabular}{l|l}
$x$ \\
\end{tabular} & & & & \begin{tabular}{|l|}
$x$ \\
\end{tabular} & & & & $\mathrm{x}$ & & $\mathrm{x}$ & & & & & & & & & & & 5 & 1 \\
\hline 126 & & & $\mathrm{X}$ & $\underline{X}$ & $\bar{X}$ & $x$ & $\mathrm{x}$ & $\mathrm{X}$ & & $\mathrm{x}$ & & $x$ & & $\mathrm{X}$ & & $\mathrm{X}$ & $X$ & & & & & & & & & & 10 & 2 \\
\hline 128 & etiense & 27.5 & & & 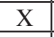 & $x$ & & & & $\mathrm{X}$ & $\mathrm{X}$ & $\overline{\mathrm{y}}$ & X & $\mathrm{X}$ & $\mathrm{X}$ & $\mathrm{X}$ & $\mathrm{X}$ & & & & & & & & & & 11 & \\
\hline 129 & & & $\underline{X}$ & $\overline{\underline{X}}$ & & & & & & & & & & & & & & & & & & & & & & & 3 & 1 \\
\hline 130 & \begin{tabular}{|l|} 
Musteriense \\
\end{tabular} & 41.280 & $x$ & $x$ & $\mathrm{X}$ & $x$ & $\mathrm{X}$ & $\mathrm{X}$ & $\frac{x}{x}$ & $\mathrm{x}$ & $\mathrm{X}$ & & & & & & & & & & & & & & & & 9 & 1 \\
\hline do $\mathrm{N}$ & & $1.100-41.280$ & 33 & 693] & \begin{tabular}{|l|l}
170 \\
\end{tabular} & 229 & $|114|$ & 46 & 1 & |419 & 25 & 96 & 10 & 14 & & 192 & 172 & 17 & & & \begin{tabular}{l|l}
56 & 2 \\
\end{tabular} & & & & & & 24 & 721 \\
\hline
\end{tabular}


Nivel 2: Color beige. Constituye una mezcla con el suelo de la cabaña reciente. Está constituido por arcilla, arena y bloques de piedra. Abundan huesos de grandes mamíferos domésticos.

Conjunto 3: Complejo de niveles numerados del 3 al 3.4, con $14 \mathrm{~cm}$ de potencia en total. Son niveles discontinuos de arcilla, que varían de color gris oscuro a claro, blanco, crema amarillo e incluso rojo. Tienen en común el aumento de la diversidad de pequeños mamíferos con respecto a los niveles 1 y 2 . Mención aparte merece el sub-nivel 3.5, un relleno de canal o trinchera antrópica, que erosiona a los niveles $7,6,5,4,3$ y 3.2, por lo que parece un evento posterior a todos ellos (Fig. 4). Aparentemente, los niveles actuales 1 y 2 se encuentran encima de 3.5 por lo que sería anterior a éstos. Su formación podría estar ligada a la fase de acumulación de la edad del hierro, conocida como Edad Fría del Bronce (2900-2300 ka BP). Ha sido detectada en el NE de España en medios abiertos (Gutiérrez Elorza \& Peña-Monné, 1998) y descrita como un momento frío y húmedo, coincidente con la expansión de los glaciares y una mayor precipitación, previa al período cálido Subatlántico, que sería un período erosivo.

Nivel 4: Horizonte de incendios o fuegos (fumiers) en el que alternan lentejones de ceniza gris-blanquecina cementada localmente. Tiene niveles de carbones y fragmentos quemados de madera y bloques de piedras quemados y agrietados por el fuego. Hay cerámica alrededor, alguna quemada. Hay perforaciones o ¿madrigueras? bordeando alguna de las hogueras. Los pequeños mamíferos son menos diversos en este nivel (Tabla 2) que en el Complejo 3.

Conjunto 5: conjunto de niveles oscuros de limo arcilloso gris-marrón con materia orgánica abundante y carbón. Comprende los sub-niveles 5 y 5.1 a 5.4. El 5 es el más rico en restos de pequeños vertebrados.

Conjunto 6: nivel de ceniza blanca con fragmentos de carbón. Aunque hay también un nivel 6.1, la microfauna sólo se encuentra en 6.

Conjunto 7: es también un complejo formado por los sub-niveles 7 a 7.5. Está compuesto fundamentalmente por ceniza rica en materia orgánica con fragmentos de carbón. En 7 predomina una arcilla limosa, de interior de cueva. La microfauna es escasa y representa un cambio con respecto a otros niveles (Tabla 2). Los arvicolinos disminuyen, siendo el único nivel en el que falta la rata de agua norteña, Arvicola terrestris (Linnaeus, 1758).

Conjunto 8: De color claro, con dos unidades, la 8, arcilla gris-beige con fragmentos de carbón y la 8.1, lentejón de ceniza con carbón y fragmentos de roca. Los pequeños mamíferos sólo están en 8. Es uno de los pocos niveles con evidencias directas de agricultura, por el hallazgo de granos de trigo, al igual que en los niveles 303, 303.2, 303.3 de la Trinchera (Peña-Chocarro et al., 2005).

Conjunto 9: Compuesto por 9 unidades, 9 a 9.8, de arcilla con cenizas y carbón.

Nivel 10: Limo blanco con más continuidad lateral que la que presentan los niveles anteriores, es de carácter menos lenticular.

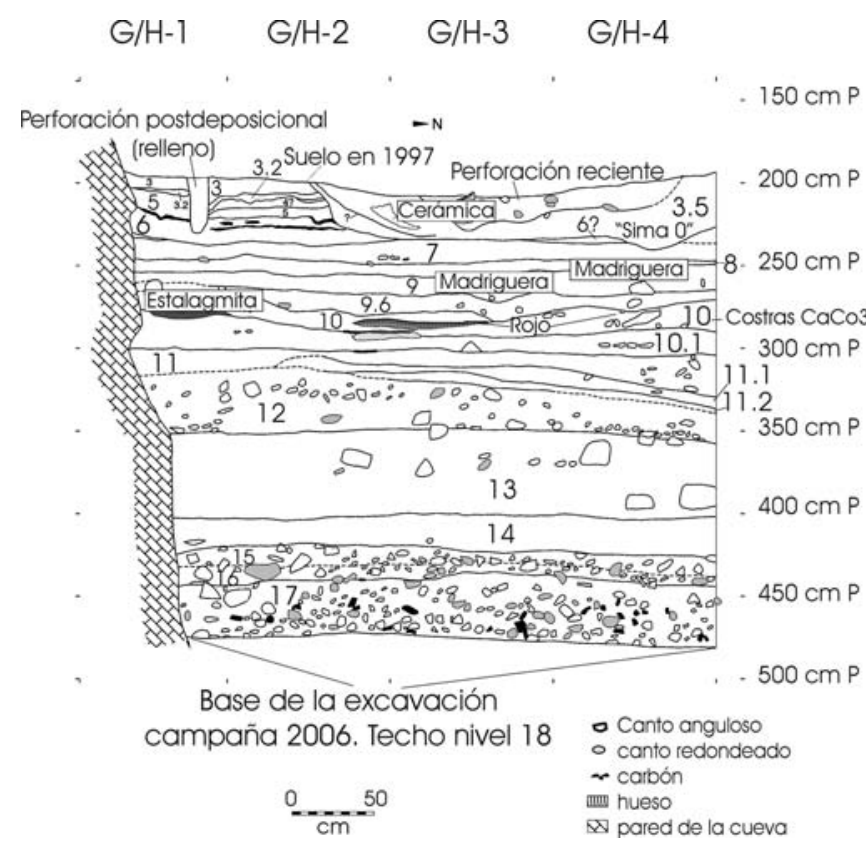

Figura 4. Estratigrafía de la Zona de la Cabaña. Los niveles están representados por los números dentro del esquema estratigráfico. Los números de la Columna de la derecha indican la profundidad de excavación en centímetros (cm P).

Stratigraphy of the Outer Vestibule or Cabin Area. The levels are represented by the numbers inside the stratigraphic scheme. The numbers at the rigth column indicate the deepness of the excavation in $\mathrm{cm}$ (cm P).

Nivel 10.1: Formado por arcilla limosa con ceniza. Tiene de 8 a $9 \mathrm{~cm}$ de potencia. Al igual que el nivel 10 tiene más continuidad lateral que los niveles anteriores. Los niveles 10 y 10.1 son litológicamente parecidos, aunque de cronología muy diferente: 6.600 y 9.000 años BP respectivamente. Hay un hiato (o hiatos) deposicional importante entre los niveles 10 y 10.1. Este aspecto no fue reconocido durante el sondeo inicial hecho en la Cabaña. También hay diferencias en las asociaciones de pequeños mamíferos: en el nivel 10 hay Sorex minutus Linnaeus, 1766 y quirópteros que están ausentes en 10.1. La presencia del pequeño murciélago de cueva del nivel 10, Miniopterus schreibersii Kuhl, 1817, puede indicar que la cueva era temporalmente deshabitada por humanos entre los 5.690 y 5.570 años, ya que en general los murciélagos no cohabitan con los humanos (también podría ser un problema de muestreo dado el pequeño tamaño y la fragilidad de los restos óseos de los quirópteros). También es de notar la presencia de Arvicola sapidus Miller, 1908 en el nivel 10. Ésta sería la primera entrada holocena de la rata de agua ibérica en el norte de la península ibérica. Tres citas indi-

Tabla 2. Distribución estratigráfica de los pequeños mamíferos del Mirón. En la columna de la izquierda sólo están representados los niveles estratigráficos que contienen fósiles de pequeños mamíferos. Las dataciones de radiocarbón provienen de Straus \& González Morales (2003, 2007).

Stratigraphic distribution of the small mammals of El Mirón Cave. On the left column, there are only the stratigraphic levels with small mammal contents. The radiocarbon data are after Straus \& González Morales (2003, 2007). 


\begin{tabular}{|l|c|}
\hline Cultura & 14 C Ka B.P. \\
\hline Medieval & $1,1-1,4$ \\
\hline Bronce & $3,2-3,7$ \\
\hline Calcólítico & $3,7-4,1$ \\
\hline Neolítico & $4,7-5,8$ \\
\hline Mesolítico & $8,4-9,6$ \\
\hline Azilian & $9-11,5$ \\
\hline Magdaleniense Superior & $11,5-13$ \\
\hline Magdaleniense Inferior & $13-17$ \\
\hline Solutrense & $17-20$ \\
\hline Gravetiense & $20-28$ \\
\hline Auriñaciense Superior & $28-35$ \\
\hline Chatelperroniense & 35 \\
\hline Auriñaciense Inferior & $35-40$ \\
\hline Musteriense & $41-$ \\
\hline
\end{tabular}

Nivel 13: Arcilla amarillento-anaranjada con gravas y cantos que desaparecen hacia la base. Casi estéril en cuanto a contenido arqueológico, a excepción de algunos huesos y sílex, que podrían ser contaminación por percolación. En la base se encuentran cantos de gran tamaño con algunos sílex asociados.

Nivel 14: arcilla compacta y plástica, de color amarillentobeige, similar a la del nivel 13. Se diferencia de éste más por su contenido arqueológico, pues presenta una mayor concentración de sílex, que por su carácter sedimentológico. A pesar de que el número de muestras es relativamente elevado, tanto los niveles 13 y 14 siguen siendo pobres en cuanto al número de especies de pequeños mamíferos.

Nivel 15: arcilla semejante a la de los niveles 13 y 14, con mayor contenido en cantos angulosos. Es un nivel rico en elementos arqueológicos.

Nivel 16: arcilla prismática, arenosa, de color marrón oscuro, con cantos angulosos $(<5 \mathrm{~cm})$. Contiene artefactos, huesos triturados y cantos redondeados, de tamaño centimétrico.

Nivel 17: Limo gris-marrón con arena, cantos angulosos y algunos redondeados. Rico en sílex y utensilios de hueso; astas y abundantes huesos largos y cráneos de cabra montesa. Algunas áreas, de color más oscuro, presentan acumulaciones de cantos redondeados, muchos rotos y/o rubefactados a causa del fuego.

Tabla 3. Cronología en miles de años (Ka), datos de radiocarbon $\left(\mathrm{C}^{14} \mathrm{BP}\right)$ de los Niveles culturales del Paleolítico y Neolítico Europeos (Straus, 2005; este trabajo). Chronology in thousand of years $(\mathrm{Ka})$, radiocarbon data $\left(C^{14} B P\right)$ of the Cultural levels of the European Paleolithic and Neolithic (Straus, 2005; this work).

can la presencia de Arvicola sapidus en yacimientos cántabros del Pleistoceno superior: en los niveles Solutrenses de La Riera (Altuna, 1986) y Las Caldas así como en el Magdaleniense de Rascaño 7 (Pokines, 1998). También la encontramos en el Pleistoceno superior del Mirón, en el Magdaleniense inicial, nivel 17 (Tabla 2). Además de lo comentado sobre A. sapidus, en 10.1, es de notar la falta de Microtus arvalis (Pallas, 1779), Sorex Linnaeus, 1758, Crocidura Wagler, 1832 y los quirópteros Myotys Kaup, 1829 y Miniopterus Bonaparte, 1837. Además es el único nivel de toda la secuencia en el que se encuentra la ardilla común, Sciurus vulgaris Linnaeus, 1758. La ardilla es un habitante de bosque más o menos denso, y suele ser raro en los yacimientos ya que constituye una presa difícil para la mayoría de los predadores causantes de las acumulaciones. Así que este dato podría ser tomado como una presencia extraordinaria, ligada a la mayor continuidad lateral de este nivel, lo que supone un área de muestreo mayor. Desde el punto de vista arqueológico el nivel 10 carece de cerámica, pero tiene industria lítica y huesos (Straus \& González Morales, 2001a).

Conjunto 11: Arcilla arenosa de color anaranjado a marrón claro, con cantos angulosos medianos a gruesos $(>10-20 \mathrm{~cm})$. En el cuadro I3, por debajo del nivel 11, se diferencian los subniveles 11.1, de color gris oscuro, y 11.2, de color amarillento claro, arcilloso, con cantos. Hay una disminución de la diversidad de pequeños mamíferos con respecto a los niveles anteriores, y esta pobreza en el número de taxones se mantiene hasta el nivel 17.

Nivel 12: Arcilla de colores anaranjado y marrón-beige claro. Contiene cantos y gravas así como huesos, un arpón Magdaleniense, y artefactos líticos, especialmente a techo.

Zona de la Trinchera (Mid-Vestibule Trench). Cuadros R7, O-P/6 y continuación de N-K/5. Niveles 300 a 314 (Fig. 5)

La diversidad en pequeños mamíferos de esta zona de la Cueva del Mirón es menor que en las demás zonas, hecho probablemente relacionado con el menor número de muestras estudiado (Tabla 2). Es interesante notar que las especies minoritarias en las demás zonas (Arvicola sapidus, Microtus gregalis, lagomorfos, quirópteros, Mustela) están ausentes aquí. Los niveles 300 a 302 están alterados por remociones y/o excavaciones no arqueológicas en la cueva, previas a 1996. Por esto no analizamos los microvertebrados de estos niveles.

Nivel 300: nivel de relleno, con gravas, cantos angulosos y redondeados, de tamaños variados, en una matriz limosa, de color marrón oscuro rica en materia orgánica. Contiene madera y mezcla de artefactos de diferentes niveles culturales.

Nivel 301: También un nivel de mezcla. Limo marrón claro con cantos redondeados que rellena perforaciones recientes y con vidrio en algunos sitios.

Nivel 301.0: lentejón de arcilla amarillenta-beige de unos 2-3 $\mathrm{cm}$ de potencia.

Nivel 301.1: nivel de ceniza gris con lentejones de carbón en la base $(6-10 \mathrm{~cm})$.

Nivel 301.2: mezcla de arcilla amarillenta-beige a techo y ceniza gris con lentejones de carbón en la base. Se observa una perforación reciente.

Nivel 302: limo rojizo-marrón de aspecto granuloso por el contenido en arena, más compacto en algunas zonas. Hay también una zona de perforación y relleno.

Nivel 303: limo arcilloso amarillo beige (puede variar de 2 a $6 \mathrm{~cm}$ de grosor). También está localmente afectado por la perforación del nivel 302. Este es el primer nivel de la Trinchera en el que se estudian los pequeños mamíferos, ya que los anteriores podrían tener problemas de contaminación.

Nivel 303.1: nivel de relleno de un hogar bajo el nivel 303. Compuesto de ceniza y carbón de color gris y negro. Está perfo- 


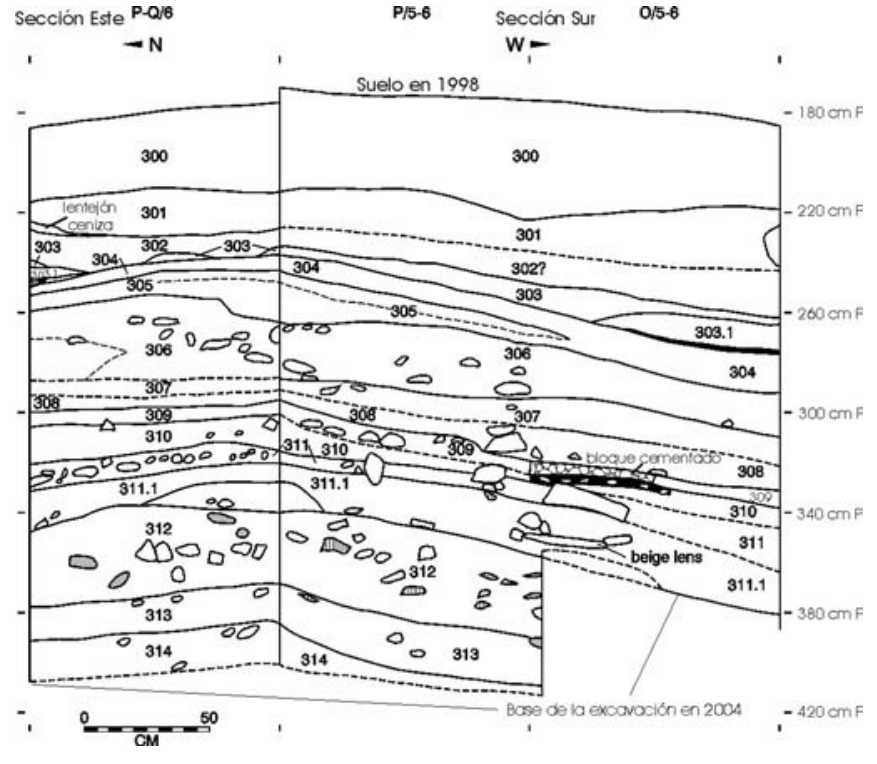

Figura 5. Estratigrafía de la Zona de la Trinchera. Los niveles están representados por los números dentro del esquema estratigráfico. Los números de la Columna de la derecha indican la profundidad de excavación en centímetros (cm P).

Stratigraphy of the Mid Vestibule or Trench Area. The levels are represented by the numbers inside the stratigraphic scheme. The numbers at the rigth column indicate the deepness of the excavation in $\mathrm{cm}$ (cm P).

rado localmente en los cuadros O6 y P6 por lo que el contenido de estos cuadros queda eliminado del estudio cuantitativo.

Nivel 303.2: arcilla amarillo-beige de 5 a $6 \mathrm{~cm}$ de potencia.

Nivel 303.3: lentejones de cenizas y carbón pareados o alternantes, de 2 a $10 \mathrm{~cm}$ de grosor. El nivel se hace más potente de este a oeste. Es el nivel más bajo con cerámica en la Zona de la Trinchera. Un dato interesante de este nivel es la presencia de trigo, lo que aporta evidencias directas de agricultura, al menos hace 5.550-5.790 B.P (Peña-Chocarro et al., 2005) en Cantabria. Aunque el nivel 303.3 carece de pequeños mamíferos, su presencia en niveles infra- y suprayacentes indica que la actividad agrícola, no debió de ser importante como para favorecer la introducción del ratón espiguero (Micromys minutus), presente en otras partes de la Península Ibérica desde el Pleistoceno (Agustí \& Galobart, 1986), pero ausente en la Cornisa Cantábrica durante el Pleistoceno y por lo menos hasta época Medieval (Pokines, 1998, este trabajo).

Nivel 304: Es un nivel formado por precipitado carbonatado blanco y pulverulento. Arqueológicamente pobre, pero el más rico en restos de pequeños mamíferos. Aunque es un nivel sin datación radiométrica, por la fauna podría ser equivalente al nivel 10 de la cabaña, en donde Apodemus Kaup, 1829 y Myoxus dominan numéricamente. Géneros típicos de frondosidad, su presencia indica un momento de expansión del bosque. También encontramos Crocidura, que aunque escasa, indicaría un clima más benigno.

Nivel 305: limo arenoso de color beige con lentejones rosado-anaranjado a gris-blanquecino, estos últimos con un alto contenido en carbonatos. Contiene pocas rocas pero se encuentran bastantes fragmentos de espeleotemas, especialmente en la zona de goteo activo del cuadro P6. Es arqueológicamente más rico que 304, con una atribución cultural al Aziliense (10.270 años BP). Ambos niveles 304 y 305 podrían estar en continuidad lateral con el nivel 10.1 de la Cabaña.

Nivel 306: limo arenoso oscuro marrón-gris, con artefactos de sílex, huesos, cantos redondeados y clastos, tanto redondeados como angulosos. En este nivel desaparecen las especies indicadoras de bosque como los lirones y ratones de campo o leonados, Apodemus); además es el único nivel de la Trinchera que tiene ambas especies de topillos de prado (Microtus agrestis Linnaeus, 1761 y M. arvalis). Arvicola terrestris es menos abundante que en los niveles superiores. Todo ello parece indicar unas condiciones más abiertas y frescas.

Zona del Corral (Vestibule Rear). Cuadros T-V/7-8; SQ/7. Niveles 99 a 119 (Fig. 6)

Los niveles 99 a 102 son estériles en pequeños mamíferos. En general también pobres en materiales arqueológicos y paleontológicos.

Nivel 99: Es un nivel actual, sin fauna, compuesto por limo suelto de color marrón rojizo claro, con cantos.

Nivel 100: también nivel reciente, con una mezcla de huesos, cantos y material de relleno de cabaña actual. Sin pequeños mamíferos.

Nivel 101: Limo gris marrón con cantos, gravilla fina y zonas encostradas por goteo que constituye la base de la superficie de relleno reciente.

Nivel 102: limo arenoso amarillo anaranjado, sin arcilla. Contiene restos dispersos de sílex y huesos.

Nivel 102.1: Lentejón fino de ceniza y carbón, que podría corresponder a un hogar. Es el primer nivel en el que encontramos pequeños vertebrados.

Nivel 102.2: Nivel arenoso, con más gravilla que el anterior, de color amarillo beige. Su potencia varía de 1 a $5 \mathrm{~cm} \mathrm{Li}$ geramente más rico en pequeños mamíferos que el nivel anterior. En casi todos los niveles del Corral, la asociación está dominada por la especie Arvicola terrestris (> 20\%) salvo en el nivel 108, en el que aumenta la biodiversidad y deja de ser el elemento mayoritario.

Nivel 103: limo arenoso gris marrón con lentejones rojizoamarillentos de arena granular. Contiene algo de sílex y huesos. Estéril en pequeños mamíferos.

Nivel 104: limo arcilloso, compacto, de color gris oscuro a marrón negruzco, con algo de grava. Contiene cantos angulosos de tamaño pequeño a medio. Contiene cenizas y materiales calcinados. Pobre en microfauna.

Nivel 105: limo arcilloso gris amarillento, con manchas de color marrón-beige y gris marrón, con algunas evidencias de procesos de crioturbación. Estéril en pequeños mamíferos.

Nivel 106: limo de un homogéneo color marrón oscuro, con algunos parches gris negruzco. Contiene huesos y sílex quemados. Grandes cantos angulosos y bloques. Es un nivel del Magdaleniense superior (equivalente al nivel 12 de la Cabaña y el 308 de la Trinchera) culturalmente rico, con huesos ennegrecidos. En este nivel se produce un incremento tanto en el número de especies como en el número mínimo de individuos. Este es el nivel del Corral en el que Microtus oeconomus (Pallas, 1776) aparece por última vez. Es notable que, a excepción del nivel 
130 de la Rampa, M. oeconomus esté presente en casi toda la secuencia del Mirón, donde desaparece en los niveles posteriores a los datados en 2.000 años BP. Por otra parte, el nivel 106 constituye el último registro de Pliomys lenki Heller, 1930 no sólo en la sección del Corral del Mirón, sino en toda la cueva. Éste sería además el dato más reciente para la extinción de la especie, puesto que las nuevas dataciones del Mirón, para este nivel 106, permiten fecharlo en 12.460 años BP.

Nivel 106.1: limo marrón claro con pequeños cantos, rodados y angulosos. Un hoyo con relleno posterior, atraviesa los niveles 105 a 107 . Hacia el sur hay madrigueras de tamaño variable. Dada una posible contaminación se ha preferido eliminar del análisis a los pequeños mamíferos de éste nivel.

Nivel 107: Limo compacto amarillo beige, deformado por caída de bloques.

Nivel 107.1: limo de color marrón claro, con fragmentos de rocas de cerca de $20 \mathrm{~cm}$ de diámetro. Todo el nivel constituye un relleno de madriguera, probablemente de lagomorfos, ampliada por la actividad de carnívoros de pequeño a mediano tamaño. Se encuentran restos arqueológicos y huesos (Fig. 6), y es pobre en pequeños mamíferos. Los niveles infra- y suprayacentes a 107.1 contienen, relativamente en relación con el resto de la secuencia, numerosos restos de pequeños carnívoros y lagomorfos (Marín Arroyo, 2007), lo que apoyaría la atribución de las madrigueras a su actividad biológica.

Nivel 107.2: limo gris verdoso, estéril. Está bioturbado por las madrigueras de 107.1. En el cuadro T10 el techo tiene una capa de ocre rojo.
Nivel 108: limo marrón oscuro a claro. Contiene cantos angulosos con evidencias de alteración (blancos). Como en 106 es rico en huesos y sílex y en algunas zonas está en contacto directo con este nivel, ya que el nivel 107 es discontinuo (Fig. 6). Aunque el color es variable, se hace más oscuro hacia la base. Contiene abundantes huesos ennegrecidos, sílex, algunos cantos redondeados con evidencias de haber sido quemados. A techo se encuentran numerosos bloques caídos. En pequeños mamíferos, el nivel 108 es el más rico de toda la secuencia del Corral y después del nivel 10 de la Cabaña, el más rico de la Cueva del Mirón. Como en 10, es el único nivel en el que se han encontrado restos fósiles del pequeño murciélago de cueva, $M i$ niopterus schreibersii. También es de notar la coincidencia en el gran número de individuos de Chionomys nivalis (Martins, 1842) en ambos niveles cuya edad y proporción del número mínimo de individuos de otras especies de pequeños mamíferos son, sin embargo distintas.

Nivel 109: limo de color marrón carente de clastos y huesos quemados. De carácter discontinuo. La diversidad de pequeños mamíferos es notablemente menor que en los niveles precedente y posterior.

Nivel 110: limo marrón negruzco y gris, rico en materia orgánica y huesos ennegrecidos, piedras y sílex. En contacto directo con 108 en las áreas donde 109 está ausente. Aquí aparece Pliomys lenki, el cual falta en niveles suprayacentes, hasta encontrarlo de nuevo en el nivel 106 como hemos señalado. La especie se encuentra también en niveles más antiguos de otras secciones (Tabla 2 y Fig. 9).

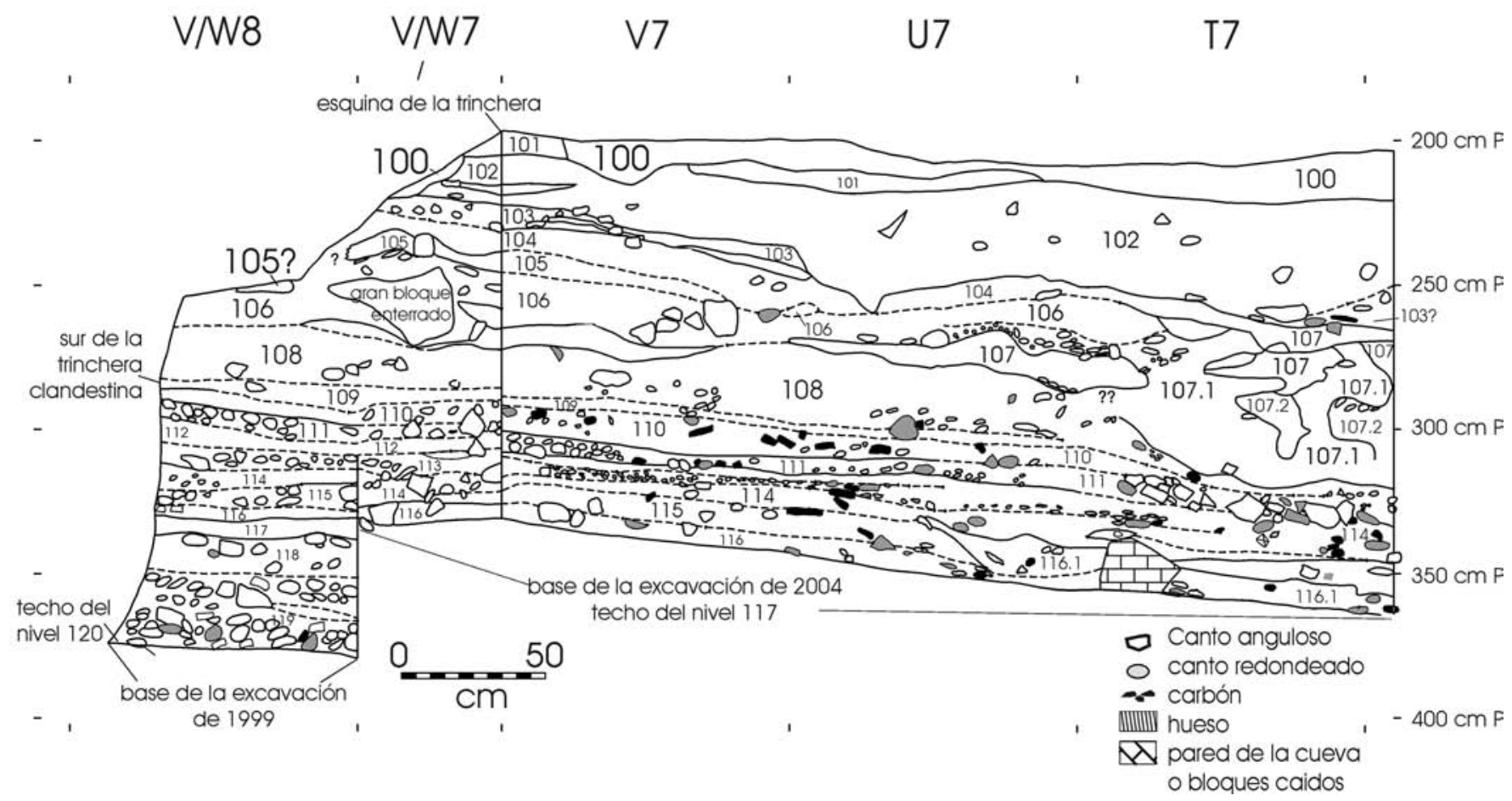

Figura 6. Estratigrafia de la Zona del Corral. Los niveles están representados por los números dentro del esquema estratigráfico. Los números de la Columna de la derecha indican la profundidad de excavación en centímetros (cm P). Stratigraphy of the Vestibule Rear area. The levels are represented by the numbers inside the stratigraphic scheme. The numbers at the rigth column indicate the deepness of the excavation in $\mathrm{cm}(\mathrm{cm} \mathrm{P})$. 
Nivel 111: limos de color marrón oscuro a negruzco. Rico en huesos ennegrecidos y sílex, como en 108 y en 110, pequeño a mediano tamaño. Contiene también cantos angulosos alterados, recubiertos de una sustancia blancuzca. Se distingue un lentejón con mayor cantidad de clastos aunque con matriz limosa; característica de este nivel y de los superiores. Su grosor varía entre 3 y $5 \mathrm{~cm}$.

Nivel 112: Limo marrón claro con menos cantos angulosos que en 111 pero rico en artefactos y fauna. Desde éste nivel hasta la base, el contenido en pequeños mamíferos y su diversidad disminuyen notablemente, con dos especies dominantes, Arvicola terrestris y Talpa europaea, sobre una empobrecida diversidad de arvicolinos e insectívoros; no se encuentran quirópteros ni lagomorfos y comadreja sólo en el nivel 113.

Nivel 113: nivel de gravas carbonatadas corroídas, alteradas y de color blanco. La matriz es un limo marrón oscuro con huesos pero poco sílex, con características del Magdaleniense inferior Cantábrico. El color presenta también alternancias claro-oscuro como en 111. Hay que señalar que es el único nivel de la zona del Corral, y de toda la secuencia del Mirón (Tabla 2) que tiene Microtus gregalis Pallas, 1779, una especie abundante en Francia durante el Pleistoceno superior, pero rara en la Península Ibérica, donde sólo se encuentra en otro yacimiento del Magdaleniense inferior Cantábrico: Erralla V, en Guipúzcoa (Pemán, 1985). La presencia de especies esteparias, procedentes del Norte y Este de Europa indicaría un momento frío durante la formación de este nivel.

Nivel 114: limo de color marrón claro con cantos, aunque en menor cantidad que en el nivel 113.

Nivel 115: limo marrón negruzco a gris claro con grandes cantos angulosos de caliza corroídos y alterados de color blanquecino.

Nivel 116: limo marrón negruzco a gris, con cantos redondeados y esquirlas de cantos, huesos ennegrecidos e industria en sílex. Menos cantos angulosos que en 115. Éste es el nivel con la menor diversidad en pequeños mamíferos de la secuencia, y a partir de aquí, hacia la base, desaparecen.

Nivel 117: limo de color claro a marrón gris con grandes bloques caídos de color blanco. El nivel presenta abundantes evidencias de fuegos, como algunos huesos calcinados, carbón $\mathrm{y}$ piedras quemadas.

Nivel 118: limo arcilloso y compacto de color marrón claro con gravas y pequeños fragmentos de caliza dispersos. Abundantes huesos. Sin bloques caídos.

Nivel 119: limo arcilloso marrón anaranjado con una capa masiva de bloques caídos redondeados y alterados de color blanco. Abundantes huesos.

Zona de la Rampa distal de la terraza aluvial (Alluvial Terrace Footslope). Cuadros X-W/10. Niveles 120130 (Fig. 7)

Se introduce la nomenclatura de excavación, poniendo entre paréntesis los niveles "400" que se utilizaron originalmente en la excavación para separar los niveles de los distintos sectores de la cueva, antes de establecer la equivalencia del nivel 120 con el nivel 400. En la excavación del Sondeo de la Rampa se ha llegado al nivel más antiguo de la Cueva del Mirón, el 130, datado en 41.280 años. El sondeo tiene $2 \mathrm{~m}^{2}$ (cuadros X-W10) excavado desde el fondo de un gran pozo de excavaciones clandestinas al pie de la rampa que sube hacia el interior oscuro de la cueva

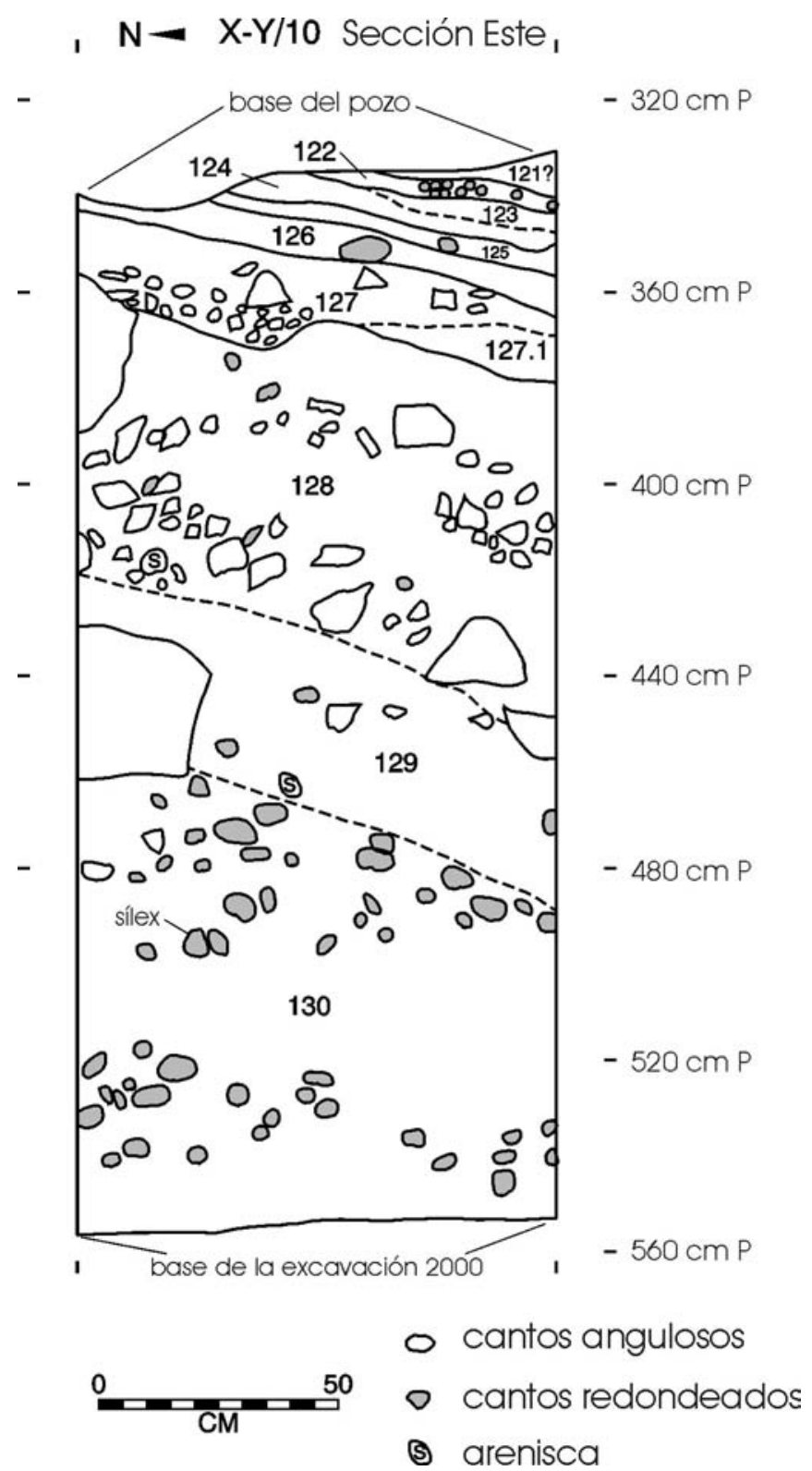

Figura 7. Estratigrafia de la Zona del Sondeo de la Rampa. Los niveles están representados por los números dentro del esquema estratigráfico. Los números de la Columna de la derecha indican la profundidad de excavación en centímetros (cm P).

Stratigraphy of the Sondage of the Foot slope area. The levels are represented by the numbers inside the stratigraphic scheme. The numbers at the rigth column indicate the deepness of the excavation in $\mathrm{cm}$ (cm P).

(Fig. 3). Ni la diversidad específica ni la abundancia (en términos de número mínimo de individuos) son las mas altas de la secuencia, aunque ambos parámetros aumentan notablemente en los niveles más antiguos (128-130). Es de notar que las especies de bosque son inexistentes en esta zona, a excepción de un único individuo de Apodemus en el nivel 128. Aunque hay todavía que esperar las muestras procedentes de las próximas excavaciones, 
es posible que esta ausencia esté ligada a las condiciones climáticas que caracterizan el Ultimo Máximo Glaciar. El número de muestras estudiadas hasta el momento en esta zona es pequeño en comparación con el resto de los sectores (Tabla 2).

Nivel 120 (=400): arcilla limosa moteada amarillo-beige, con abundantes fragmentos de rocas y cantos redondeados, situada por debajo de un pozo de unos $12 \mathrm{~cm}$. En W10 un nivel de cantos pequeños podría también ser un relleno. No se encuentran cerámica ni artefactos "modernos" en 120 a pesar de estar justo por debajo del "pozo clandestino".

Nivel 121 (=400.1): limo marrón con fragmentos de roca, materia orgánica e industrias líticas.

Nivel 122 (=401): limo arcilloso, amarillo-beige, homogéneo, compacto con fragmentos de roca, grava y cantos redondeados. Algo de sílex y huesos.

Nivel 123 (=401.1): nivel lenticular fino, limoso marrón, con fragmentos de rocas. Pasa lateralmente al 122 en el cuadro W10. Contiene huesos y sílex en forma de puntas Solutrenses.

Nivel 124 (=401.2): nivel limoso marrón, con clastos de rocas y arena, bajo 123, que pasa lateralmente a 122 en el cuadro W10. Es arqueológicamente estéril.

Nivel 125 (=402): limo marrón oscuro con sílex (puntas Solutrenses) y huesos, de 10 a $12 \mathrm{~cm}$.

Nivel 126 (=403): limo arcilloso-arenoso de color beige, con cantos redondeados y angulosos. Contiene numerosos huesos, artefactos líticos (puntas Solutrenses) y óseos (caninos y astas de ciervo perforados).

Nivel 127 (=404): capa de color oscuro, marrón grisáceo, con fragmentos de rocas, grandes lascas y otros artefactos y abundantes restos de grandes mamíferos (cabra montesa) representados por huesos y dientes aislados.

Nivel 128 (=405): limo arcilloso amarillo brillante, compacto y liso, que presenta un contacto neto con el nivel 127. La base contiene más fragmentos de roca y es más gris que el techo. Contiene algunas lascas de sílex. Rico en restos óseos.

Nivel 129 (=406): es un nivel que presenta un paso lateral, hacia la base, del nivel 128. Es una arcilla maleable de color amarillo brillante y algo limosa. Se encuentra rodeando grandes bloques de caliza.

Nivel 130: pasa lateralmente al nivel 129, se distingue de éste por ser más limoso y con un color más rojizo. Contiene numerosos cantos rodados de diverso tamaño. Se encuentra por debajo de los grandes bloques de caliza. Contiene lascas, dos denticulados, huesos y carbón disperso. Es el único nivel de toda la secuencia del Mirón en el que se han encontrado restos del topo de río, Galemys pyrenaicus (E. Geoffroy, 1811). Es el nivel más antiguo del presente análisis.

\section{LOS PEQUEÑOS MAMÍFEROS DE LA CUEVA DEL MIRÓN}

La mayoría de los pequeños mamíferos del Pleistoceno tardío y Holoceno del Mirón se hallan entre la fauna actual de la Cornisa Cantábrica a excepción de Pliomys lenki, Microtus oeconomus y M. gregalis (Tabla 1). En la actualidad hay 47 especies de pequeños mamíferos en Asturias, Cantabria y País Vasco (Cornisa Cantábrica a partir de ahora) incluyendo los cinco órdenes mencionados, aunque de los carnívoros sólo tenemos en cuenta a los pequeños mustélidos (comadrejas, martas y visones). Los datos de la fauna actual tienen varias fuentes: el Atlas de los Mamíferos Terrestres de España (Palomo \& Gisbert, 2002), el estudio de las egagrópilas de lechuza común o de campanario (Pokines, 1998) y observaciones de otros autores (Iza et al., 1985; Galán, 1997; Blanco, 1998 a, b). Según estos datos, las especies de pequeños mamíferos que habitan hoy en la Cornisa Cantábrica varían según la región, pero en total no llegan a la treintena (Tabla 1). Esto implica que si contamos a los quirópteros, las especies del Mirón representan un 57\% de la fauna actual; pero si los descontamos, ya que por su fragilidad seguramente están infravalorados en el registro fósil con respecto a los muestreos y análisis actuales, entonces la fauna del Mirón representa el $86 \%$ de la fauna de pequeños mamíferos actuales de la Cornisa Cantábrica, sin descontar la fauna introducida recientemente por el hombre (Rattus, Mus y Muscardinus).

\section{MATERIALES, METODOLOGÍA, NOMENCLATURA}

Para la obtención de pequeños fósiles se han utilizado tamices de luz de malla de $2 \mathrm{~cm}$ el mayor y de 1 a $2 \mathrm{~mm}$ el menor. La recuperación de estos fósiles no sería posible si se utilizan tamices de luz de malla más grandes ya que la mayoría de los restos de musarañas, musgaños y murciélagos (Soricomorpha y Chiroptera) son de menor talla, por lo que la representación de estos órdenes así como la de los roedores más pequeños $(\mathrm{Mu}-$ rinae) estaría bastante sesgada. Para conocer el significado del posible sesgo hemos comparado con trabajos de otros autores (Pokines, 1998; Zubeldia Garmendia, 2006).

Una vez separados los microfósiles del sedimento ya lavado, se vuelven a lavar en una cubeta de ultrasonidos para eliminar las partículas de matriz más fina. Posteriormente, para su estudio, se montan los elementos diagnósticos en soportes diversos y se archivan en pequeñas cajas de plástico transparente, etiquetadas con la sigla completa de la muestra, que consta de los siguientes datos: Yacimiento El Mirón, fecha de campaña, $n^{\circ}$ de muestra, cuadro, sector, nivel estratigráfico (ver Figs. 4-7) y tramo (el tramo, spit, es una unidad menor, de escala centimétrica, lo que implica que el muestreo de los pequeños mamíferos del Mirón es prácticamente continuo pues se hace cada centímetro o cada pocos centímetros, Figs. 4-7). Gracias a la excavación arqueológica de la Cueva del Mirón se ha podido obtener una de las más importantes secuencias de fósiles de pequeños mamíferos del Holoceno y finales del Pleistoceno superior cántabro (Tabla 2).

La identificación de cada especie se basa en elementos diagnósticos, craneales y postcraneales, del esqueleto de estos pequeños vertebrados (Figs. 8, 9, 10, 11): en general el número mínimo de individuos (NMI) se calcula a partir del número de primeros molares inferiores en el caso de los arvicolinos, un molar diagnóstico en el resto de los pequeños mamíferos o un elemento postcraneal igualmente determinable; además se tiene en cuenta la simetría bilateral del esqueleto de los vertebrados. En El Mirón se han estudiado hasta el momento 721 muestras, 
con un total de 3.403 NMI. Otros 100.000 restos óseos de pequeños mamíferos, aves, anfibios, reptiles y peces están todavía por identificar.

La metodología utilizada es la bioestratigráfica, es decir el análisis tanto cualitativo cómo cuantitativo de la distribución de las especies por niveles y tramos o tallas en las secuencias estratigráficas de las distintas zonas. Un estudio tafonómico preliminar de los microvertebrados del Mirón indica que éstos son el producto de la acumulación de egagrópilas producidas por rapaces nocturnas principalmente (ya que la mayoría de los restos, aunque rotos, presentan un moderado estado de digestión y constituyen una buena representación del esqueleto completo), con algún aporte ocasional por parte de pequeños carnívoros como la comadreja, Mustela nivalis Linnaeus, 1766, que está presente en casi toda la secuencia (Tabla 2), el gato silvestre Felis sylvestris Schreber, 1775 y el zorro, Vulpes vulpes Linnaeus, 1758; los cuales se alimentan de pequeños mamíferos (Carvalho \& Gomes, 2004; Hernández, 2005) y podrían utilizar la cueva eventualmente como refugio y/o comedero. Como se ha comentado en el apartado de Estratigrafía, un ejemplo de utilización del Mirón por parte de los carnívoros son los niveles 107 a 107.2 del Corral. Otro factor de acumulación sería entradas ocasionales; éste podría ser el caso del topo común, cuyos restos suelen estar mejor conservados que los de otros pequeños mamíferos, aunque esto puede estar también ligado a la robustez del esqueleto postcraneal de este pequeño mamífero excavador. Por otra parte, según la propuesta de Eastham (1995), el topo habría podido ser cazado por el hombre por su piel.

La ausencia de restos de pequeños mamíferos en determinados niveles podría ser debida a la menor ocupación de los mismos por parte de las rapaces, hecho controlado por otros factores, climáticos o posiblemente la presión de la presencia humana. En los niveles actuales sí parece haber una relación directa entre el empobrecimiento general de la fauna debido a las actividades humanas, que trae como consecuencia una considerable disminución de hábitats favorables, agravándose con la introducción de predadores nuevos, así como la eliminación, por parte también del hombre, de las aves rapaces, las cuales son las principales generadoras de acumulaciones de pequeños mamíferos en las cuevas. El estudio de egagrópilas de rapaces actuales muestra que, en las zonas humanizadas, la diversidad disminuye con respecto a zonas con menor impacto humano (Brunet-Lecomte \& Delibes, 1984; observaciones personales).

El análisis bioestratigráfico se realiza en dos fases, en la primera se analiza la secuencia estratigráfica de cada zona para analizar la distribución tanto temporal como espacial. En la segunda fase hemos reunido las muestras correspondientes a cada zona en una única secuencia, estudiando tanto los cambios estratigráficos como, en los casos en que se discute, por niveles culturales (Tabla 3) para detectar posibles cambios relacionados con la actividad humana.

\section{SISTEMÁTICA}

La nomenclatura sistemática sigue la propuesta por García Perea \& Gisbert (1997) y Wilson \& Reeder (2005). En la descripción de los dientes de las distintas familias de pequeños mamíferos utilizaremos la nomenclatura establecida por diferentes autores (ver descripción más adelante). Se utilizarán las siglas: I para los incisivos, $\mathrm{C}$ caninos, $\mathrm{P}$ premolares y $\mathrm{M}$ los molares. Una letra mayúscula indica que el elemento dental es superior y una minúscula, inferior. La colección de microfósiles del Mirón (MIR 1-130, 300-306, Tabla 2) se conserva provisionalmente en el Área de Paleontología del Departamento de Ciencias de la Tierra de la Universidad de Zaragoza.

En este apartado también se incluye una breve síntesis sobre el hábitat, distribución geográfica y estratigráfica de cada especie, en comparación con el resto de la Península Ibérica y Europa. Hay que señalar que las especies de pequeños mamíferos del Mirón difieren sobre todo en las proporciones numéricas con respecto a otros yacimientos de la Cornisa Cantábrica, a excepción de la persistencia de Pliomys lenki (nivel 106, alrededor de 12.000 años) con respecto a otros yacimientos Ibéricos (Pokines, 1998; Arrizabalaga et al., 2003; Baena et al., 2005; Zubeldia Garmendia, 2006; éste trabajo). Las diferencias con yacimientos franceses cercanos del Pirineo oriental y la Gascogne son mayores, siendo de notar la rareza de los roedores arvicolinos Arvicola sapidus, Pliomys lenki y Chionomys nivalis en los yacimientos del Pleistoceno superior de Francia (Chaline, 1972; Marquet, 1989; Eastham, 1995).

También es notable el contraste con las asociaciones faunísticas de otros yacimientos del final del Cuaternario de la Península Ibérica (Sesé \& Sevilla, 1996; López-García, 2006), especialmente la ausencia de especies mediterráneas como el microtino ibérico Iberomys cabrerae (Thomas, 1906), y los insectívoros Atelerix algirus (Lereboullet, 1842), Neomys anomalus Cabrera, 1907, o Talpa occidentalis Cabrera, 1907, entre otras, en la Cornisa Cantábrica.

Los murciélagos (O. Chiroptera) son escasos. Sólo aparecen una especie de gran tamaño del género Myotis y otra de pequeño tamaño, Miniopterus schreibersii. Es notable la ausencia de Rhinolophus Lacépède, 1779, género generalmente representado por una o más especies en otros yacimientos de Cantabria como Covalejos (Sesé, 2005). La rareza de murciélagos, en general en la Cornisa Cantábrica (Pokines, 1998; Pemán, 2000; Baena et al., 2005; Zubeldia Garmendia, 2006; éste trabajo), contrasta con la riqueza en yacimientos del Sur de Francia como L'Hortus (Jullien, 1972).

Los pequeños carnívoros, en su mayoría de la Familia Mustelidae, se encuentran en El Mirón representados por la comadreja, Mustela nivalis, especie común en la Península Ibérica (Palomo \& Gisbert, 2002) y en general en los yacimientos Pleistocenos. Otros carnívoros de mayor talla los estudia Marín Arroyo (2007).

Las especies de roedores, a excepción de Pliomys lenki, viven en Europa en la actualidad. M. gregalis y M. oeco- 
nomus migraron hacia el norte de Europa, desapareciendo de la Península Ibérica en el Pleistoceno superior y en el Holoceno respectivamente (Pokines, 1998; este trabajo). La especie Chionomys nivalis se encuentra en la región pero sólo en la alta montaña, entre 1.500 y $2.000 \mathrm{~m}$ de altitud (Palomo \& Gisbert, 2002).

Los lagomorfos, representados en El Mirón, consisten fundamentalmente en dientes aislados de Lepus y Oryctolagus (Marín Arroyo, 2007; este trabajo).

Orden ERINACEOMORPHA Gregory, 1910

Familia Erinaceidae Fischer von Waldheim, 1817 Género Erinaceus Linnaeus, 1758

\section{Erinaceus europaeus Linnaeus, 1758}

El erizo europeo es escasísimo en El Mirón, un único resto es asignable a esta especie en el nivel 7 (Tablas 1 y 2). Por esta razón no vamos a dar más detalles sobre esta especie pues desconocemos su significado estratigráfico o ecológico en las asociaciones de pequeños mamíferos del Mirón.

Orden SORICOMORPHA Gregory, 1910

Familia Soricidae Fischer von Waldheim, 1817 Género Sorex Linnaeus, 1758

\section{Sorex gr. S. coronatus Millet, 1758 -} S. araneus Linnaeus, 1758

Fig. 8.a-8.b

Las especies del género Sorex son difíciles de distinguir basándonos en caracteres craneales, especialmente cuando sólo contamos con dientes aislados o mandíbulas sin dientes (Brunet-Lecomte \& Delibes, 1984; Casteig \& Escala, 1988; López-Fuster \& Ventura, 1996). Los restos de Sorex del Mirón son escasos y fragmentarios por lo que no es posible hacer este análisis, aunque podemos distinguir una forma algo más robusta de otra que es algo más grácil. Los sorícidos se distinguen por tener el cóndilo articular desdoblado, con dos facetas articulares separadas por la zona interarticular que puede variar en longitud (dorso-ventral) y en anchura (latero-medial). Las especies de Sorex se distinguen de las de Crocidura por tener los dientes rojos y el cóndilo articular grácil (más largo que ancho, Fig. 8). Por su distribución geográfica parece probable que la especie del Mirón sea Sorex gr. coronatus-araneus. La especie $S$. coronatus se encuentra desde el Pleistoceno superior y en la actualidad en la zona de Ramales de la Victoria y en toda la región Cántabra (Pokines, 1998). La especie S. araneus es una especie gemela, supuestamente no-simpátrica en la Península Ibérica con $S$. coronatus, aunque sí más al este en Europa (Pokines, 1998). Sin embargo algunos autores (Pemán, 1990b; Zubeldia Garmendia, 2006) proponen una
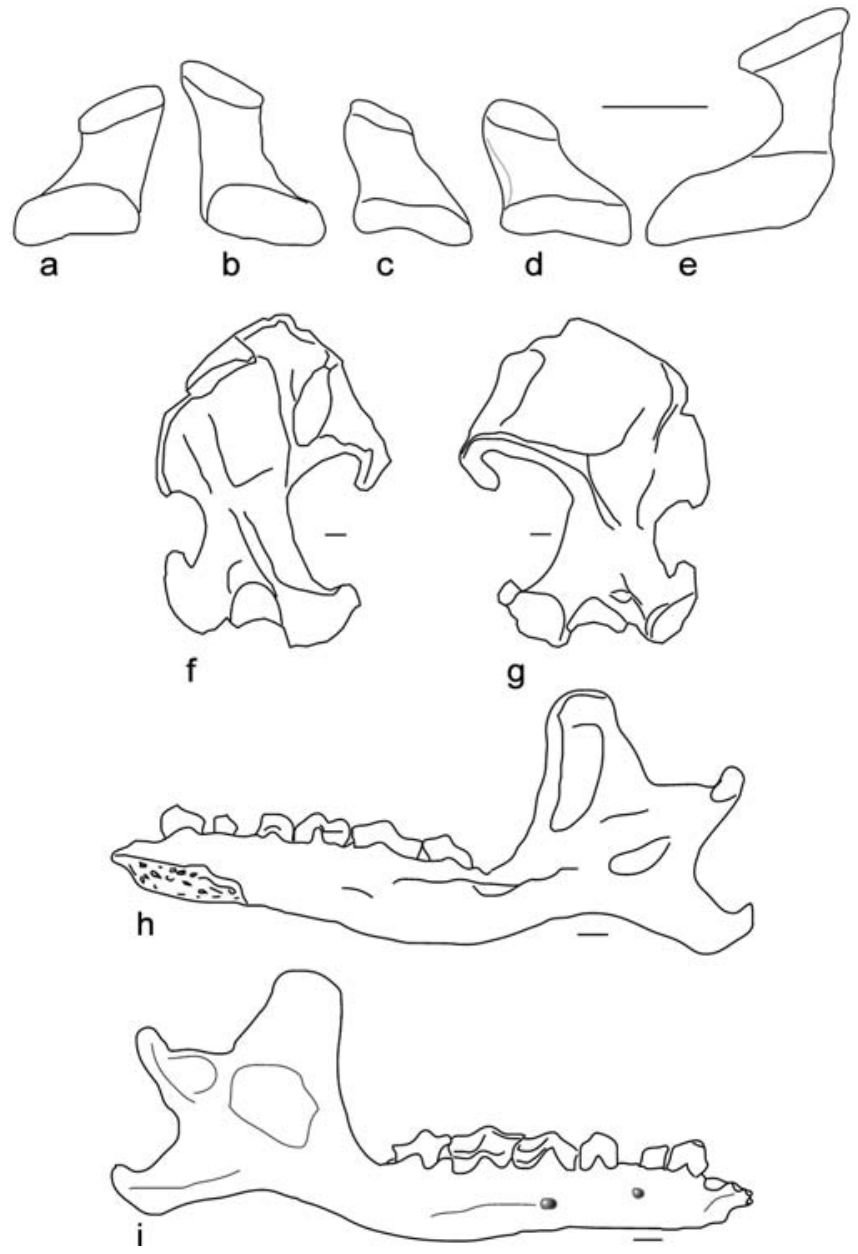

Figura 8. Los Insectívoros (Soricomorpha) Cuaternarios de la Cueva del Mirón, Ramales de la Victoria, Cantabria. a-e: Cóndilos articulares de diferentes especies del nivel 10 (MIR10); a: Sorex coronatus Millet, 1758-S. araneus Linnaeus, 1758 derecho; b: idem, izquierdo; c-d: Crocidura russula (Hermann, 1780) izquierdo; e: Neomys fodiens (Pennant, 1771) derecho; f-g: húmero derecho de Talpa europaea Linnaeus, 1758 del nivel 1, vistas posterior (f) y anterior (g); h-i: mandíbula derecha de Talpa europea Linnaeus, 1758 del nivel 10, vistas medial (h) y lateral (i). Dibujos con cámara clara. Las escalas representan $1 \mathrm{~mm}$.

Insectivores (Soricomorpha) of the Quaternary of the El Mirón Cave, Ramales de la Victoria, Cantabria, Spain. a-e: Articular condyles of different species of level 10; $\boldsymbol{a}$ : Sorex coronatus Millet, 1758-S. araneus Linnaeus, 1758 right; $\boldsymbol{b}$ : idem, left; $\boldsymbol{c}$-d: Crocidura russula (Hermann, 1780) left; $\boldsymbol{e}$ : Neomys fodiens (Pennant, 1771) right; $f$-g: right humerus of Talpa europaea Linnaeus, 1758 from level 1 , posterior $(\boldsymbol{f})$ and anterior (g) views; $\boldsymbol{h}$-i: rigth mandible of Talpa europea Linnaeus, 1758 from level 10, medial (h) and lateral $(\boldsymbol{i})$ views. Light camera drawings. Bars represents $1 \mathrm{~mm}$.

zona de intersección, en el norte de la Península Ibérica (López Fuster et al., 1999). 
Hábitat y distribución geográfica: tres especies de Sorex se encuentran en el norte de la Península: la zona de intersección entre la musaraña común $S$. araneus y $S$. coronatus es una banda que se extiende al norte, en los Pirineos, aunque ésta última se extiende hasta Galicia y hacia el sur por el Sistema Ibérico. La musaraña ibérica se encuentra en el Sistema Central hasta la desembocadura del Tajo y de allí a Galicia (López-Fuster \& Ventura, 1996; LópezFuster et al., 1999). Son especies que habitan en lugares húmedos con una buena cobertera vegetal herbácea (prados húmedos para $S$. coronatus) o arbustiva e incluso arbórea (Pokines, 1998).

Distribución estratigráfica: $S$. araneus aparece en el Pleistoceno inferior de Europa (Maul, 1990). S. coronatus en el Pleistoceno superior (Pokines, 1998).

\section{Sorex minutus Linnaeus, 1766}

Es la musaraña de dientes rojos más pequeña del género Sorex. Su diminuto tamaño y la coloración de las cúspides, la hace fácilmente distinguible de otras especies de musaraña.

Hábitat y distribución geográfica: Ocupa la Europa templada, y en España el norte, entrando por la Cuenca del Duero, hasta Portugal (Blanco, 1998 a). Su presencia está ligada a una buena cobertera vegetal, preferentemente herbácea, en medios húmedos y templados.

Distribución estratigráfica: Sorex minutus se conoce desde el Pleistoceno inferior en toda Europa (Furió Bruno, 2003).

Género Neomys Kaup, 1829

\section{Neomys fodiens (Pennant, 1771)}

Fig. 8.e

El musgaño acuático, Neomys fodiens, es el sorícido actual de mayor tamaño de Europa. Habita en las proximidades de los cursos de agua. Como las especies de Sorex, tiene los dientes rojos. Se distingue claramente del resto de sorícidos por su cóndilo articular con faceta interarticular más alargada y estrecha, faceta ventral alargada hacia la cara medial y sus robustos dientes, propios de consumidor de pequeños invertebrados con concha o caparazón. En España hay dos especies de musgaños: $N$. fodiens o musgaño patiblanco y $N$. anomalus o musgaño de Cabrera. La especie $N$. fodiens es de mayor talla. Los restos de El Mirón se asignan a la especie $N$. fodiens por su gran talla, la altura coronoides es de 6 mm (Pemán, 1983).

Hábitat y distribución geográfica: En la actualidad Neomys fodiens se encuentra ampliamente repartido por
Europa y norte de la Península Ibérica mientras que Neomys anomalus tiene una distribución ligada a macizos montañosos de la Península Ibérica y centro-este de Europa. Están siempre ligados a masas de agua, arroyos o lagos pues se alimenta de invertebrados acuáticos. $N$. anomalus parece estar menos ligada al medio acuático que $N$. fodiens; se encuentra en prados y bosques húmedos (Blanco, 1998 a).

Distribución estratigráfica: Neomys fodiens se conoce al menos desde el Pleistoceno medio en Europa occidental (Jammot, 1974).

Género Crocidura Wagler, 1832

\section{Crocidura russula (Hermann, 1780)}

Fig. 8.c-8.d

La musaraña de dientes blancos es escasa en El Mirón, hay fragmentos de mandíbula, en las que se conserva bien el cóndilo, y fragmentos de cráneo. En uno de los maxilares se observa que el protocono de P3 está formando el borde antero-lingual del diente y en la base de la corona, en vista labial, el borde anterior es anguloso. Estas características permiten asignar este material a la especie C. russula.

Hábitat y distribución geográfica: Las especies del género Crocidura en la Península Ibérica son C. suaveolens, septentrional y atlántica, y $C$. russula, de amplia distribución en todo tipo de hábitats, incluso en medios humanizados (Blanco, 1998 a; Rey \& Landín, 1973).

Distribución estratigráfica: De la distribución estratigráfica de Crocidura en El Mirón se desprende que es rara (Tabla 2, Fig. 12), falta en la mayoría de los niveles Holocenos, y cuando se encuentra, es escasa. En el Pleistoceno es prácticamente inexistente salvo al final, ya prácticamente en el tránsito Pleistoceno-Holoceno. En Europa Crocidura russula se conoce desde el Pleistoceno inferior (Rzebik-Kowalska, 1998).

Familia Talpidae Fischer von Waldheim, 1817 Género Galemys Kaup, 1829

\section{Galemys pyrenaicus (E. Geoffroy, 1811)}

Como se ha comentado en la estratigrafía, un húmero del desmán del pirineo o topo de río es el único registro fósil de esta especie en El Mirón (Rampa, Nivel 130). Superficialmente se asemeja al húmero de las especies del género Talpa Linnaeus, 1758, del que se distingue, entre otros caracteres, por la menor anchura latero medial de su extremidad distal. 
Hábitat y distribución geográfica: El desmán ibérico o topo de río es un animal que vive en la proximidad de corrientes de aguas limpias, sin contaminar, de los ríos del Pirineo (Español y Francés, donde fue definida la especie), y de zonas montañosas en el resto de España y Portugal en la actualidad (Peyre, 1956; Alegre \& Hernández, 1990; Castién \& Gosálbez, 1992).

Distribución estratigráfica: El género Galemys se separa del género Desman desde el Plioceno (Rzebik-Kowalska, 1994). En la Península Ibérica se encuentra desde el Pleistoceno Inferior (López Antoñanzas \& Cuenca-Bescós, 2002; Furió Bruno, 2003). La especie Galemys pyrenaicus es un endemismo Ibérico que se cita desde el Pleistoceno Medio en Portugal (Marks et al., 2002) aunque es más común desde el Pleistoceno Superior (Pokines, 1998). La única cita de esta especie en el Cuaternario Francés es la de Jeannet et al. (1996).

Género Talpa Linnaeus, 1758

\section{Talpa europaea Linnaeus, 1758} Fig. 8.f-8.i

Los topos son animales cavadores, que se caracterizan por el robusto miembro anterior y por tener las mandíbulas alargadas con las apófisis angular y coronoide robustas que contrastan con su delicado cóndilo articular, simple y cilíndrico (Fig. 8h, i). Esta estructura es muy distinta de la de otros insectívoros como los sorícidos. Los restos de Talpa del Mirón pertenecen a una especie de gran talla y aunque la dentición y restos craneales de individuos adultos son escasos, por su robustez pensamos que son asignables a la especie Talpa europaea. Hay que señalar, sin embargo, que en algunos yacimientos de la Cornisa Cantábrica, como el Magdaleniense de Rascaño 5, 3 y Altamira o el Auriñaciense de Cueto de la Mina 7 (Pokines, 1998) se cita Talpa occidentalis. Como esta especie es escasa y difícil de distinguir de T. europaea si se carece de un estudio morfométrico detallado, de momento asignamos nuestra especie del Mirón a la especie más común y robusta, T. europaea como hemos indicado.

Hábitat y distribución geográfica: las especies del género Talpa son pequeños mamíferos de vida hipogea que necesitan suelos profundos para excavar las galerías en las que habitan. Son prácticamente ciegos y rara vez salen de sus madrigueras excepto en la época de reproducción. Autores como Eastham (1995) proponen que los hombres del Magdaleniense podrían haber cazado topos para aprovechar sus pieles en Dufaure. En el caso del Mirón es necesario un estudio tafonómico más detallado de los restos, tanto craneales como postcraneales para conocer cuáles son las causas de su presencia en la cueva, ya que en general, son difíciles presas de los predadores habituales, causan- tes de la acumulación de otros pequeños vertebrados. Sin embargo hay autores que lo citan, aunque como elementos raros, en las egagrópilas de Tito alba (Alegre et al., 1989; Campos Marcos et al., 2003).

Distribución estratigráfica: la especie Talpa europaea se encuentra desde el Pleistoceno inferior, tanto en Europa (Maul, 1990; Paunovic \& Rabeder, 1996) como en la Península Ibérica (Rofes \& Cuenca-Bescós, 2006).

\section{Orden CHIROPTERA Blumenbach, 1779}

Los restos de quirópteros son escasos en El Mirón, aunque esta escasez puede ser consecuencia del muestreo y la fragilidad de los huesos. Dada su rareza mencionaremos únicamente que los restos de gran tamaño son atribuibles a una de las especies del género Myotis Kaup, 1829 y los de menor tamaño a la especie Miniopterus schreibersii (Kuhl, 1817). Sobre la especie de mayor tamaño no podemos comentar mucho pero de la segunda podemos decir que es el representante más pequeño de los murciélagos de cueva europeos. Se encuentra generalmente en yacimientos cársticos desde el Pleistoceno inferior de Europa (Kowalski, 1956; Horacek, 1976; Sevilla García, 1988; Maul, 1990).

$$
\begin{aligned}
& \text { Orden CARNIVORA Bowdich, } 1779 \\
& \text { Género Mustela Linnaeus, } 1758
\end{aligned}
$$

\section{Mustela nivalis Linnaeus, 1766}

Los pequeños carnívoros son escasos en El Mirón aunque se encuentran en casi toda la secuencia. Los restos encontrados, por su tamaño y morfología, son asignables a Mustela nivalis, la comadreja.

Distribución estratigráfica: las comadrejas se conocen desde el Pleistoceno medio en Europa (Maul, 1990) y en España desde el Pleistoceno medio (García García, 2003).

Orden RODENTIA Griffith, 1827

Familia Sciuridae Hemprich, 1820

Género Sciurus Linnaeus, 1758

\section{Sciurus vulgaris Linnaeus, 1758}

La ardilla común Europea o ardilla roja, está representada por un único resto como se ha comentado en la estratigrafía (Cabaña, Nivel 10.1, Fig. 4 y Tablas 1 y 2). El resto fósil es un incisivo característico de esta especie por su intenso color rojo-anaranjado y sus acanaladuras labiales. Dado lo escaso de estos restos no vamos a comentar más de lo que ya se ha dicho en el apartado de estratigrafía. 
Familia Muridae Illiger, 1815

\section{Subfamilia Arvicolinae Gray, 1821}

Los arvicolinos, subfamilia que incluye a topillos, neverones y ratas de agua, son pequeños roedores de hábitos generalmente cavadores, que habitan en medios abiertos con suelos profundos en los que excavan sus madrigueras. Su distribución actual es holárctica, con escasas excepciones. La sistemática paleontológica de los arvicolinos está basada en la morfología y biometría de los dientes yugales (molares) que se caracterizan por su hipsodoncia o corona alta, que en la mayoría de las especies actuales alcanza la hipselodoncia (perdida de raíces con la ontogenia). Parámetros obtenidos en el análisis morfométrico de la dentición como el tamaño y la morfología oclusal (longitud mesio-distal, anchura, desarrollo de los triángulos labiales y linguales y de los complejos anterior o mesial y posterior o distal), altura de la corona, presencia/ausencia de raíces, presencia/ausencia de cemento en los entrantes, grosor del esmalte y el número de entrantes y salientes (también llamados triángulos por su morfología: triángulos de dentina rodeados por una pared de esmalte que puede cerrarlos por completo o casi cuando son confluyentes) en la superficie oclusal son los principales distintivos de un arvicolino. Las hipótesis filogenéticas o relaciones de parentesco y por lo tanto su clasificación están basadas en la evolución de estos caracteres (Chaline, 1972; van der Meulen, 1973; Brunet-Lecomte et al., 1987; Brunet-Lecomte \& Chaline, 1990; Rekovets \& Nadachowski, 1995; Maul \& Markova, 2007). El incremento de los estudios genéticos es una nueva fuente de información sobre las relaciones filogenéticas de los arvicolinos por lo que su posición dentro del orden Rodentia hace que muchas de las hipótesis filogenéticas "tradicionales" estén en continua discusión (Conroy \& Cook, 2000; Jaarola et al., 2004; Piertney et al., 2005), por lo que la sistemática de los arvicolinos está en plena revisión (Repenning, 1968; Chaline et al., 1999). En este trabajo seguiremos la propuesta de Chaline et al. (1999) para la sistemática de la subfamilia Arvicolinae, y la nomenclatura y análisis de parámetros de van der Meulen (1973).

El elemento más importante de la dentición es el primer molar inferior (a partir de ahora m1). Gran parte del análisis morfométrico se hace sobre la superficie oclusal de este diente (van der Meulen, 1973).

Género Arvicola Lacépède, 1799

\section{Arvicola terrestris (Linnaeus, 1758)}

Fig. 9.a-9.d

Las especies del género Arvicola pertenecen al grupo de ratas toperas o ratas de agua en España (topillos de agua en Europa). La especie A. terrestris es el arvicolino más grande de la fauna europea, aunque en la Península Ibérica le supera ligeramente en tamaño la rata de agua mediterránea, Arvicola sapidus Miller, 1908. La especie A. terrestris tiene el esmalte de los molares con diferenciación tipo Microtus, es decir, ligeramente más grueso en la parte mesial de los triángulos de la superficie oclusal que en la distal. En la especie A. sapidus la diferenciación es la inversa, con el esmalte más grueso en la parte distal, lo que se conoce por esmalte tipo Mimomys Major, 1902 (Fig. 9).

Hábitat y distribución geográfica: en la actualidad la rata de agua norteña tiene una amplia distribución EuroAsiática. En España se halla sólo en el norte, en la zona Euro-Siberiana. En el resto de Eurasia, donde no hay competencia con A. sapidus habita en medios fluviales y lacustres, nidificando en sus orillas. Sin embargo en presencia de la rata de agua mediterránea, se retira a los prados y vegas de los ríos. Dado su gran tamaño suele ser la presa principal del búho real (Bubo bubo), constituyendo en ocasiones su única dieta (Frafjord, 2003). Esto puede repercutir en la composición de las asociaciones de pequeños mamíferos, si el principal predador de los alrededores del yacimiento es el búho, por lo que un aumento en el número de ambas especies de Arvicola, debe de ser analizado con precaución.

Distribución estratigráfica: Arvicola terrestris se encuentra desde la segunda mitad del Pleistoceno medio en Europa (Heinrich, 1990). Es relativamente frecuente en los yacimientos del Pleistoceno tardío de la Cornisa Cantábrica (Pokines, 1998).

\section{Arvicola sapidus Miller, 1908} Fig. 9.e-9.g

Externamente A. sapidus o rata de agua meridional se asemeja a la norteña, A. terrestris. Es el arvicolino de mayor tamaño de la fauna de roedores española. Se diferencia de A.terrestris por la forma del complejo anterior y por el esmalte diferenciado plesiomórfico, tipo Mimomys.

Hábitat y distribución geográfica: especie típica de orillas de ríos y acequias de regadío de la Península Ibérica y Sur-Centro de Francia (Pokines, 1998; observaciones personales y Colectivo de Salas de los Infantes, Burgos). Prefiere zonas con aguas estancadas y riberas densamente pobladas y en zonas contaminadas es desplazada por la rata común (Arrizabalaga et al., 1986). Infrecuente en el norte de España o Francia; al igual que durante el Pleistoceno-Holoceno (Zabala, 1983; Ventura \& Sans-Fuentes, 1997; Pokines, 1998). Desconocemos cuándo hace su entrada en la Cornisa Cantábrica pues sólo se encuentra en el Gravetiense de Rascaño 7 (Altuna, 1981), el Solutrense de Las Caldas y La Riera, el Magdaleniense inferior de El Juyo nivel 8 (Pokines, 1998) y en el Magdaleniense inferior y comienzos del Holoceno del Mirón (Tabla 2). 
En el Pleistoceno medio hay numerosas citas con confer o affinis, que indican que la especie está aún por revisar (Cuenca-Bescós et al., 1999).

Distribución estratigráfica: La especie Arvicola sapidus aparece en el Pleistoceno medio. El origen de la rata de

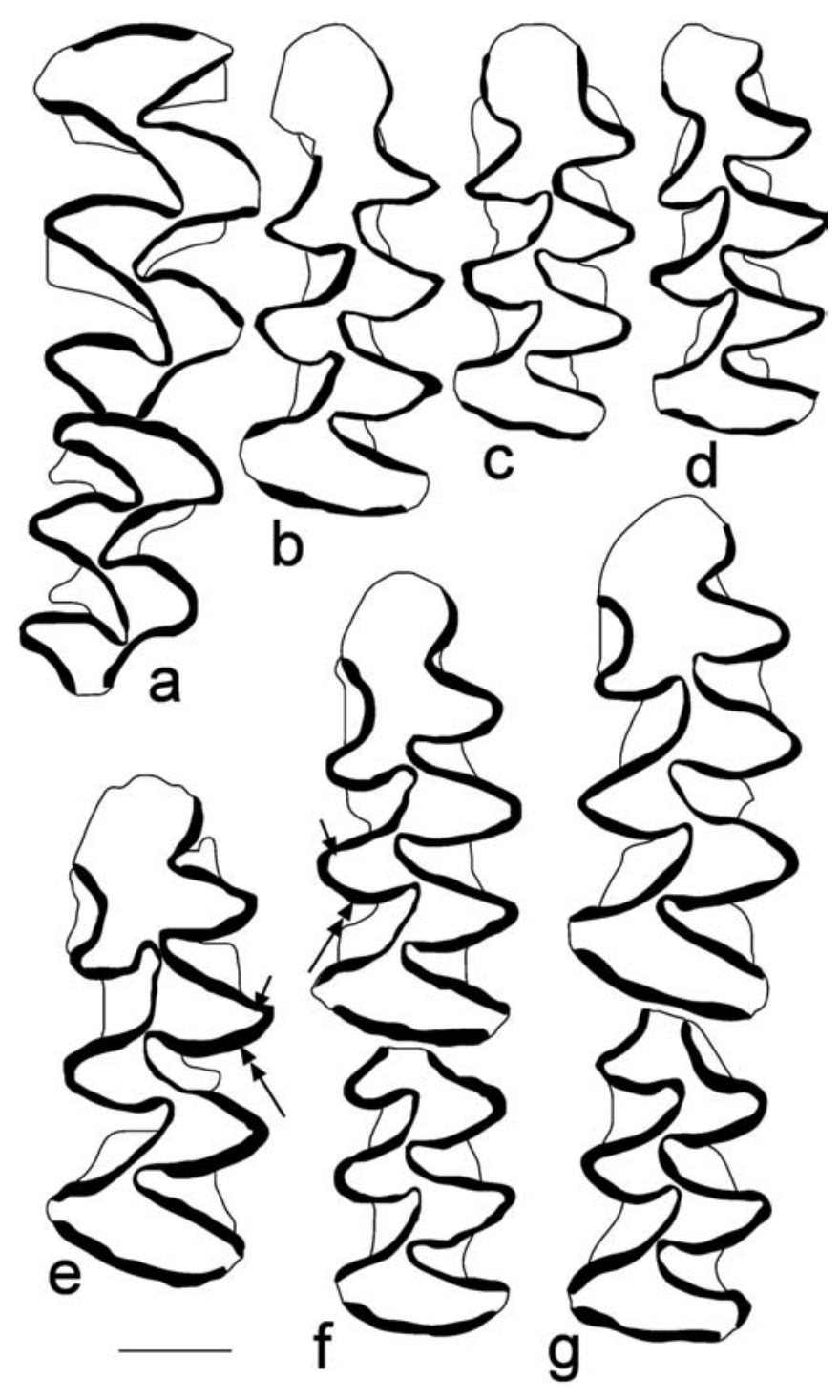

agua meridional es aún confuso. Se ha discutido mucho sobre su evolución a partir de Mimomys savini Hinton, 1910, que daría lugar a A. terrestris y A. sapidus, clado que se originaría en el Pleistoceno medio. Sin embargo los autores están en desacuerdo sobre la especie ancestral que da origen a A. sapidus (Ruiz Bustos \& Sesé, 1985; Ruiz Bustos, 1988; Koenigswald \& Kolfschoten, 1996; Abbassi et al., 1998).

Género Microtus Schrank, 1798

\section{Microtus agrestis (Linnaeus, 1761) Fig. 10.f}

Las especies de los géneros Microtus, Terricola y Chionomys tienen el esmalte diferenciado tipo Microtus (Fig. 10). La especie M. agrestis es de tamaño mediano; después de Chionomys nivalis es el tercer arvicolino en tamaño del Mirón. Carece de raíces y tiene cemento en los entrantes. El m1 tiene 4 triángulos casi cerrados en el complejo anterior. Se caracteriza por la asimetría y alternancia de los triángulos t4 y t5 y t6-t7 así como la fuerte alternancia de los ángulos entrantes, lo que lo diferencia de $M$. arvalis. Además, en M. agrestis el M2 (segundo molar superior) tiene tres salientes linguales o, lo que es lo mismo, 4 triángulos cerrados. Como ambas especies son morfológicamente semejantes, hay autores que las agrupan (Pokines, 1998; Baena et al., 2005).

Hábitat y distribución geográfica: también se le conoce como topillo agreste o de montaña. El actual M. agrestis vive en el Norte de la Península Ibérica y en el Norte de Europa y Asia, desde el Reino Unido y la Península Escandinava hasta Siberia. En el norte de la Península Ibérica, se encuentra desde los Pirineos a Galicia y Norte de Portugal y falta en la región mediterránea. Prefiere los pastos húmedos, márgenes de bosque e incluso páramos y dunas en Europa (Pokines, 1998). En España es un indicador de clima atlántico. Se encuentra en el Montseny, una montaña mediterránea, en la que, por su altura, se de-

Figura 9. Arvicolinos, Arvicola terrestris (Linnaeus, 1758) y Arvicola sapidus Miller, 1908 (Arvicolinae, Rodentia) del Cuaternario de la Cueva del Mirón, Ramales de la Victoria, Cantabria. a-d: dibujos de cámara clara de la superficie occlusal de los molares de Arvicola terrestris; a: maxilar izquierdo con M1 y M2 del nivel 3; b: m1 izquierdo del nivel 6; c-d: m1 izquierdos del nivel 3; e-g: Arvicola sapidus del nivel 10, $\mathrm{m} 1$ izquierdo (e), mandíbula (f-g) con m1m2 derechos (los dibujos se han invertido, para facilitar la comparación). Las flechas indican el mayor grosor de esmalte de la parte posterior de los triángulos de esmalte de Arvicola sapidus en relación con los de A. terrestris. Observar también el mayor tamaño (longitud y anchura) de los molares de A. sapidus. Dibujos con cámara clara. La escala representa $1 \mathrm{~mm}$.

Arvicolinae, Arvicola terrestris (Linnaeus, 1758) and Arvicola sapidus Miller, 1908 (Arvicolinae, Rodentia) of the Quaternary of El Mirón Cave, Ramales de la Victoria, Cantabria, Spain. a-d: Light camera drawings of the occlusal surface of the molars of Arvicola terrestris; a: left maxila with M1 and M2 from level 3; b: left m1 from level 6; $c$-d: left $\mathrm{ml}$ from level 3; $\boldsymbol{e}-\mathrm{g}$ : Arvicola sapidus from level 10, left $\mathrm{ml}(\boldsymbol{e})$, right mandible $(\boldsymbol{f}-\boldsymbol{g})$ with $\mathrm{m} 1 \mathrm{~m} 2$ ( $\mathrm{f}$ and $\mathrm{g}$ drawings reversed to make possible the comparisons). The arrows indicate the enamel differenciation, thicker in the posterior part of the triangles of Arvicola sapidus; thicker in the anterior part in A. terrestris. Observe also the bigger size of A. sapidus in relation to A. terrestris. Bars represents $1 \mathrm{~mm}$. 

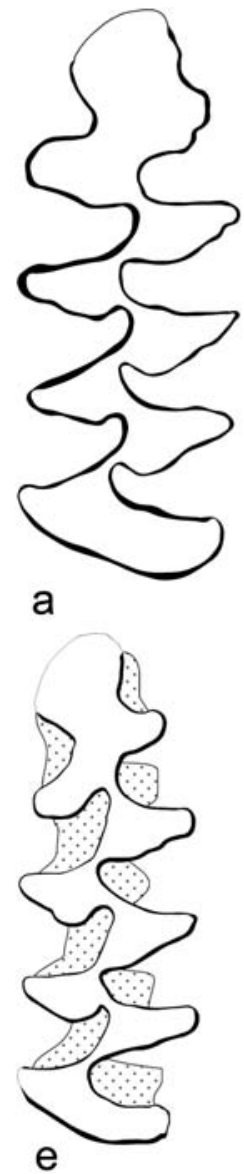

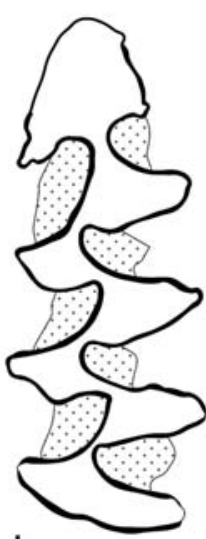

b

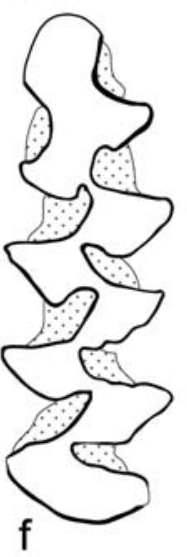

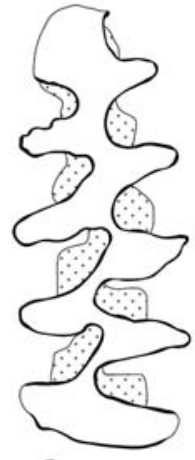

c

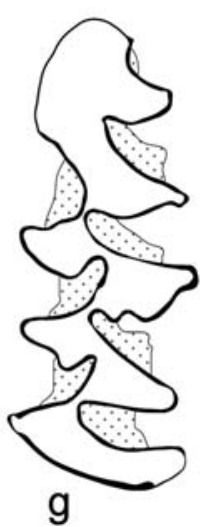

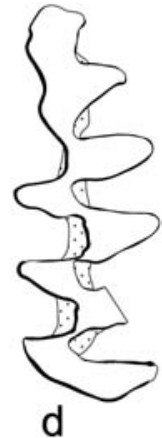

d

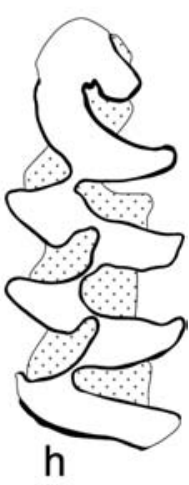

Figura 10. Otros Arvicolinos (Rodentia) del Cuaternario de la Cueva del Mirón, Ramales de la Victoria, Cantabria. Dibujos con cámara clara de la superficie occlusal de los m1. Todos son molares izquierdos excepto el b, que se ha invertido para facilitar la comparación. a: Pliomys lenki Heller, 1930 del nivel 130; b: Chionomys nivalis (Martins, 1842) del nivel 128 (invertido); c: Terricola lusitanicus Gerbe, 1879 del nivel 17; d: Microtus gregalis Pallas, 1779 del nivel 113; e: Microtus arvalis (Pallas, 1779) del nivel 13; f: Microtus agrestis (Linnaeus, 1761) del nivel 107; g-h: Microtus oeconomus (Pallas, 1776) de los niveles 124 y 12 respectivamente. La escala representa $1 \mathrm{~mm}$.

Other Arvicolinae (Rodentia) of the Quaternary of El Mirón Cave, Ramales de la Victoria, Cantabria Spain. Light camera drawings of the occlusal surface of the m1. All are left molars but the b, reversed to make possible the comparisons. a: Pliomys lenki Heller, 1930 from level 130; b: Chionomys nivalis (Martins, 1842) from level 128 (reversed); c: Terricola lusitanicus Gerbe, 1879 from level 17; $\boldsymbol{d}$ : Microtus gregalis Pallas, 1779 from level 113; $\boldsymbol{e}$ : Microtus arvalis (Pallas, 1779) from level 13; $\boldsymbol{f}$ : Microtus agrestis (Linnaeus, 1761) from level 107; $\boldsymbol{g}-\boldsymbol{h}$ : Microtus oeconomus (Pallas, 1776) from levels 124 and 12 respectively. Bars represent $1 \mathrm{~mm}$.

sarrollan ecosistemas más septentrionales: en el encinar, el hayedo, las parcelas desforestadas con cobertura herbácea, e incluso en muros de piedra y campos de cultivo (Arrizabalaga et al., 1986).

Distribución estratigráfica: las primeras citas de formas "agrestes" se conocen desde el Pleistoceno inferior (Villany, 8-11, en Hungría, Maul, 1990). Sin embargo el verdadero topillo agreste actual hace su aparición más tardíamente, a finales del Pleistoceno medio en Europa (Marquet, 1989) y durante el Pleistoceno superior en España (Villalta, 1972) y la región Cántabra (Pemán, 1990b).

\section{Microtus arvalis (Pallas, 1779) Fig. 10.e}

El topillo campesino o común tiene el m1 semejante al de $M$. agrestis, pero se diferencia de éste por la disposición casi simétrica y en paralelo de t4-t5 y especialmente de t6-t7, así como de los correspondientes ángulos entrantes; esto le confiere un complejo anterior más redondeado en contraste con el más anguloso de $M$. agrestis. También es de talla ligeramente menor, aunque se necesita una muestra lo suficientemente grande para poder estimar la diferencia. El M2 tiene dos salientes linguales o tres triángulos cerrados, a diferencia del M2 de M. agrestis que tiene 4 triángulos cerrados.

Hábitat y distribución geográfica: $M$. arvalis tiene una repartición semejante a la de $M$. agrestis aunque es una especie más oportunista, con una distribución más extensa y menos discontinua que la del topillo agreste. También en la Península Ibérica se extiende más hacia el sur y puede encontrarse en multitud de ámbitos, desde pastos a bosques caducifolios y coníferas (Palacios, 1988; Alcántara de la Fuente, 1992; González Esteban et al., 1994; Blanco, 1998b; Pokines, 1998), siempre con cierta humedad; por lo que las actuales condiciones de aridez del mediterráneo le han obligado a refugiarse en los macizos montañosos (Palomo \& Gisbert, 2002) y ha desaparecido de áreas costeras del Mediterráneo Español en las que vivió durante el Pleistoceno superior (Guillem, 1995).

Distribución estratigráfica: al igual que el topillo agreste, las formas "arvalis" aparecen ya en el Pleistoceno inferior (Maul, 1990). Sin embargo M. arvalis aparece en Pleistoceno medio de España (Arribas, 1994), y resto de Europa (Rekovets \& Nadachowski, 1995) algo más tempranamente que $M$. agrestis.

\section{Microtus oeconomus (Pallas, 1776)}

Fig. 10.g-10.h

El topillo de los pantanos, topillo ártico, o de los humedales fríos, es el más escaso de los Microtus del Mi- 
rón (Tabla 2). El m1 tiene tres triángulos cerrados, con $\mathrm{t} 4$ y t5 alternos y éste último confluye ampliamente con el t7 y el lóbulo anterior. El complejo anterior es asimétrico pues el t6 es un saliente apenas marcado. El entrante lingual mesial es reducido.

Hábitat y distribución geográfica: $M$. oeconomus, es un habitante típico de la Tundra y del norte de la Taiga Holártica, desde Canadá hasta Holanda y Escandinavia; donde se encuentra en llanos húmedos, turberas y pantanos. Aunque en la actualidad se encuentra bien representado en Europa norte y central (Nadachowski, 1982; Pokines, 1998) desaparece de las Islas Británicas (y probablemente de Europa occidental al norte de los Pirineos) a comienzos del Holoceno (Sutcliffe \& Kowalski, 1976).

La desaparición de esta especie en la Península Ibérica es más reciente, se ha encontrado en los niveles romanos de la Cueva de Amalda (Pemán, 1990a, b) y en los niveles 3 y 5 (Bronce temprano y Calcolítico) del Mirón (Tabla 2). M. oeconomus es un animal solitario que no puede competir con $M$. arvalis, ya que este último forma grandes grupos (Pokines, 1998), factor que hay que tener en cuenta al analizar su distribución estratigráfica. Aunque tenemos pocos datos del resto de la Península, una de las últimas citas de M. oeconomus es la de los niveles tardiglaciares de la Cueva Dels Ermitons, en Gerona (Alcalde Gurt, 1982). Su presencia en los niveles holocenos del Mirón y Amalda es una de las últimas conocidas en toda España. En los niveles Magdalenienses (V, VI y VI') de Erralla se encuentra en grandes cantidades, al igual que $M$. arvalis - agrestis (ver Pemán, 1985) por lo que podemos deducir que la extensión de las zonas húmedas era importante durante el Magdaleniense en Erralla. La proximidad de Erralla y Amalda hacen pensar que el paisaje de la zona (Cestona) era abierto, húmedo y relativamente frío durante buena parte del Magdaleniense y hasta época Romana en el Holoceno. En El Mirón M. oеconomus, aunque escaso, está presente en casi toda la secuencia coincidiendo en general con $M$. arvalis y períodos de abundancia de $A$. terrestris (Tabla 2, Fig. 12) por lo que podemos pensar que esta asociación representa momentos de mayor humedad. La presencia de Neomys fodiens, la musaraña acuática, también concuerda. Hay que señalar que, salvo en el nivel 130 de la Rampa, M. oeconomus está presente en casi toda la secuencia del Mirón, tanto en el Pleistoceno como en buena parte del Holoceno, hasta los 2.000 años. Sin embargo falta durante el Aziliense (por encima de los niveles 104.2-102 del Corral), datado entre los 11.500 y 9.000 años (Straus, 2005). El significado de esta desaparición debe de estar ligado con un período de sequedad, ¿el Dryas III?, en el que desaparecerían los humedales que constituyen el hábitat óptimo de la especie. El nivel 106 representa un período de apertura, con la aparición de prados en detrimento del bosque, seguramente ligado a la sequedad (Figs. 12,13), donde es significativo el gran número de individuos de $M$. arvalis y $M$. agrestis, ambas especies de prados abiertos (Fig. 13).

Distribución estratigráfica: como en otras especies de Microtus, las primeras referencias de formas con morfología de M. oeconomus son del Pleistoceno inferior (Maul, 1990; Rekovets \& Nadachowski, 1995) de Europa centrooriental. También hay formas parecidas en el Pleistoceno medio, como M. oeconomus-ratticepoides (López Antoñanzas \& Cuenca-Bescós, 2002). La especie M. oeconomus aparece en Europa occidental (Francia, España) en el Pleistoceno superior (Alcalde Gurt, 1982; Pemán, 1990a, b; Eastham, 1995; Pokines, 1998).

\section{Microtus gregalis Pallas, 1779 Fig. 10.d}

Sólo hay un ejemplar de Microtus gregalis (Tabla 2) en El Mirón, en el nivel 113 del Corral. Los m1 de este topillo se distinguen del resto de las especies de Microtus del Mirón por su acusada asimetría labio-lingual y la comunicación del reducido a inexistente triángulo 6 con el complejo anterior. Tiene el $\mathrm{m} 1$ de mayor longitud, en relación con la anchura, que otros topillos, lo que le confiere un aspecto grácil.

Hábitat y distribución geográfica: El topillo de cráneo estrecho, M. gregalis, habita en la tundra y estepa Euro-Siberiana donde vive en complejas colonias de madrigueras con numerosas entradas y salidas ocupadas durante largos períodos de tiempo (Pokines, 1998).

Distribución estratigráfica: La especie $M$. gregalis se cita en yacimientos del Pleistoceno inferior de Europa oriental y central (Maul, 1990) aunque aparentemente sólo al final del Pleistoceno medio y únicamente durante los momentos más fríos del Pleistoceno superior se encuentra en Europa occidental, en el Reino Unido (Currant, 1986), Francia (Marquet, 1989) y España (Pokines, 1998; Sesé, 2005). Su presencia en el nivel 113 del Mirón confirma la entrada de este roedor en España, exclusivamente en la Región Cantábrica, al final del Pleistoceno superior.

Género Chionomys Miller, 1908

\section{Chionomys nivalis (Martins, 1842)}

Fig. 10.b

La especie Chionomys nivalis es el topillo "tipo" Microtus más grande de la península, aunque Iberomys cabrerae (Thomas, 1906) tiene los molares más anchos transversalmente. El m1 de Ch. nivalis es característico por su lóbulo anterior, en forma de seta con el sombrero fuertemente inclinado hacia el lado labial. En el lado lingual sólo hay 
4 entrantes, uno menos que en la mayoría de las especies de Microtus. En los individuos juveniles este carácter está menos marcado y puede confundirse con Microtus agrestis ya que el cuarto entrante lingual varía de ligeramente provergente en los individuos juveniles a muy provergente en los adultos.

Hábitat y distribución geográfica: Es un habitante típico de alta montaña, por encima de la línea de árboles de las regiones alpinas, hasta los 2000 metros de altura, aunque el rango de altitud puede variar y depender de otros factores (Mitchell-Jones et al., 1999; Luque-Larena et al., 2002), por lo que se le conoce también como ratilla nival o neverón. Su hábitat parece estar más controlado por la disponibilidad de terrenos rocosos con fisuras o pedreras, soleados, sin vegetación, al borde de pastos, que por la altura (Pokines, 1998). También, durante el Pleistoceno superior y Holoceno, hasta el calcolítico, Ch. nivalis se encuentra en yacimientos situados en cotas bajas, a menos de 250 metros sobre el actual nivel del mar, como Amalda (205 m), Aizbiarte (220 m), Cueto de la Mina (complejo de La Llera, al lado de la cueva de La Riera, 30 m), Ekain (90 m), entre otros (Pokines, 1998). Es posible que el incremento de cota con respecto al paleonivel Pleistoceno del mar debido a la glaciación haya influido en esta distribución. En el resto de España y sur de Francia el Musteriense pudo ser una época favorable a la dispersión del neverón, pues se encuentra en zonas de las que ha desaparecido en la actualidad como el yacimiento francés de l'Hortus (Chaline, 1972; Cabrera-Millet et al., 1982) y en España en el de la Carigüela, en Granada (Ruiz Bustos, 2000), Los Toros, en Teruel (Gil \& Sesé, 1985) y Gabasa en Huesca (Gil \& Lanchares, 1987). Es probable que en los momentos más fríos del Pleistoceno superior la expansión de zonas rocosas, sin vegetación fueran favorables a la dispersión de la especie a cotas más bajas, o montañas del interior peninsular. La mejora climática del Holoceno no debió de ser tan uniforme como para reducir por completo las poblaciones de $C h$. nivalis que han sobrevivido hasta la actualidad como demes aislados en macizos montañosos de la Península Ibérica (García-Perea \& Gisbert, 1997). También en el resto de Europa se encuentra en los macizos montañosos mediterráneos, desde los Pirineos hasta los Tatra pasando por los Alpes y por el mediterráneo oriental desde el Monte Olimpus en Grecia hasta el Líbano e Israel y en el oriente medio hasta los Montes Zagros de Irán (Pokines, 1998).

Distribución estratigráfica: la morfología "nivalis" se encuentra ya desde el final del Pleistoceno inferior. Aunque la especie $C h$. nivalis aparece al final del Pleistoceno medio en Francia (Desclaux, 1996-1997), no es bien conocida hasta el Pleistoceno superior en Francia (Marquet, 1989) y España (Sesé Benito \& Soto Rodríguez, 1988; Pokines, 1998).
Género Terricola Fatio, 1867

\section{Terricola lusitanicus Gerbe, 1879}

Fig. 10.c

El grado de confluencia de los triángulos 6 y 7 , que forman el segundo rombo pitimiano, así como la inclinación de los triángulos labiales permiten clasificar a la especie de Terricola de El Miron como T. lusitanicus. En la Península Ibérica hay en la actualidad tres o cuatro especies de $T e$ rricola según los autores: T. duodecimcostatus (de SélysLongchamps, 1839), T. pyrenaicus (de Sélys-Longchamps, 1839) y T. lusitanicus (Gerbe, 1879) en Brunet-Lecomte \& Chaline (1993) o cuatro, con T. gerbei (Gerbe, 1879), en Niethammer \& Krapp (1982) y Giannoni et al. (1993). La diferenciación morfológica de las especies de Terricola es complicada (Brunet-Lecomte et al., 1987; Brunet Lecomte \& Chaline, 1990, 1993). La especie de Terricola del Mirón tiene el $\mathrm{m} 1$ con morfología de T. lusitanicus: el "rombo pitimiano 2" está relativamente aislado de la parte anterior en T. lusitanicus y en T. pyrenaicus mientras que en T. duodecimcostatus confluye ampliamente. Cuando T. lusitanicus y T. duodecimcostatus son alopátricos este carácter es más variable e individuos aislados pueden ser difíciles de distinguir basándonos solo en este rasgo (Brunet Lecomte et al., 1987). La distinción entre T. lusitanicus y T. pyrenaicus se basa en una mayor inclinación hacia distal de los triángulos labiales de T. lusitanicus. También es de notar el abombamiento de los ápices labiales de estos triángulos, lo que constituye una novedad evolutiva de la especie T. lusitanicus.

Hábitat y distribución geográfica: Las especies de $T e$ rricola de la Península Ibérica son formas cavadoras que presentan gran similitud en sus hábitos; sin embargo, $T$. duodecimcostatus excava y empuja la tierra hacia delante con ayuda de los incisivos mientras que T. lusitanicus y $T$. pyrenaicus empujan la tierra hacia atrás con ayuda de sus miembros posteriores (Giannoni et al., 1993). La utilización de los incisivos (al igual que en Arvicola terrestris) está en relación con la excavación de suelos más duros que los de las especies que lo hacen con los miembros posteriores (Giannoni et al., 1992). Terricola lusitanicus necesita suelos profundos para hacer sus madrigueras, por lo que está ligada a clima más atlántico que $T$. duodecimcostatus. Ambas especies son simpátricas en Castilla y León mientras que en Cantabria sólo se encuentra T. lusitanicus, especie que puede estar en simpatría con T. pyrenaicus (Brunet-Lecomte et al., 1987; Brunet-Lecomte, 1991). El topillo pirenaico prefiere los suelos profundos, con una buena cubierta vegetal, mientras que el lusitano los prefiere más someros y con afloramientos rocosos dispersos (Borghi et al., 1990).

Distribución estratigráfica: las especies de Terricola actuales de la Península Ibérica aparecen tardíamente, en el Pleistoceno superior (Pokines, 1998; Guillem, 1995a, b). 
Género Clethrionomys Tilesius, 1850

\section{Clethrionomys glareolus (Schreber, 1780)} Fig. 11.h-11.i

La especie $C$. glareolus es el único arvicolino actual de la península Ibérica que tiene a la vez raíces y cemento en los entrantes labiales y linguales (Fig. 11). Otra peculiaridad del topillo rojo es el esmalte continuo, sin zonas libres (salvo en individuos seniles) y con el mismo grosor en todo el perímetro oclusal. Los molares tienen triángulos confluyentes, no cerrados o aislados como en el resto de los arvicolinos actuales. Salvo en el nivel 7, su presencia es constante y prácticamente invariable durante el Holoceno del Mirón, sin embargo al final del Pleistoceno es escasa y está ausente en los niveles anteriores al Magdaleniense (ver tablas 1 y 2 ).

Hábitat y distribución geográfica: El topillo rojo es uno de los pocos arvicolinos actuales que vive en bosque caducifolio, más o menos abierto o en zonas en donde la vegetación es arbustiva o compuesta por hierbas altas. Es un buen indicador de paisaje con cobertera vegetal en un clima templado húmedo (Pemán, 1985, 1990a, b). Se encuentra en la Eurasia templada, desde el lago Baikal hasta las Islas Británicas. En España tiene una distribución actual septentrional (Ventura et al., 1993; Pokines, 1998) aunque puede encontrarse en los macizos montañosos del Levante español que gozan de un clima eurosiberiano como el mencionado macizo del Montseny en Cataluña (Arrizabalaga et al., 1986).

Distribución estratigráfica: la especie $C$. glareolus aparece en el Pleistoceno inferior y desde entonces tiene una amplia distribución Europea hasta la actualidad (Tesakov, 1996).

\section{Género Pliomys Méhely, 1914}

\section{Pliomys lenki Heller, 1930}

Fig. 10.a

Se caracteriza por tener raíces y carecer de cemento en los ángulos entrantes (Fig. 10). Su tamaño relativamente grande en relación con otros arvicolinos (a excepción de las especies de Arvicola), unido a la presencia de raíces y la ausencia de cemento en los entrantes hacen de esta especie un microtino inconfundible. Desde su descripción original, en el yacimiento de Sackdilling (Alemania) los estudios sobre Pliomys lenki muestran que es una especie con una morfología relativamente estable y además es muy longeva (Bartolomei et al., 1975; Chaline, 1975) en relación con las rápidas radiaciones que sufren los demás arvicolinos. A falta de un estudio sistemático más completo podemos decir por la talla que $P$. lenki del Mirón se encuentra en el extremo de mayor tamaño de las poblaciones de Pliomys lenki del Pleistoceno superior. Algunos autores como Maul \& Markova (2007), ponen P. lenki en sinonimia con P. coronensis (Méhely, 1914), especie que se extingue en Europa central en el Pleistoceno medio. A falta de una revisión del género Pliomys, continuaremos utilizando P. lenki para las formas que se encuentran en Europa Occidental. El aumento de talla de Pliomys lenki es también señalado por Pemán (1990 a) en el yacimiento de Amalda (niveles IVa-X) y como en ésta localidad, el esmalte presenta una diferenciación de tipo Microtus. En Boscochiesanuova, Italia (Bartolomei et al., 1975), es también notable la diferenciación de esmalte. Esta evolución de la diferenciación del grosor de esmalte debe de estar ligada con el aumento de la hipsodoncia y de la aparición de las zonas libres de esmalte como también ponen de manifiesto otros autores para otras líneas de arvicolinos (Maul, 2001).

Hábitat y distribución geográfica: El género Pliomys está relacionado con Dinaromys bogdanovi (Martino, 1922) endemismo Balcánico actual (Chaline et al., 1999) conocido también como topillo de Martino o de los Balcanes (Serbia, Croacia, Bosnia-Herzegovina, Montenegro y Macedonia). D. bogdanovi es una especie de alta montaña, comparable por su ecología con Chionomys nivalis. Por sus relaciones filogenéticas y yacimientos en los que se encuentra, es posible que Pliomys lenki tuviera una ecología similar a la de ambas especies actuales, el neverón y el topillo balcánico.

Distribución estratigráfica: la especie Pliomys lenki ha sido citada en numerosos yacimientos del Pleistoceno inferior y medio de Alemania, Polonia, Rumania, Hungría, la antigua Checoslovaquia, Italia, Francia y España (Bartolomei et al., 1975). Es posible que la especie perviva en Europa meridional (Italia y Francia) hasta el final del Pleistoceno medio / comienzos del superior (Chaline, 1975; Chaline \& Marquet, 1976; Marquet, 1989; Ferraris et al., 1990), sin embargo es en la Península Ibérica y un único yacimiento en Francia, la Grotte du Sanglier (Marquet, 2001), donde la especie sobrevive hasta el final del Pleistoceno superior, poco antes del período climático frío conocido como Dryas III, al final de la última glaciación (Würm). La especie se refugia en España durante gran parte del Würm, encontrándose en los yacimientos de El Juyo, Amalda, Lezetxiki y Ekain (Altuna, 1972; Zabala, 1984; Pemán, 1990a, b; Pokines, 1998) en el Cantábrico, Els Ermitons en Gerona (Alcalde Gurt, 1982), en Gabasa, Huesca (Gil \& Lanchares, 1988) e incluso en yacimientos más meridionales y mediterráneos, como Cova Negra, en el sur de Valencia (Guillem, 1995). Su presencia en El Mirón es intermitente, reaparece en el nivel 106, tras haber desaparecido de niveles anteriores, para finalmente extinguirse. Esta última aparición podría tratarse de un efecto Lázaro (Fara, 2001; Cuenca-Bescós et al., 2006). 
$P$. lenki parece ser una especie ligada a medios esteparios, abiertos, montanos y fríos según la mayoría de los autores (Bartolomei et al., 1975; Marquet, 1989; este trabajo). Como resalta Chaline (1975), la especie migra durante el Pleistoceno desde el este hacia el suroeste de Europa, persistiendo únicamente en España (este trabajo) y sur de Francia (Marquet, 2001) hasta el final del Pleistoceno. ¿Está relacionada esta migración con el enfriamiento progresivo del clima, siempre más benigno en España que en el resto de Europa continental?, ¿O está relacionada mas con una entrada de otros pequeños mamíferos que compiten por el mismo medio?

Durante el Pleistoceno Superior su presencia está relacionada con momentos fríos en Gabasa, Huesca (Gil \& Lanchares, 1988) y en Cova Negra, Valencia, donde Pliomys se encuentra asociado con Allocricetus Schaub, 1930, en la fase seca (F, unos 20.000 años, Guillem, 1995). Por otra parte, su presencia en general en yacimientos en cuevas hace pensar que $P$. lenki está ligada a un substrato rocoso. En cuanto a la competencia con otros mamíferos sólo podemos mencionar que la entrada de especies adaptadas a los lugares favoritos en que habita $P$. lenki, como Chionomys nivalis, podría ser la causa final de su extinción por competencia.

\section{Subfamilia Murinae Illiger, 1815}

Los murinos son roedores con dientes yugales radiculados, coronas bajas (braquidontas) y superficie oclusal formada por 4 a 6 cúspides principales y un número variable de cúspides secundarias en el lado labial de los molares. Su fórmula dental es 1Ii3Mm como la de los arvicolinos.

Género Apodemus Kaup, 1829

\section{Apodemus sylvaticus Linnaeus, 1758 o Apodemus flavicollis (Melchior, 1834)}

El género Apodemus se caracteriza por tener la superficie oclusal con 6 cúspides principales en el primer molar (tanto inferior como superior), y 4 en los molares segundo y tercero. En la cara labial $\mathrm{m} 1$ tiene 3 cúspides secundarias, $\mathrm{m} 2$ de 2 a una y $\mathrm{m} 3$ es reducido, con la parte posterior acuminada. Las especies actuales de Apodemus de la Península Ibérica son A. sylvaticus y A. flavicollis, el ratón de campo y el ratón leonado respectivamente. Morfológicamente son muy parecidas, comparten numerosos caracteres dentales y aunque A. flavicollis tiene una talla mayor que A. sylvaticus, en simpatría sus medidas se solapan por lo que es bastante difícil separar ambas especies si no se hace un análisis morfométrico detallado. La diferencia de talla, manifiesta en Europa Central y Norte disminuye hacia el sur haciendo que la distinción entre las dos especies en la Península Ibérica (y en general en todas las penínsulas mediterráneas) sea problemática (Nores, 1988; Alcántara de la Fuente, 1992).

Hábitat y distribución geográfica: ambas especies tienen una distribución amplia, la especie A. flavicollis tiene una repartición discontinua en Europa y en España se encuentra sólo en el norte, desde los Pirineos hasta Asturias, mientras que $A$. sylvaticus es más mediterránea y se encuentra en toda la Península (Alcántara de la Fuente, 1992).

Distribución estratigráfica: ambas especies Apodemus sylvaticus y A. flavicollis se conocen desde el Pleistoceno inferior (Maul, 1990).

\section{Familia Myoxidae Gray, 1821}

Los glíridos o lirones son roedores que se caracterizan por tener la superficie oclusal de sus molares surcada por crestas transversales separadas por valles, tener raíces y ser braquidontos (Fig. 11).

Género Myoxus Zimmermann, 1780

$$
\begin{gathered}
\text { Myoxus glis (Linnaeus, 1766) } \\
\text { Fig. 11.f-11.g }
\end{gathered}
$$

Es el mayor de los lirones, y uno de los mayores roedores, europeos. Se distingue por tener los dientes de contorno rectangular a cuadrado y superficie oclusal plana, con crestas transversas claramente separadas por valles relativamente anchos. Estas crestas son de desarrollo continuo, labio-lingual. En los molares inferiores las crestas se giran hacia la parte anterior y en los superiores se curvan hacia la posterior. Entre las crestas principales hay crestas secundarias, más cortas, que no alcanzan las caras labial ni lingual.

Hábitat y distribución geográfica: El lirón gris es una especie de bosque cálido que habita en la actualidad en Europa Central y Meridional hasta el Cáucaso y en el norte de España, siendo pieza de caza en Europa central; también se encuentra en el sur de Inglaterra pero ésta podría ser una introducción de mediados de siglo XX (Krystufek \& Haberl, 2001). También puede ser un comensal ocasional (Pokines, 1998). En el yacimiento de Erralla aparece en niveles cálidos o templados (II, III, V) de la secuencia aunque asociado con especies mas frías, de espacios abiertos y heliófilas como el neverón (Pemán, 1985).

Distribución estratigráfica: el gran lirón gris Муохиs glis se conoce desde el Pleistoceno medio, en Europa central entra cuando desaparecen las especies de Myoxus del Pleistoceno inferior (Nadachowski, 1990). En Francia no aparece hasta la segunda mitad del Pleistoceno medio 

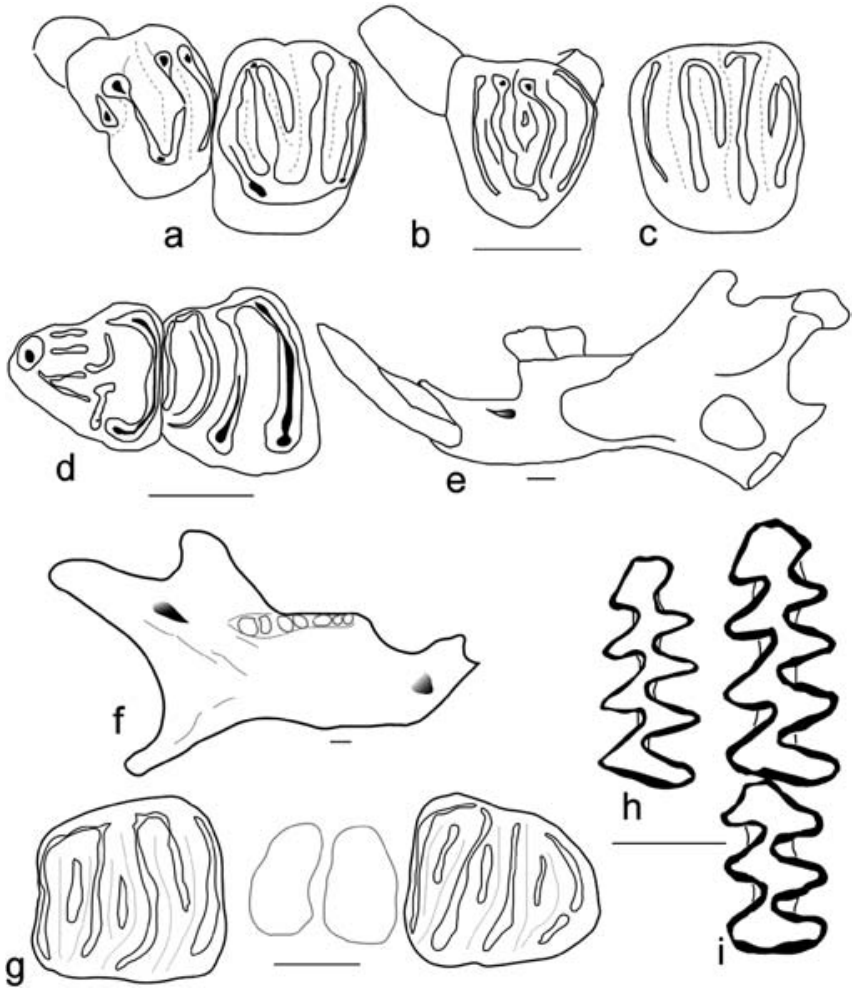

Figura 11. Otros arvicolinos y otros roedores del Cuaternario de la Cueva del Mirón, Ramales de la Victoria, Cantabria. Dibujos con cámara clara de la superficie occlusal de los molares y la cara lateral de las mandíbulas. a-g: molares y mandíbulas de Gliridos del nivel 10. a-e: Eliomys quercinus (Linnaeus, 1766); a: maxilar izquierdo con P4M1, b: maxilar izquierdo con D4, c: M12 derecho (invertido), d: mandíbula izquierda con p4m1, e: mandíbula izquierda en vista lateral. Observar el gran foramen de la lámina angular de la mandíbula, carácter apomorfico entre los roedores Cuaternarios de la Península Ibérica. f-g: Myoxus glis (Linnaeus, 1766); f: mandíbula izquierda, sin molares, en vista medial, g: mandíbula izquierda con m1 los alveolos de $\mathrm{m} 2$ y m3. h-i: Clethrionomys glareolus (Schreber, 1780); h: $\mathrm{m} 1$ izquierdo, i: mandíbula derecha con $\mathrm{m} 1 \mathrm{~m} 2$ (invertida). La escala representa $1 \mathrm{~mm}$. Other Arvicolinae and other rodents of the Quaternary of El Mirón Cave, Ramales de la Victoria, Cantabria, Spain. Light camera drawings of the occlusal surface of the molars and lateral and medial views of the mandibles. Some drawins are reversed to make comparisons easy. a-g: molars and mandibles of Gliridae from level 10. a-e: Eliomys quercinus (Linnaeus, 1766); $\boldsymbol{a}$ : left maxila with P4M1, $\boldsymbol{b}$ : left maxilla with D4, $\boldsymbol{c}$ : right M12 (reversed), $\boldsymbol{d}$ : left mandible with $\mathrm{p} 4 \mathrm{ml}, \boldsymbol{e}$ : left mandible in lateral view. See the big foramen in the angular laminae of the mandible, an apomorfic character among the Quaternary rodents of the Iberian Peninsula.f-g: Myoxus glis (Linnaeus, 1766); $f$ : left mandible, without molars, in medial view, $g$ : left mandible with $m 1$, alveoli of $m 2$ and $m 3$. $\boldsymbol{h}$-i: Clethrionomys glareolus (Schreber, 1780); $\boldsymbol{h}$ : left m1, $\boldsymbol{i}$ : right mandible with $\mathrm{mlm} 2$ (reversed). Bars represent $1 \mathrm{~mm}$.
(Desclaux, 1996-1997) y en España no se conoce más que en el Pleistoceno superior (Pokines, 1998).

Género Eliomys Wagner, 1840

\section{Eliomys quercinus (Linnaeus, 1766) \\ Fig. 11.a-11.e}

El lirón careto es un glírido de porte mediano, aunque es más pequeño que Myoxus glis sus molares son semejantes en tamaño. Es el único roedor español con un foramen amplio en la lámina angular de la mandíbula. Los molares son característicos por su superficie oclusal cóncava, con crestas transversas que recorren el diente labio-lingualmente y un gran desarrollo de las cúspides principales.

Hábitat y distribución geográfica: El lirón careto es una especie ampliamente distribuida por la Europa templada y Mediterránea, el norte de África y Levante. Se encuentra en los bosques y zonas de arbustos de toda la Península Ibérica (Moreno, 2002) ligado a claros pedregosos y como el lirón gris, es también un comensal ocasional. Es notable su ausencia en el Pleistoceno superior de Cantabria, pues sólo se conoce en el Auriñaciense de Cueto de la Mina (Pokines, 1998). Su presencia en yacimientos de la edad del Bronce $\left(\mathrm{C}^{14}=1.380-1.340 \mathrm{BP}\right)$ como La Encantada, en Ciudad Real puede estar relacionada con el hombre aunque de una manera indirecta, ya que el hombre favorece unas especies, por la creación de medios artificiales y elimina a otras (Morales Muñiz, 1986). Otro ejemplo de Eliomys ligado a enterramientos (y basureros) del Bronce es el de La Balsa la Tamariz, en Tauste, Zaragoza (Laplana \& Cuenca-Bescós, 1995). En El Mirón la especie entra al final del Magdaleniense, cuando comienza la expansión de los bosques en la Cornisa Cantábrica (aunque con desapariciones temporales debido al deterioro climático del Dryas III y desaparece después del óptimo climático del Holoceno, seguramente ligado a la deforestación provocada por el hombre a partir del Calcolítico (Tabla 2 y Fig. 12).

Distribución estratigráfica: el lirón careto se origina en el Mediterráneo y se conoce en España desde el Pleistoceno inferior, en secuencias como Casablanca, Castellón (Agustí \& Galobart, 1986).

\section{ANÁLISIS BIOESTRATIGRÁFICO DE LOS PEQUEÑOS MAMÍFEROS DE EL MIRÓN E IMPLICACIONES PALEOAMBIENTALES Y PALEOCLIMÁTICAS}

La distribución estratigráfica de los pequeños mamíferos del Mirón es variable según las especies. En la se- 
cuencia estratigráfica compuesta, en la que se han unido, utilizando criterios de correlación estratigráfica, cronológica y cultural, los cuatro sectores excavados, vemos que la mayoría de los pequeños mamíferos se encuentran en toda la secuencia, con variaciones en el número de individuos (Tabla 2 y Figs. 12, 13, 14). Pero hay especies que no cumplen este patrón:

Pliomys lenki se extingue en el Magdaleniense superior (Tabla 2, Fig. 12). Coincidiendo con la extinción de P. lenki, con un ligero solapamiento en el caso de Eliomys quercinus, aparecen las especies más ligadas al bosque de toda la secuencia, E. quercinus, Myoxus glis y Clethrionomys glareolus (Fig. 12). Coincidiendo con la aparición de las especies de bosque entra también la musaraña de dientes blancos, de carácter mediterráneo, Crocidura russula. Como vemos en la figura 14, la mediterraneidad, en función de la proporción entre los arvicolinos, roedores de medios abiertos y/o esteparios y los murinos, especies más mediterráneas (Alcántara de la Fuente, 1992), coincide también con la aparición de estas especies de bosque. El murino Apodemus sylvaticus, relacionado con bosque y lindes de bosque, aunque algo menos que los lirones, aumenta también en la parte alta de la secuencia, cuando se asientan las condiciones de mediterraneidad. Los arvicolinos, aunque no llegan a desaparecer del todo, disminuyen notablemente.

Es de notar que hacia el Holoceno tardío, durante el final del Bronce (Tabla 2 y Figs. 12,13) hay un incremento de arvicolinos de medios fríos y húmedos (M. oeconomus y Ch. nivalis), hecho que coincide con la desaparición de las especies de bosque (niveles $2+3$ y 3 , el 3 datado en 3.700 años BP). Este evento faunístico de la secuencia del Mirón se correlaciona tentativamente con la pequeña edad del hielo del final del Holoceno, que precede al período cálido Romano (Martínez-Cortizas et al., 1999) y que supuso un enfriamiento global que siguió al óptimo climático del Holoceno (Indermuhle et al., 1999; Uriarte Cantolla, 2003).

El aumento del bosque coincide más o menos con el llamado Óptimo Holoceno en el que subieron las temperaturas; antes del declive de temperatura de alrededor de los 2.000 años calibrados que precede al Período Romano Cálido del que hemos hablado (Martínez-Cortizas et $a l .$, 1999). El posterior declive del bosque y aumento de las especies ligadas a terrenos sin vegetación podría ser consecuencia de la deforestación que se va haciendo notoria especialmente a partir de finales del Bronce (Uriarte Cantolla, 2003).

La Península Ibérica se divide, por el clima y la distribución de la vegetación, en dos grandes regiones, la Eurosiberiana y la Mediterránea. Un indicador de mediterraneidad entre los pequeños mamíferos es por ejemplo el endemismo ibérico Iberomys cabrerae. Como esta especie falta en El Mirón hemos elaborado un índice de mediterraneidad a partir de las proporciones de Murinos+Glíridos (ratones y lirones respectivamente) con respecto a los $\mathrm{Ar}$ vicolinos (Fig. 14). Los primeros representan el clima mediterráneo (cálido) y los segundos al eurosiberiano (frío). Hemos elegido las tres secciones completas (dejando el sondeo de la Rampa) para elaborar este índice. En la Fig. 14 se puede observar que a partir del Holoceno inicial (Mesolítico), con algunas variaciones correspondientes a los enfriamientos Holocenos mencionados, se instala en España un régimen mediterráneo (Óptimo Holoceno) en el que aumenta el número de Murinos+Glíridos, indicadores el bosque mediterráneo.

Se observa que después del denominado óptimo climático del Holoceno, identificable en El Mirón en los niveles Mesolíticos hasta el final del Calcolítico (Figs. 12, 13 y 14) hay un deterioro importante en el número de especies, que disminuye drásticamente en los niveles recientes (1 y 2), lo que debe de estar relacionado con la escasez de las muestras por una parte y por otra, con una mengua de la actividad de las rapaces nocturnas al estar la Cueva ocupada permanentemente por los pastores y sus rebaños.

Es notable la persistencia de $M$. oeconomus y Chionomys nivalis hasta prácticamente el final del Holoceno, aunque ambas especies faltan en la actualidad en la franja costera Cantábica (Tabla 1). En el caso del neverón no ha desaparecido por completo de la Península Ibérica pues se encuentran poblaciones relictas en los macizos montañosos, donde quedan lugares favorables para esta especie, como roquedos soleados y desprovistos de vegetación (Luque-Larena et al., 2002). También en el Holoceno es de señalar la extinción (al menos local) del lirón careto, especie de bosque cálido que se encuentra en la actualidad en la zona. Las especies de múridos Mus (el ratón casero), Micromys minutus (el ratón espiguero) y Rattus (rata gris y negra) viven en la actualidad en Cantabria así como en el resto de España pero faltan en el Mirón. El único múrido presente en el Cuaternario del Mirón es Apodemus, que se encuentra bien representado en todos los niveles Holocenos aunque es raro en los niveles anteriores al Magdaleniense Superior. La falta de múridos "modernos" en El Mirón permite comprender algo más su dispersión en tiempos históricos: estos múridos no colonizan el Norte de España hasta prácticamente la actualidad (Pemán, 1985, 1990a, b; Pokines, 1998; este trabajo) y lo hacen probablemente a partir del momento en que la agricultura y el comercio se generalizan y extienden hacia el norte a través de rutas comerciales como la Ruta de la Plata que, al menos en el centro de la Península Ibérica, actúan como vías de dispersión del ratón casero y el gorrión común (Morales Muñíz et al., 1995).

Resumiendo, en la Tabla 2 y Fig. 12 vemos que la distribución de los roedores en el Pleistoceno-Holoceno del Mirón se caracteriza por:

1. La presencia esporádica de algunas especies como Arvicola sapidus, Microtus gregalis, Erinaceus, Sciurus, Galemy, entre otras. 


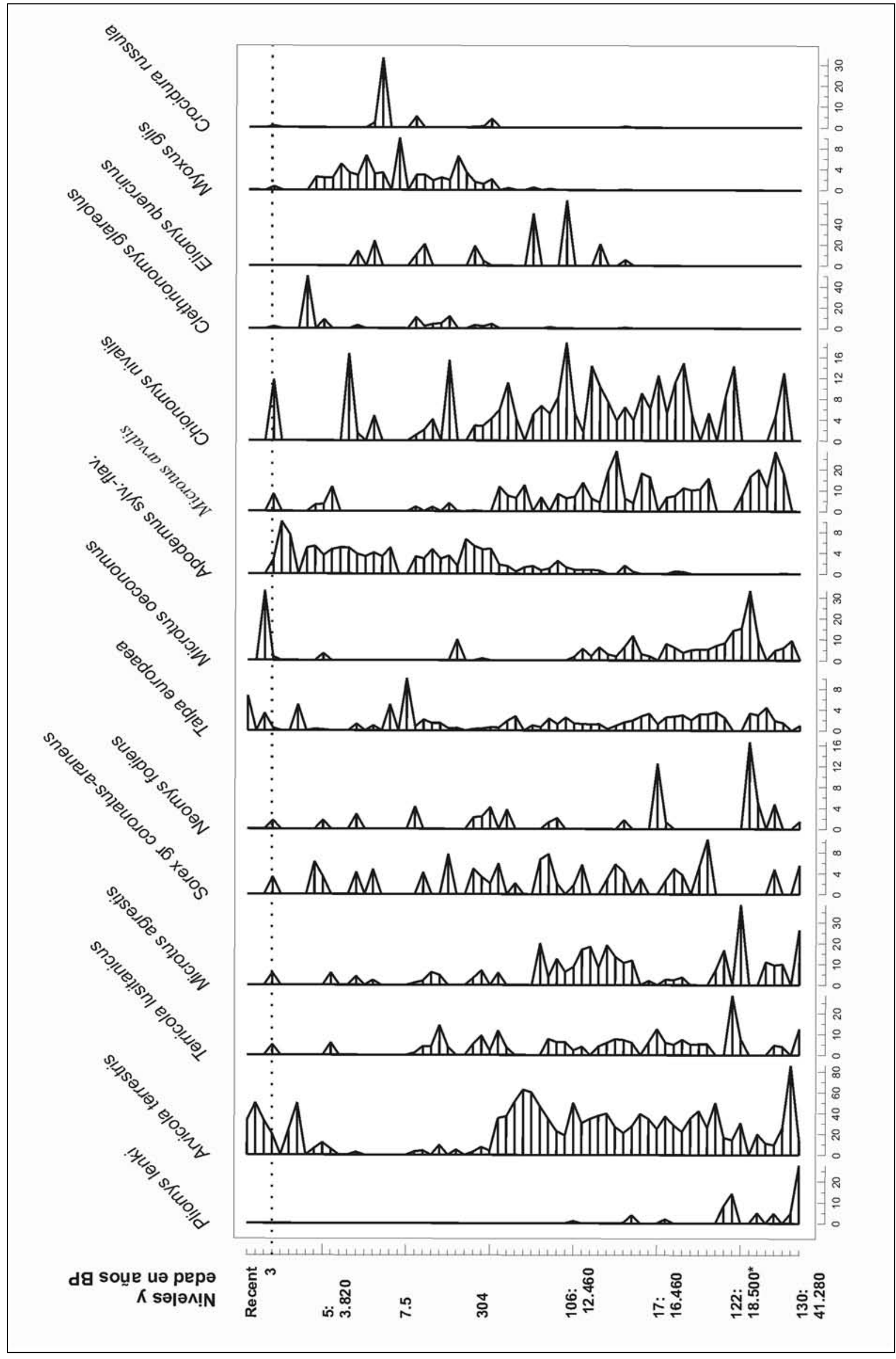


2. La presencia casi continúa en toda la secuencia y hasta la actualidad de A. terrestris y Talpa europaea, y otras que aunque no llegan hasta la actualidad se encuentran en prácticamente todos los niveles como las especies de los géneros Terricola y Microtus.

3. El elevado número de especies de arvicolinos frente a múridos en comparación con otros yacimientos del Holoceno de la Cornisa Cantábrica.

\section{EVOLUCIÓN DEL CLIMA Y DEL PAISAJE}

La mayoría de los pequeños mamíferos del Mirón tienen representantes actuales que viven en el norte de España y son típicos de la "España eurosiberiana", región climática caracterizada por su carácter atlántico, generalmente más húmedo que el de la "España mediterránea". Tomando las propuestas de los distintos autores (Chaline et al., 1999; Cuenca-Bescós et al., 2005) hacemos una clasificación de las especies por su hábitat óptimo. En una primera aproximación y de forma general podemos decir que hay siete grupos distintos de pequeños mamíferos en función del hábitat:

1. Especies de bosque: Eliomys quercinus, Myoxus glis, Apodemus sylvaticus, A. flavicollis y Clethrionomys glareolus

2. Especies de medios abiertos, que pueden ser separados en dos tipos, las de prado húmedo: las del género Sorex, Arvicola terrestris, Terricola lusitanicus y Talpa europaea

3. y las especies de prado seco: Crocidura russula, Microtus agrestis y $M$. arvalis

4. Masas de agua, turberas y prados encharcados: $M i$ crotus oeconomus, Neomys fodiens, A. sapidus

5. Alpinas: Chionomys nivalis y ¿Pliomys lenki?

6. Generalistas: Mustela nivalis

7. Hipogeos: Miniopterus schreibersii y las especies de Myotis, al menos en época de cría

Esta clasificación carece de límites netos pues taxones de bosque pueden encontrarse en bordes de prados secos con abundante vegetación arbustiva (Eliomys, Apodemus) y los de masas de agua pueden adaptarse a prados húmedos (Arvicola). Por otra parte, las especies fósiles no tienen porqué tener los mismos requerimientos ecológicos que sus representantes actuales por lo que su distribución y relación con el hábitat actual puede ser un efecto biogeográfico. Esta clasificación es sólo una aproximación a la evolución paleoambiental de la secuencia Cuaternaria del Mirón con pequeños mamíferos (Fig. 13):

1. El agua de forma permanente está presente en casi todos los niveles salvo en los niveles Mesolíticos, Neolíticos y Calcolíticos. Esta disminución del agua coincide sin embargo con un aumento del bosque. Esto puede estar relacionado con el óptimo climático del Holoceno, un clima más mediterráneo y por tanto, más seco en los períodos estivales.

2. Los prados están siempre presentes aunque en el Paleolítico superior (por datación del $\mathrm{C}^{14}$, equivalente al Gravetiense) se reduce, coincidiendo con un aumento importante de las especies acuáticas. Aunque en la figura 13 no se han separado los dos ambiente, el prado seco está peor representado que el húmedo.

3. Los roquedos sin vegetación tienen representación en toda la secuencia. El incremento del roquedo del nivel Musteriense está ligado al de Pliomys (Fig. 13).

4. El bosque, prácticamente ausente durante el Paleolítico superior hasta el Aziliense, es decir, durante el estadio isotópico MIS 2, conocido también como última glaciación Würm, o Würm IV. Durante el llamado último máximo glaciar (UMG), que coincide con el Solutrense, se registra el valor más bajo del bosque en la secuencia (en el Musteriense también pero aún quedan muchas muestra por estudiar como para poder llegar a una conclusión. Se recupera notablemente a partir de Mesolítico (Óptimo climático del Holoceno) para volver a disminuir hacia el final del Bronce (Fig. 13).

\section{CORRELACIÓN CON LOS DATOS POLÍNICOS Y GEOMORFOLÓGICOS}

El clima durante los últimos 40.000 años en el norte de Iberia es conocido principalmente gracias a los análisis polínicos, al estudio de los testigos de hielo, al aporte de los iceberg (Heinrich, 1988; Sánchez Goñi et al., 2000; Sánchez Goñi \& d'Errico, 2005), así como a la evolución de la geomorfología glaciar y climática en la Península Ibérica (Gutiérrez Elorza \& Peña, 1998; Gutiérrez Elorza \& Sesé Martínez, 2001; García-Ruiz et al., 2003). La sucesión de la vegetación durante el Holoceno se divide en tres fases (Sánchez Goñi et al., 2000):

Figura 12. Distribución cuantitativa (en porcentajes) de los pequeños mamíferos de la secuencia del Mirón. Los números de la base indican el \% de cada especie con respecto al total de especies en cada nivel. Se han omitido las especies representadas por un solo individuo en un único nivel. También se han eliminado los Chiroptera y Lagomorpha. El orden de las especies sigue el de su primera aparición (FAD) en la secuencia.

Quantitative distribution (in percentages) of the small mammals from the El Miron sequence. The numbers at the bottom indicate \%, in Minimum Number of Individuals. In this analisys we do not consider the species represented by one individual only at one level, and also Chiroptera and Lagomorpha. The order of the species, from left to rigth follows that of its first appearance data $(F A D)$ in the sequence. 
Distribución por hábitats de los pequeños mamíferos cuaternarios de la Cueva de EI Miron

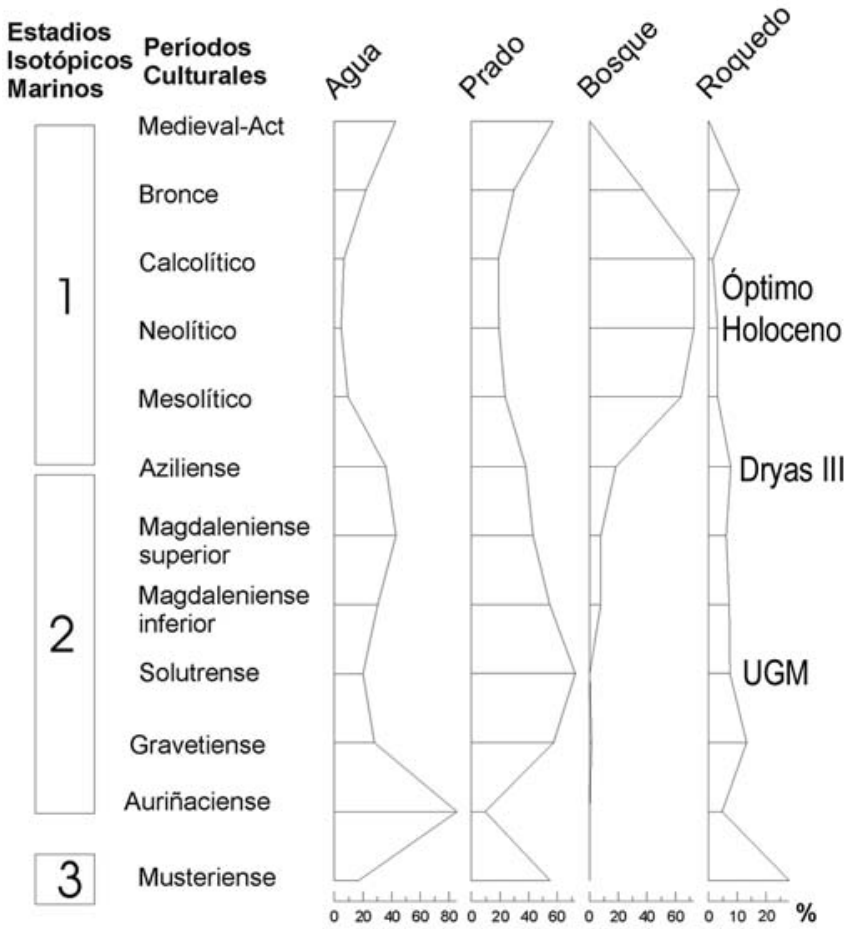

Figura 13. Distribución cuantitativa de los pequeños mamíferos de la secuencia del Mirón agrupados por hábitat. En la primera columna de la derecha figuran los estadios isotópicos marinos (MIS), correlacionados con los niveles estratigráficos y períodos culturales por las dataciones de Carbono 14 (Straus \& González Morales, 2003, 2007). En la segunda columna, los mismos niveles estratigráficos de la Tabla 2, están agrupados por su contenido arqueológico y período cultural. A la izquierda se han representado los principales eventos climáticos del final del cuaternario: UMG, el último máximo glaciar y el período frío del final del Pleistoceno superior, el Dryas III. Obsérvese que en el UMG, y desde el final del MIS 3 faltan las especies de bosque, y el prado, que indica dominio de medios abiertos alcanza su valor máximo en el UMG.

Quantitative distribution of the small mammals of the El Mirón sequence grouped by habitat (Agua =Water; Prado=Meadow; Bosque $=$ Woodland, Roquedo=rocky hills, caves, bare land). In the first column at the left there are the Marine Isotopic Stages (MIS), correlated by radiocarbon data (Straus \& González. Morales, 2003, 2007). In the second column, the same stratigraphic levels of Table 2, grouped by its archeological content and cultural period. At the rigth there is a correlation with the main climatic events of the end of the Quaternary: UMG is the Last Glacial Maximum, the Dryas III is the last cold stage of the end of the Late Pleistocene and Optimo Holoceno is the Climatic Holocene Optimum of the first part of the Holocene. Note that in the UMG as well as from the end of the MIS 3 on, the species that represent the woodland dessapear and the meadows have their maximum values.
Fase a: comienzos del Holoceno, cálida, mediterránea, boscosa (roble y quejigo)

Fase b: fase húmeda caracterizada por el aumento de los helechos

Fase c: disminución importante del bosque, aumento de los brezos (Ericáceas) y fluctuaciones de humedad, que se mantiene aunque algo menos que en la fase anterior. La desaparición del olivo indica condiciones frías.

En relación con la evolución holocena de los pequeños mamíferos del Mirón (Figs. 12 y 13) podemos decir que la fase mediterránea y boscosa también se detecta, con el aumento de las especies de bosque. La fase húmeda es difícil de caracterizar a esta escala. La fase fría se correlaciona con la disminución del bosque, aumento del roquedo, agua, y condiciones abiertas, de prado.

Al final del Pleistoceno el período frío del Dryas III (Aziliense) se correlaciona con un retroceso del bosque y un aumento de las especies de medios abiertos.

El avance de los glaciares y el retroceso de la línea de costa pueden estar en relación con la expansión de las especies de carácter alpino.

\section{CONCLUSIONES}

Tras más de tres décadas de estudio de los pequeños mamíferos en yacimientos pleistocenos y holocenos de la Cornisa Cantábrica, podemos afirmar que éstos proporcionan una información significativa sobre los cambios climáticos y medioambientales ocurridos durante los últimos 50.000 años BP Para llegar a esta conclusión asumimos que los pequeños mamíferos son una parte importante de los ecosistemas terrestres y forman parte de la dieta de numerosos predadores. Su pequeño tamaño los excluye en general como componentes de la dieta humana (al menos durante el Pleistoceno superior y Holoceno inicial) por lo que su presencia en los yacimientos arqueológicos se debe a otros factores de acumulación; aunque no se descarta el comensalismo ocasional y la utilización, también ocasional de su piel o como alimento.

La cueva del Mirón está rellena por sedimentos que datan desde los 41.000 años BP hasta la actualidad, en una secuencia bastante completa, dividida en cerca de 100 niveles arqueológicos o tallas la mayoría de ellos ricos en restos de pequeños mamíferos fósiles. En esta secuencia se han estudiado un total de 721 muestras que han permitido determinar 26 especies de pequeños mamíferos basándonos en un total de 3.403 restos craneales. Hay además cerca de

Figura 14. Expresión de la Mediterraneidad y su evolución en la secuencia del Mirón en función de la proporción de los Arvicolinos frente a los Murinos+Glíridos. "Mediterraneity" and its evolution in the sequence of El Mirón based on the ratio between Arvicolinae and Murinae+Gliridae. 

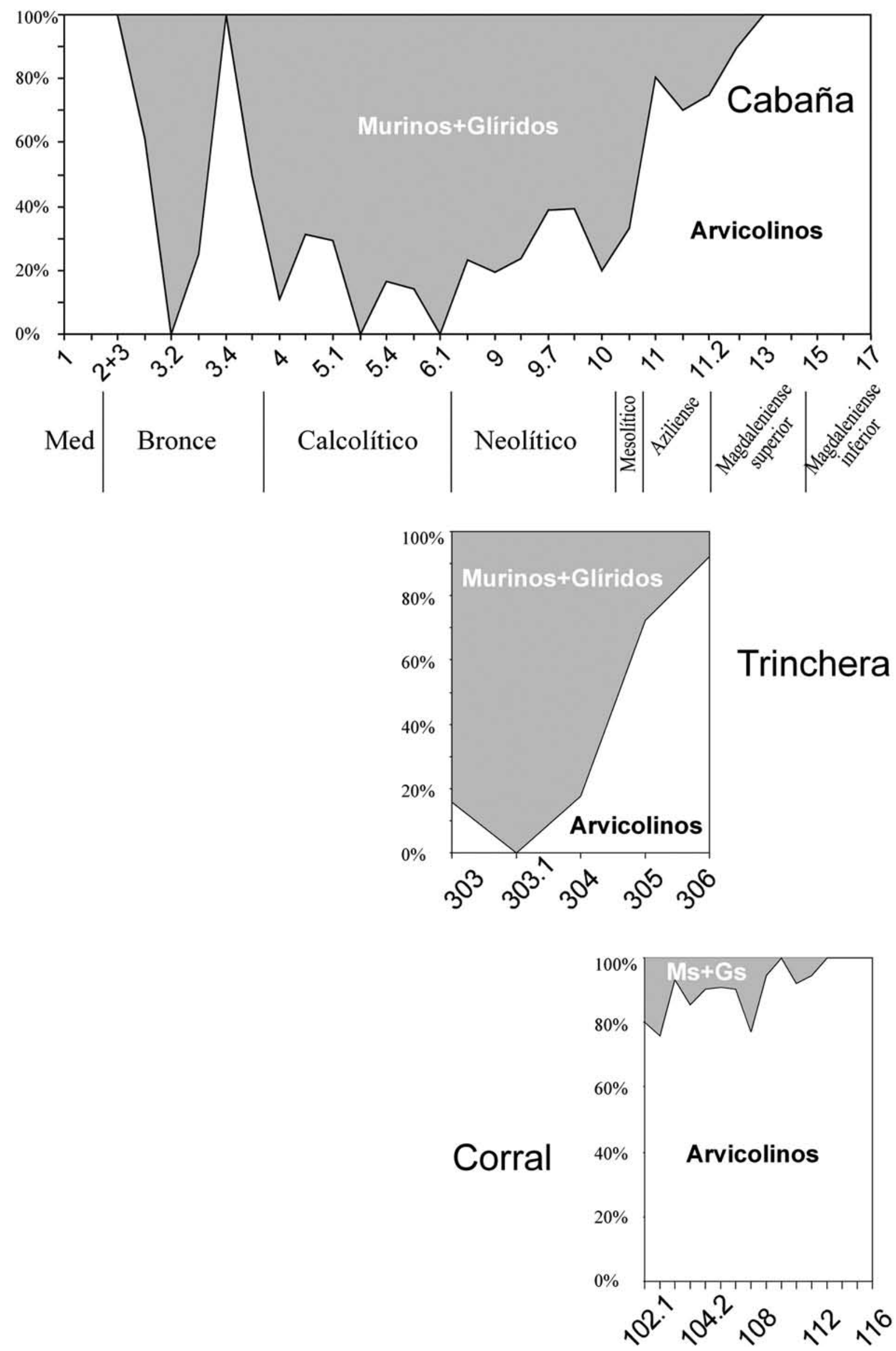
100.000 restos óseos de pequeños mamíferos, aves, anfibios, reptiles y peces que están todavía por identificar.

La fauna fósil del Pleistoceno y Holoceno de la cueva del Mirón representa cerca del $90 \%$ de los pequeños mamíferos actuales de la Cornisa Cantábrica, descontando los quirópteros y los introducidos recientemente por el hombre.

La distribución estratigráfica de los microvertebrados del Mirón es variable según las especies; en general se distribuyen a lo largo de la secuencia con variaciones más o menos importantes en el número de individuos que hay en cada nivel. Las excepciones son: Pliomys lenki que se extingue en el Magdaleniense y coincidiendo con la extinción de $P$. lenki, con un ligero solapamiento en el caso de Eliomys quercinus, aparecen las especies ligadas al bosque. Otras especies tienen una presencia esporádica, a veces un solo registro en toda la secuencia.

Coincidiendo con la aparición de las especies de bosque disminuyen las de medios abiertos, los arvicolinos, y entra también la musaraña de dientes blancos, de carácter mediterráneo. El aumento del bosque, basándonos en el incremento de especies ligadas a este medio, coincide más o menos con el llamado Óptimo Holoceno en el que subieron las temperaturas, antes del declive de temperatura del final del Bronce, cuando hay un incremento de los arvicolinos de medios fríos y húmedos, dato que podría correlacionarse con la pequeña edad del hielo del Bronce. Es notable la persistencia de M. oeconomus y Chionomys nivalis hasta prácticamente el final del Holoceno, aunque ambas especies faltan en la actualidad en la zona costera.

La agrupación de las especies de pequeños mamíferos en función de su hábitat óptimo permite concluir que los cambios paleoambientales y climáticos ocurridos en los últimos 41.000 años BP en esta región de Cantabria son importantes: durante el Würm final (MIS 2) prácticamente no hay bosques mientras que al comienzo del Holoceno (MIS 1) éste se desarrolla notablemente.

Finalmente podemos resumir que:

El estudio de la distribución bioestratigráfica, la composición de las asociaciones y la conservación (tafonomía) de los pequeños mamíferos del Mirón nos permite deducir que las asociaciones de la microfauna de los niveles del final del Pleistoceno y del Holoceno de la Cueva del Mirón reflejan la composición y evolución de las faunas circundantes y por lo tanto son útiles tanto en la reconstrucción paleoclimática como ambiental de los alrededores de la misma.

No parece haber habido una ocupación humana continua durante el Holoceno en El Mirón ya que las especies comensales habrían proliferado en todos los niveles. A favor de esta observación hay que destacar también la alta diversidad de especies en todos los niveles salvo en el actual lo que indica una ocupación importante de las rapaces causantes de la acumulación de pequeños vertebrados, incompatible con el hombre.
La distribución de roedores, insectívoros, quirópteros, conejos y pequeños carnívoros a lo largo de la secuencia El Mirón muestra que hay importantes cambios climáticos en los últimos 41.000 años BP que se reflejan en el aumento/disminución de las especies mediterráneas con respecto a las eurosiberianas.

La entrada de los múridos modernos, comensales del hombre, es más tardía en la Cornisa Cantábrica que en el sur y centro de España.

El Mirón registra la última aparición de la especie Pliomys lenki en Europa.

\section{AGRADECIMIENTOS}

Agradezco las discusiones con Juan Manuel López-García y Angel Hernández. Al equipo de excavación del Mirón. Parte del material de comparación proviene de: Instituto Pirenaico de Ecología de Zaragoza (Dr. Juan Pablo Martínez Rica), Universidad de Zaragoza, Museo Nacional de Ciencias Naturales (Dra. J. Barreiro) y CAS (Burgos). La excavación de la Cueva del Mirón, dirigida por LGS y MGM cuenta con el apoyo económico de la Fundación M. Botín, Gobierno de Cantabria, Ministerio de Educación y Ciencia de España, US National Science Foundation, National Geographic Society, University of New Mexico y L.S.B. Leakey Foundation, así como la ayuda logística de la Villa de Ramales de la Victoria en Cantabria. La investigación de G.C.-B. se enmarca dentro de los proyectos $\mathrm{PO}$ BOS 2003-8938 y CGL2006-13532-C03-02 y Grupos Consolidados 2007 Gobierno de Aragón, además de la Ayuda Salvador de Madariaga (M.E.C) durante su estancia en la Universidad de Nuevo Mexico.

\section{BIBLIOGRAFÍA}

Abbassi, M., Desclaux, E., Marquet, J. C. \& Chaline, J. 1998. Répartition et Évolution des Arvicola Lacépède, 1799 (Rodentia, Mammalia) au cours du Pleistocene Moyen et supérieur en France et en Ligurie. Quaternaire, 9, 105-116.

Agustí, J. \& Galobart, A. 1986. La sucesión de micromamíferos en el complejo cárstico de Casablanca (Almenara, Castellón: problemática biogeográfica). Paleontologia $i$ evolució, 20, 57-62.

Agustí, J., Alcalde, B., Burjachs, F., Juan-Muns, N., Oller, J., Ros, M.T. \& Rueda, J.M. 1987. El yacimiento del Paleolítico Medio de la Cueva 120 (La Carrotxa, Cataluña). Primeros resultados. VII Reunión sobre el Cuaternario AEQUA, 1, 1-4.

Alcalde Gurt, G. 1982. Presènsia interessant de Pliomys lenki i de Microtus oeconomus en el reompliment de la cova dels Ermitons (La Garrotxa, Girona). Acta Geológica Hispánica, 17, 281-282.

Alcalde, G. 1986. Les faunes de rongeurs du Pléistocène supérieur et de l'Holocène de Catalogne (Espagne) et leurs significations palèoécologiques et palèoclimatiques. Paris, Diplôme E.P.H.E., 120 pp. (inédito). 
Alcalde, G. 1988. Els rosegadors en l'Arqueología Catalana. Cota Zero, 4, 65-69.

Alcalde, G. \& Brunet, P. 1985. Contribució al coneixement del medi i el clima durant el Pleistocè superior i l'holocè a Catalunya, amb l'aplicació de l'anàlisis factorial de les correspondències a les associacions de rosegadors. Paleontología i Evolució, 19, 49 -55.

Alcántara de la Fuente, M. 1992. Distribución y preferencias de hábitat de los micromamíferos (Insectivora y Rodentia) de la Sierra de Guadarrama. Tesis Doctoral. Universidad Complutense de Madrid, 263 pp. (inédita).

Alegre, J. \& Hernández, A. 1990. Datos sobre la distribución de algunas especies de micromamíferos en la zona montañosa de la Provincia de León. Tierras de León, 77-78, 131-152.

Alegre, J., Hernández, A., Purroy, F. \& Sánchez, A. 1989. Distribución latitudinal y patrones de afinidad trófica geográfica de la lechuza común (Tyto alba) en León. Ardeola, 36, 41-54.

Altuna, J. 1970. Fauna de Mamíferos del Yacimiento Prehistórico de Aitzbitarte IV (Rentería, Guipúzcoa). Munibe, 22, 3-41.

Altuna, J. 1972. Fauna de mamíferos de los yacimientos prehistóricos de Guipúzcoa. Munibe, 24, 1-464.

Altuna, J. 1981. Restos óseos del yacimiento prehistórico del Rascaño (Santander). In: El Paleolítico Superior de la cueva del Rascaño (Eds. J. Echegaray \& I. Barandiarán). Museo de Altamira Monografías, 3, 221-269.

Altuna, J. 1986. The mammalia faunas from the prehistoric site of La Riera. In: La Riera Cave (Eds. L. G. Straus \& G.A. Clark). Anthropological Research Papers, 36, 237-274.

Altuna, J., Cuenca-Bescós, G., Elorza, M., García, J.C., Lobo, J., Mariezkurrena, K., Pérez, M., Sanchiz, B., González, M. \& Guy, L. 2004. Post - pleistocene faunas from the archaelogical site of El Miron cave (Ramales de la Victoria, Cantabria, Spain). In: Miscelánea en homenaje a Emiliano Aguirre (Eds. E. Baquedano \& S. Rubio Jara). Zona Arqueológica, 4 (2), 41 -49.

Álvarez, M. T., Morales, A. \& Sesé, C. 1992. Mamíferos del yacimiento del Pleistoceno Superior de Cueva Millán (Burgos, España). Estudios geológicos, 48, 193-204.

Andrews, P. 1990. Owls, Caves and Fossils. The Natural History Museum Publications, London, 1-231.

Arribas, A. 1994. El yacimiento mesopleistoceno de Villacastín (Segovia, España. Geología y Paleontología de micromamíferos. Boletín Geológico y Minero, 105, 146-166.

Arrizabalaga i Blanch, A, Montagud i Blas, E. \& Gosálbez i Noguera, J. 1986. Introducció a la Biologia i Zoogeografia dels petits maífers (Insectivors i Rosegadors) del Montseny (Catalunya). Papers de Treball, Generalitat de Catalunya, CIRIT, 1-113.

Arrizabalaga, A., Altuna, J., Areso, P., Elorza, M., García, M., Iriarte, M.J., Mariezkurrena, K., Mujika, J., Pemán, E., Tarriño, A., Uriz, A., Viera, L. \& Straus, L.G. 2003. The Initial Upper Paleolithic in Northern Iberia: New Evidence from Labeko Koba. Current Anthropology, 44, 413-421.
Baena, J., Carrión, E., Ruiz, B., Ellwood, B., Sesé, C., Yravedra, J., Jordá, J., Uzquiano, P., Velázquez, R., Manzano, I., Sánchez-Marco, A. \& Hernández, F. 2005. Paleoecología y comportamiento humano durante el Pleistoceno Superior en la comarca de Liébana: La secuencia de la Cueva de El Esquilleu (Occidente de Cantabria, España). Museo de Altamira. Monografías, 20, 461-487.

Bartolomei, G., Chaline, J., Fejfar, O., Jánossy, D., Jeannet, M., Koenigswald, W. \& Kowalski, K., 1975. Pliomys lenki (Heller 1930) (Rodentia, Mammalia) in Europe. Acta Zoologica Cracoviensa, 20, 393-467.

Blanco, J. C. 1998a. Mamíferos de España I. Insectívoros, Quirópteros, Primates y Carnívoros de la Península Ibérica, Baleares y Canarias. Editorial Planeta, Barcelona, 464 pp.

Blanco, J. C. 1998b. Mamíferos de España II. Cetáceos, Artiodáctilos, Roedores y Lagomorfos de la Península Ibérica, Baleares y Canarias. Editorial Planeta, Barcelona, $464 \mathrm{pp}$.

Borghi, C. E., Giannoni, S. M. \& Martínez Rica, J. P. 1990. Soil removed by voles of the genus Pitymys in the Spanish Pyrenees. Pirineos, 136, 3-18.

Brunet-Lecomte, P. 1991. Répartition géographique des campagnols du genre Microtus (Arvicolidae, Rodentia) dans le nord-ouest ibérique. Arquivos do Museu Bocage, 2, 11-29.

Brunet-Lecomte, P. \& Chaline, J. 1990. Relations phylogénétiques et évolution des campagnols souterrains d'Europe (Terricola, Arvicolidae, Rodentia). Comptes Rendues Academie des Sciences, Paris, 311, Sér. II, 745-750.

Brunet-Lecomte, P. \& Chaline, J. 1993. Mise au point sur Microtus (Terricola) pyrenaicus gerbei (Gerbe, 1879) (Rodentia, Arvicolidae). Mammalia, 571, 139-142.

Brunet-Lecomte, P. \& Delibes, M. 1984. Alimentación de la lechuza común Tyto alba en la cuenca del Duero, España. Doñana, Acta Vertebrata, 11, 213-229.

Brunet-Lecomte, P., Brochet, G., Chaline, J. \& Delibes, M. 1987. Morphologie dentaire comparée de Pitymys lusitanicus et $P$. duodecimcostatus (Arvicolidae, Rodentia) dans le nord-ouest de l'Espagne. Mammalia, 51, 145-158.

Cabrera Millet, M., Britton-Davidian, J. \& Orsini, P. 1982. Génétique biochimique comparée de Microtus cabrerae Thomas, 1906 et de trois autres espèces d'Arvicolidae méditerranéens. Mammalia, 46, 381-388.

Campos Marcos, M. A., Balmori Martínez, A., Canales Basabe, F., Onrubia Baticón, A. \& Sáenz de Buruaga Tomillo, A. 2003. Estudio Mastozoológico del entorno de Salburua (Vitoria-Gasteiz). Informe Inédito Centro de Estudios Ambientales de Vitoria-Gasteiz, Consultora de Recursos Naturales, S.L., 178 pp.

Carvalho, J. C. \& Gomes, P. 2004. Feeding resource partitioning among four sympatric carnivores in the PenedaGeres National Park (Portugal). Journal of Zoology, 263 275-283.

Casteig, F. J. \& Escala, C. 1988. Morfometría de Sorex coronatus Millet, 1828 (Insectivora, Mammalia) en Navarra. Miscelánea Zoológica, 12, 309-317.

Castien, E. \& Gosàlbez, J. 1992. Distribución geográfica y hábitats ocupados por Galemys pyrenaicus (Geoffroy, 
1911) (Insectivora: Talpidae) en los Pirineos occidentales. Doñana, Acta Vertebrata, 19, 37-44.

Chaline, J. 1972. Les rongeurs du Würmien II de la grotte de 1'Hortus (Valflaunès, Hérault). Etudes quaternaires, 1, 233-240.

Chaline, J. 1975. Evolution et rapports phyletiques des campagnols (Arvicolidae, Rodentia) apparentés à Dolomys et Pliomys dans l'hemisphère nord. Comptes Rendues Academie des Sciences, Paris, D, 281, 33-36.

Chaline, J. \& Marquet, J.-C. 1976. Les conséquences stratigraphiques de la persistance en France dans le Würm ancien del rongeurs reliques Pliomys lenki et Allocricetus bursae (Rodentia). Comptes Rendues Academie des Sciences, Paris, 282, 1941-1942.

Chaline, J., Brunet-Lecomte, P., Montuire, S., Viriot, L. \& Curant, F. 1999. Anatomy of the arvicoline radiation (Rodentia): palaeogeographical, palaeoecological history and evolutionary data. Annales Zoologici Fennici, 36, 239-267.

Conroy, C.J. \& Cook, J.A. 2000. Molecular Systematics of a Holarctic Rodent (Microtus: Muridae). Journal of Mammalogy, 81, 344-359.

Courty, M.-A. \& Vallverdu, J. 2001. The Microstratigraphic Record of Abrupt Climate Changes in Cave Sediments of the Western Mediterranean. Geoarchaeology: An International Journal, 16, 467-500.

Cuenca-Bescós, G., Canudo, J. I. \& Laplana, C. 1995. Los Arvicólidos (Rodentia, Mammalia) de los niveles inferiores de Gran Dolina (Pleistoceno Inferior, Atapuerca, Burgos, España). Revista Española de Paleontología, 10, 202-218.

Cuenca-Bescós, G., Laplana Conesa, C., Canudo, J. I. \& Arsuaga, J. L. 1997. Small mammals from Sima de los Huesos. Journal of Human Evolution, 33, 175-190.

Cuenca-Bescós, G., Canudo, J. I. \& Laplana, C. 1999. Análisis bioestratigráfico de los roedores del Pleistoceno Medio del yacimiento de Galería (Sierra de Atapuerca, Burgos). Memorias. Arqueología en Castilla y León. Atapuerca: Ocupaciones humanas y paleoecología del yacimiento de Galería, 7, 189-210.

Cuenca-Bescós, G., Rofes, J. \& García-Pimienta, J. C. 2005. Early europeans and environmental change across the Early-Middle Pleistocene transition: small mammalian evidence from Trinchera Dolina cave, Atapuerca, Spain. In: Early-middle Pleistocene transitions: the land-ocean evidence (Eds. M.J. Head \& P.L. Gibbard). Geological Society of London, Special Publication, 247, 277-286.

Cuenca-Bescós, G., González Morales, M., Barco, J. \& Straus, L. 2006. Upper Pleistocene Pliomys lenki (Rodentia, Mammalia) in Iberia: a tale of flickering extinction. Journal of Vertebrate Paleontology, 26, 53A.

Currant, A.P. 1986. The Late Glacial mammal fauna of Gough's Cave, Cheddar, Somerset. Proceedings University of Bristol Speleological Society, 17, 286-304.

Desclaux, E. 1996-1997. Contribution des Micromammifères à la connaissance des paléoenvironnements des chasseurs de la Grotte du Lazaret à Nice. Archéam Cahiers du Cercle d'Histoire et d'Archeologie des Alpes-Maritimes, 4, 7-11.
Eastham, A. 1995. Chapitre 19. La Microfaune. In: Les derniers chasseurs de rennes du Monde Pyrénéen. L'Abri dufaure: un gisement tardiglaciaire en Gascogne (Ed. L. G. Straus). Mémoire Societé Préhistorique de France, 22, 235-245.

Fara, E. 2001. What are Lazarus taxa? Geological Journal, 36, 291-303.

Ferraris, M., Sala, B. \& Scola, V. 1990. The Late Pleistocene fauna with Pliomys lenki from the Ghiacciaia Cave loess (Northern Italy). Quaternary International, 5, 71-79.

Frafjord, K. 2003. Do eagle owls select larger water voles? Fauna norvegica, 23, 42-47.

Furió Bruno, M. 2003. Los Insectivoros (Mammalia) del Pleistoceno Inferior de Fuente Nueva 3 y Barranco León (Orce, Granada). In: El Pleistoceno Inferior de barranco León y Fuente Nueva 3, Orce (Granada) (Coord. J. Agustí, B. Martínez-Navarro \& I. Toro). Arqueología Monografías. Consejería de Cultura de la junta de Andalucía, 147-157.

Galán C. 1997. Fauna de Quirópteros del País Vasco (Bats Fauna from the Basque Country). Munibe, 49, 77-100.

García García, N. 2003. Osos y otros carnívoros de la Sierra de Atapuerca. Fundación Oso de Asturias, Oviedo, 1-570.

García-Perea, R. \& Gisbert, J. 1997. Lista patrón de los mamíferos de la Península Ibérica, Islas Baleares y Canarias. Galemys, 9, 1-38.

Garcia-Ruiz, J.M., Valero-Garcés, B.L., Marti-Bono, C. \& Gonzalez-Samperiz, P. 2003. Asynchroneity of maximum glacier advances in the central Spanish Pyrenees. Journal of Quaternary Science, 181, 61-72.

Giannoni, S. M., Borghi, C. E. \& Martínez Rica, J. P. 1992. New data on the burrowing behaviour of Microtus (Pitymys) duodecimcostatus. Zeitschrift für Säugetierkunde, 57, 23-28.

Giannoni, S. M., Borghi, C. E. \& Martínez Rica, J. P. 1993. Comparing the burrowing behaviour of the Iberian mole voles (Microtus (Terricola) lusitanicus, M. (T.) pyrenaicus and M. (T.) duodecimcostatus). Mammalia, 57, 4, 483-490.

Gil, E. \& Lanchares, E. 1988. Los roedores del yacimiento musteriense de la Cueva de Gabasa (Pirineo Aragonés). Interés paleoecológico. Geogaceta, 3, 5-7.

Gil, E. \& Sesé, C. 1985. Los roedores (Mammalia) del sitio de ocupación Musteriense de la Cueva de los Toros (Teruel). Col-Pa, 40, 41-49.

González-Esteban, J., Villate, I. \& Gosálbez, J. 1994. Requerimientos ambientales de Microtus arvalis asturianus Miller, 1908 (Rodentia, Arvicolidae) en la Península Ibérica. Doñana, Acta Vertebrata, 21, 109-118.

Gosálbez, J. 1993. Utilización de las egagrópilas de rapaces nocturnas en el estudio de los micromamíferos. Boletin SECEM, 2, 22-27.

Guillem, P. 1995a. Paleontología continental: microfauna. En: El Cuaternario del País Valenciano. Asociación Española para el Estudio del Cuaternario y Universitat de València, València, 227-233.

Guillem, P. 1995b. Bioestratigrafía de los micromamíferos (Rodentia, Mammalia) del Pleistoceno Medio, Superior y Holoceno del País Valenciano. Saguntum, 38, 11-18. 
Guillem, P. 1999. Los micromamíferos (Rodentia, Insectivora y Chiroptera) de la Secuencia Holocena de la Cova de les Cendres y Cova Bolumini. II Congrès de Neolític a la Península Ibérica, Saguntum, 2, 31-36.

Guillem, P. 2001. Los micromamíferos y la secuencia climática del Pleistoceno Medio, Pleistoceno Superior y Holoceno, en la fachada central mediterránea. In: De Neandertales a Cromañones. El inicio del poblamiento humano en las tierras valencianas (ed. V. Villaverde). Universitat de València, Valencia, 57-72.

Gutierrez Elorza, M. \& Peña Monné, J.L. 1998. Geomorphology and late Holocene climatic change in Northeastern Spain. Geomorphology, 23, 205-217.

Gutierrez Elorza, M., \& Sesé Martínez, V.H. 2001. Multiple talus flatirons, variations of scarp retreat rates and the evolution of slopes in Almazán Basin (semi-arid central Spain). Geomorphology, 38, 19-29.

Heinrich, H. 1988. Origin and consequences of cycle ice rafting in the northeast Atlantic Ocean during the past 130,000 years. Quaternary Research, 9, 142-152.

Heinrich, W.-D. 1990. Some aspects of evolution and biostratigraphy of Arvicola (Mammalia, Rodentia) in the central european pleistocene. In: International Symposium Evolution, Phylogeny and Biostratigraphy of Arvicolids (Rodentia, Mammalia) (Eds. O. Fejfar \& W.-D. Heinrich). Rohanov, 165-182.

Hernández, A. 2005. Topos en la dieta de zorros rojos en el noroeste de España. Galemys, 17, 87-90.

Hernández, A., Sánchez, A. J. \& Alegre, J. 1987. Datos sobre el régimen alimenticio del Mochuelo común (Athene noctua) y la Lechuza común (Tyto alba) en hábitats esteparios en la cuenca del Duero (León y Zamora, España). I Congreso Internacional de Aves Esteparias, León, 183-192.

Horácek, I. 1976. Review of Quaternary Bats in Czechoslovaquia. Lynx, 18, 35-58.

Indermuhle, A., Stocker, T.F., Joos, F., Fischer, H., Smith, H.J., Wahlen, M., Deck, B., Mastroianni, D., Tschumi, J., Blunier, T., Meyer, R. \& Stauffer, B. 1999. Holocene carbon-cycle dynamics based on $\mathrm{CO}_{2}$ trapped in ice at Taylor Dome, Antarctica. Nature, 398, 121-126.

Iza, J.B., Castien, E., Mendiola, I. \& Peman, E. 1985. Algunos aspectos de la ecología de los micromamíferos del País Vasco. Munibe, 37, 101-110.

Jaarola, M., Martinkova, N., Gunduza, I., Brunho, C., Zima, J., Nadachowski, A., Amori, G., Bulatova, N.S., Chondropoulos, B., Fraguedakis-Tsolis, S., Gonzalez-Esteban, J., Lopez-Fuster, M.J., Kandaurov, A.S., Kefelioglud, H., Mathias, M.L., Villatei, I. \& Searl, J.B. 2004. Molecular phylogeny of the speciose vole genus Microtus (Arvicolinae, Rodentia) inferred from mitochondrial DNA sequences. Molecular Phylogenetics and Evolution, 33, 647-663.

Jammot, D. 1974. Les Insectivores de Cagny (Somme). Soricidae (Insectivora, Mammalia). Bulletin pour l'Association Française du Quaternaire, 41-42, 187-189.

Jeannet, M., Allard, M. \& Juillard, F. 1996. Première decouverte de Galemys pyrenaicus (Insectivora, Desmaninae) dans le Quaternaire français. Revue de Paléobiologie, 15, 205-213.
Jullien, R. 1972. Les chiroptères du Würmien II de la grotte de l'Hortus (Valflaunès, Hérault). Etudes Quaternaires Mémoire. La grotte Moustérienne de l'Hortus, 1, 247-265.

Koenigswald, W. v. \& Kolfschoten, T. v. 1996. The MimomysArvicola boundary and the enamel thickness quotient (SDQ) of Arvicola as stratigraphic markers in the Middle Pleistocene. The early Middle Pleistocene in Europe (Ed. C. Turner). Proceedings of the SEQS Cromer Symosium, 211-226.

Kowalski, K. 1956. Insectivores, bats and rodents from the Early Pleistocene bone breccia of Podlesice near Krocyce (Poland). Acta Palaeontologica Polonica, 4, 331-394.

Krystufek, B. \& Haberl, W. 2001. Dormouse associations in Slovenia - a new approach to an old tradition. Trakya University Journal of Scientific Research, 2, 171-177.

Laplana Conesa C. \& Cuenca-Bescós, G. 1995. Los microvertebrados (anfibios, reptiles y mamíferos) asociados al yacimiento de la Edad del Bronce de La Balsa la Tamariz (Tauste, Zaragoza). Col-Pa, 47, 55-69.

León García, J. 1998. Cantabria Subterránea. Catálogo de las Grandes Cavidades. Diputación Regional de Cantabria, Consejería de Cultura, Santander, 1- 700.

López Antoñanzas, R. \& Cuenca-Bescós, G. 2002. The Gran Dolina Site (Lower to Middle Pleistocene, Atapuerca, Burgos, Spain. New palaeoenvironmental data based on the distribution of small mammals. Palaeogeography, Palaeoclimatology, Palaeoecology, 186, 311-334.

López-Fuster, M. J. \& Ventura, J. 1996. A morphometrical review of the Sorex araneus-arcticus species group from the Iberian Peninsula (Insectivora, Soricidae). Bonner Zoologische Beiträge, 46, 327-337.

López-Fuster, M.J., Ventura, J., García-Perea, R. \& Gisbert, J. 1999. The Sorex araneus group in the northern Iberian System (Spain): a contact zone between $S$. coronatus and S. granarius? Acta Theriologica, 44, 113-122.

López-García, J.M. 2006. Los roedores, insectívoros, quirópteros y anfibios en relación a las ocupaciones humanas del Holoceno inicial de la Cueva del Mirador (Atapuerca, Burgos). Tesis de Licenciatura, Universitat Rovira i Virgili de Tarragona, 122 pp. (inédita).

López-García, J.M. \& Morales Hidalgo, J.I. 2007. Análisis preliminar de los Roedores (Mammalia) del Nivel Nb del Abric Romani (Capellades, Barcelona). Actas del III Encuentro de Jóvenes Investigadores en Paleontología, 95-103.

Luque-Larena, J.J., López, P. \& Gosálbez, J. 2002. Microhabitat use by the snow vole Chionomys nivalis in alpine environments reflects rock-dwelling preferences. Canadian Journal of Zoology, 80, 36-41.

Marín Arroyo, A. B. 2007. La fauna de Mamíferos en el Cantábrico Oriental durante el Magdaleniense y Aziliense: Nuevos Enfoques y Líneas de Investigación Arqueozoológicas. Tesis Doctoral, Universidad de Cantabria, 684 pp. (inédita).

Marks, A.E., Brugal, J.-Ph., Chabai, V.P., Monigal, K., Goldberg, P., Hockett, B., Peman, E., Elorza, M. \& Mallol, C. 2002. Le gisement pléistocène moyen de Galeria Pesada (Estrémadure, Portugal). Premiers résultats. Paléo, 14, 77-100. 
Marquet, J.C. 1989. Paleoenvironnement et Chronologie des sites du domaine Atlantique français d'age Pleistocene moyen et supèrieur d'apres l'étude des rongeurs. Thèse, Université de Bourgogne, 637 pp. (inédita).

Marquet, J.C. 2001. Les rongeurs de la Grotte du Sanglier. (Reilhac, Lot). Préhistoire du Sud-Ouest, 4, 175-182.

Martínez-Cortizas, A., Pontevedra-Pombal, X., Garcia-Rodeja, E., Novoa-Muñoz, J.C. \& Shotyk, W. 1999. Mercury in a Spanish peat bog: Archive of climate change and atmospheric metal deposition. Science, 284, 939-942.

Maul, L. 1990. Üeberblick über die unterpleistozänen Kleinsäugerfaunen Europas. Quartärpaläontologie, 8, 153-191.

Maul, L. 2001. The transition from hypsodonty to hypselodonty in the Mimomys savini-Arvicola lineage. Lynx, 32, 247-253.

Maul, L. \& Markova, A. 2007. Similarity and regional differences in Quaternary arvicolid evolution in Central and Eastern Europe. Quaternary International, 160, 81-99.

Meulen, A. van der 1973. Middle Pleistocene smaller Mammals from the Monte Peglia (Orvieto, Italy), with Special Reference to the Phylogeny of Microtus (Arvicolidae, Rodentia). Quaternaria, 17, 1-144.

Mitchell-Jones, A. J., Amori, G., Bogdanowicz, W., Krystufek, B., Reijnders, P. J. H., Spitzenberger, F., Strubbe, M., Thissen, J. B. M., Vohralík, V. \& Zima, J. (Eds.) 1999. The Atlas of European Mammals. Societas Europaea Mammalogica. Poyser Natural History Series, Academic Press, London, 484 pp.

Morales Muñiz, A. 1986. Análisis de la fauna de vertebrados recuperada en las sepulturas del poblado del Bronce del Cerro de La Encantada (Provincia de Ciudad Real). Oretvm, 2, 159-196.

Morales Muñiz, A. \& Rodríguez, J. 1997. Black rats (Rattus rattus) from medieval Mertola (Baixo Alentejo, Portugal). Journal of Zoololgy London, 241, 623-642.

Morales Muñiz, A., Cereijo Pecharroman, M. A., Hernández Carrasquilla, F. \& Lettow-Vorbeck, L.V. 1997. Of Mice and Sparrows: Commensal Faunas from the Iberian Iron Age in the Duero Valley (Central Spain). International Journal of Osteoarchaeology, 5, 127-138.

Moreno, E. \& Rey, J. M. 1980. La alimentación de la lechuza común (Tyto alba) en la provincia de Huesca y su aplicación a la zoogeografía de los micromamíferos: insectívoros y roedores. II Jornadas Iberoamericanas de Zoología y Conservación de Vertebrados. Cáceres, 235-236.

Moreno, S. 2002. Lirón Careto Eliomys quercinus (Linnaeus, 1766). Galemys, 14, 1-16.

Nadachowski, A. 1982. Late Quaternary rodents of Poland with special reference to morphotype dentition analysis of voles. Panstwowe Wydawnictwo Naukowe, Warszawa-Kraków, 1-108.

Nadachowski, A. 1990. Lower Pleistocene Rodents of Poland: faunal succession and biostratigraphy. Quartärpaläontologie, 8, 215-223.

Niethammer, J. \& Krapp, F. 1982. Handbuch der saugertiere europas. Band I: Nagetiere I. (Muridae). Akademische Verlagsgesellschaft, Wiesbaden, 1-649.
Nores, C. 1979. Comparación del régimen alimenticio de Strix aluco y Tyto alba en la Costa Oriental Asturiana. Revista Facultad Ciencias, Universidad Oviedo, 20-21, 189-194.

Nores, C. 1988. Diferenciación biométrica de Apodemus sylvaticus y Apodemus flavicollis en la Cordillera Cantábrica. Primeros resultados. Revista Biología, Universidad de Oviedo, 6, 109-116.

Nores, C. 2003. Ratón espiguero Micromys minutus (Pallas, 1771). Galemys, 15, 3-10.

Oms, O., Agustí, J., Gabàs, M. \& Anadón, P. 2000. Lithostratigraphical correlation of micromammal sites and biostratigraphy of the Upper Pliocene to Lower Pleistocene in the Northeast Guadix-Baza Basin (southern Spain). Journal of Quaternary Science, 15, 43-50.

Palacios, F. 1988. Nuevos datos acerca de la distribución del Topillo campesino, Microtus arvalis Pallas 1778 en la Península Ibérica. Doñana, Acta Vertebrata, 15, 169-171.

Palomo, L. J. \& Gisbert, J. 2002. Atlas de los mamíferos terrestres de España. Dirección General de Conservación de la Naturaleza-SECEM-SECEMU, Madrid, 1-564.

Paunovic, M. \& Rabeder, G. 1996. Die altpleistozänen Kleinsäugerfaunen Razvodje und Tatinja draga in SüdKroatien. Beiträge zur Paläontologie, 21, 69-84.

Pemán, E. 1983. Biometría y sistemática del género Neomys Kaup, 1771 (Mammalia, Insectivora) del País Vasco. Munibe, 35, 115-148.

Pemán, E. 1985. Aspectos climáticos y ecológicos de los Micromamíferos del yacimiento de Erralla. Munibe, 37, 49-57.

Pemán, E. 1987. Los micromamíferos del yacimiento de Iruaxpe I (Guipúzcoa). Munibe, 39, 85-86.

Pemán, E. 1988. Los micromamíferos de Urtao II (Oñati, Guipúzcoa). Munibe, 41, 77-78.

Pemán, E. 1990a. Los micromamíferos de la cueva de Amalda y su significado. Comentarios sobre Pliomys lenki (Heller, 1930) (Rodentia, Mammalia). In: La Cueva de Amalda (Zestoa, Pais Vasco) Ocupaciones paleolíticas y postpaleoliticas (Eds J. Altuna, A. Baldeón \& K. Mariezkurrena). Colección Barandiarán, 4, 225-238.

Pemán, E. 1990b. Los micromamíferos en el Pleistoceno Superior del País Vasco. Munibe, 42, 259-262.

Pemán, E. 2000. Los micromamíferos de Labeko Koba (Arrasate, País Vasco). In: Labeko Koba (País Vasco). Hienas y Humanos en los albores del Paleolítico superior (Eds. A. Arrizabalaga \& J. Altuna). Munibe, 52, 183-185.

Peña-Chocarro, L., Zapata, L., Iriarte, M.J., González Morales, M. \& Straus, L.G. 2005. The oldest agriculture in northern Atlantic Spain: new evidence from El Mirón Cave (Ramales de la Visctoria, Cantabria). Journal of Archaeological Science, 32, 579-587.

Peyre, A. 1956. Ecologie et biogeographie du desman (Galemys pyrenaicus G.) dans les Pyrénées francaises. Mammalia, 20, 405-418.

Piertney, S.B., Stewart, W.A., Lambin, X., Telfer, S., Aars, J. \& Dallas, J.F. 2005. Phylogeographic structure and postglacial evolutionary history of water voles (Arvicola terrestris) in the United Kingdom. Molecular Ecology, 14, 1435-1444. 
Pokines, J.T. 1998. The Paleoecology of Lower Magdalenian Cantabrian Spain. Bar International Series, 713, 1-189.

Pokines, J.T. 2000. Microfaunal research design in the Cantabrian Spanish Paleolithic. Journal of Anthropological Research, 56, 95-112.

Rekovets, L. \& Nadachowski, A. 1995. Pleistocene Voles (Arvicolidae) of the Ukraine. Paleontologia $i$ evolució, 28-29, 145-245.

Repenning, C.A. 1968. Mandibular musculature and the origin of the subfamily Arvicolinae (Rodentia). Acta Zoologica Cracoviensia, 13, 29-72.

Rey, J. M. \& Landin, A. 1973. Sobre la presencia de Crocidura suaveolens en el sur de Andalucía (Mammalia, Insectivora). Boletín de la Real Sociedad Española Historia Natural (Biología), 71, 9-16.

Riquelme Cantal, J.A. \& Morales Muñiz, A. 1997. A Porcupine find from Roman Africa with a review of Archaeological data from circummediterranean sites. Archaeofauna, 6, 91-95.

Rofes, J. \& Cuenca-Bescós, G. 2006. First evidence of the Soricidae (Mammalia) Asoriculus gibberodon (Petényi, 1864 ) in the Pleistocene of North Iberia. Rivista Italiana di Paleontologia e Stratigrafia, 112, 301-315.

Ruiz, A. \& Camacho, I. 1973. Datos sobre la alimentación de Bubo bubo y determinación de micromamíferos en Sierra Nevada mediante egagrópilas. Cuadernos Ciencias Biológicas, 2, 57-61.

Ruiz Bustos, A. 1988. Presencia de caracteres mimomianos en Arvicola mosbachensis, Schmictgen, 1911, del yacimiento de Cúllar de Baza-I. Consideraciones sobre su origen. II Congreso Geológico de España. Comunicaciones, Granada, 1, 325-328.

Ruiz Bustos, A. 2000. Estudio paleoecológico de los sedimentos con presencia del hombre de neandertal en la cueva de la Carihuela (Piñar, Granada). In: Síntesis ambiental del Würm mediterráneo en la Cordillera Bética. Edita Ayuntamiento de Piñar, 1-91.

Ruiz Bustos, A. 2004. Micromamíferos y Bioestratigrafía. Laboratorio de Micromamíferos del Instituto Andaluz de Ciencias de la tierra CSIC- Universidad de Granada, 2, 1-141.

Ruiz Bustos, A. \& Sesé, C. 1985. Evolución de los géneros Mimomys, Arvicola y Allophaiomys (Arvicolidae, Rodentia, Mammalia) en el Plioceno y Pleistoceno de la Península Ibérica. Estudios geológicos, 41, 99-104.

Rzebik-Kowalska, B. 1994. Pliocene and Quaternary Insectivora (Mammalia) of Poland. Acta Zoologica Cracoviensa, 37, 77-136.

Rzebik-Kowalska, B. 1998. Fossil History of Shrews in Europe. In: Evolution of Shrews. Mammal Research Institute Polish Academy of Sciences (Eds. J.M. Wójcik \& M. Wolsan), 2, 23-92.

Sánchez Goñi, M. F. \& d'Errico, F. 2005. La historia de la vegetación y el clima del último ciclo climático (OIS5OIS1, 140.000-10.000 años BP) en la Península Ibérica y su posible impacto sobre los grupos paleolíticos. Museo y Centro de Investigación de Altamira Monografías, 20 , 115-129.
Sánchez Goñi, M.F., Turon, J.-L., Eynaud, F., Shackleton, N.J. \& Cayre, O. 2000. Direct land/sea correlation of the Eemian, and its comparison with the Holocene: a high - resolution palynological record of the Iberian margin. Geologie en Mijnbouw, 79, 345-354.

Sesé, C. 2005. Aportación de los micromamíferos al conocimiento paleoambiental del Pleistoceno Superior en la Región Cantábrica: Nuevos datos y síntesis. Museo y Centro de Investigación de Altamira Monografías, 20, 167-200.

Sesé, C. \& Sevilla, P. 1996. Los Micromamíferos del Cuaternario peninsular español: cronoestratigrafía e implicaciones bioestratigráficas. Revista Española de Paleontología, $n^{\circ}$ extraordinario, 278-287.

Sesé Benito, C. \& Soto Rodríguez, E. 1988. Los Micromamíferos (Rodentia, Insectivora y Lagomorpha) de la Cueva de Ambrosio (Almeria, Spain). In: La Cueva de Ambrosio (Almeria, España) y su posición cronoestratigráfica en el Mediterráneo Occidental (Ed. S. Ripoll López). BAR International Series, 462, 157-168.

Sevilla García, P. 1988. Estudio paleontológico de los Quirópteros del Cuaternario español. Paleontologia i Evolució, 22, 113-233.

Straus, L.G. 2005. A mosaic of change: the Middle-Upper Paleolithic transition as viewed from New Mexico and Iberia. Quaternary International, 37, 47-67.

Straus, L.G. \& González Morales, M. 2001a. El Mirón Cave 2001: Continuing Excavations by the Universities of Cantabria and New Mexico. Old World Archaeology Newsletter, 23 (2), 1-5.

Straus, L.G. \& González Morales, M. 2001b. The upper paleolithic in El Mirón Cave (Ramales, Cantabria, Spain). Le Paléolithique supérieur européen. Bilan quinquennal 2001-2006, Commission VIII. XVe Congrès UISPP, ERAUL, 97, 135-139.

Straus, L.G. \& González Morales, M. 2003. El Mirón Cave and the C14 Chronology of Cantabrian Spain. Radiocarbon, 45, 41-58.

Straus, L.G. \& González Morales, M. 2007. Further Radiocarbon dates for the Upper Paleolithic of El Mirón Cave (Ramales de la Victoria, Cantabria, Spain). Radiocarbon, 49, 1205-1214.

Straus, L.G., González Morales, M., Farrand, W.R. \& Hubbard, W.J. 2001. Sedimentological and Stratigraphic Observations in El Mirón, a Late Quaternary Cave Site in the Cantabrian Cordillera, Northern Spain. Geoarchaeology: An International Journal, 16, 603-630.

Straus, L.G., González Morales, M. \& Fano Martínez, M. A. 2006. The Upper Paleolithic record in the Asón River Basin, Eastern Cantabria (Spain. Research \& Publications, 2000-2005). Le Paléolithique supérieur européen. Bilan quinquennal 2001-2006, Commission VIII. XVe Congrès UISPP, ERAUL 115, 117-128.

Sutcliffe, A.J. \& Kowalski, K. 1976. Pleistocene Rodents of the British Isles. Bulletin of the British Museum (Natural History), Geology, 27, 1-147.

Tesakov, A. 1996. Evolution of bank voles (Clethrionomys, Arvicolinae) in the late Pliocene and early Pleistocene 
of Eastern Europe. Acta Zoologica Cracoviensia, 39, 541-547.

Uriarte Cantolla, A. 2003. Historia del Clima de la Tierra. Servicio Central de Publicaciones del Gobierno Vasco, Vitoria-Gasteiz, 1-306.

Vargas, J.M. \& Palomo, L.J. 1990. Selección de la lechuza común (Tyto alba) sobre el topillo común (Microtus duodecimcostatus). Doñana, Acta Vertebrata, 17, 223-229.

Ventura, J. \& Sans-Fuentes, M.A. 1997. Geographic variation and divergence in nonmetric cranial traits of Arvicola (Mammalia, Rodentia) in southwestern Europe. Zeitschrift für Säugetierkunde, 62, 99-107.

Ventura, J., López-Fuster, M.J. \& Gosàlbez, J. 1993. A morphometric analysis of cranial variation in the bank vole, Clethrionomys glareolus (Schreber, 1780) (Rodentia, Arvicolidae) from the Iberian Peninsula. Zoologischer Anzeiger, 231, 183-193.

Villalta, J. F. 1972. Presencia de la Marmota y otros elemen- tos de la fauna esteparia en el Pleistoceno catalán. Acta Geológica Hispánica, 7, 170-173.

Wilson, D.E. \& Reeder, D. M. (eds.) 2005. Mammal Species of the World. A Taxonomic and Geographic Reference. Johns Hopkins University Press, Third Ed., Baltimore, Maryland, 2, 1-142.

Zabala, J. 1983. Primera cita de Arvicola sapidus (Miller 1908, Mammalia, Rodentia) para la provincia de Guipúzcoa. Munibe, 35, 109-114.

Zubeldia Garmendia, H. 2006. Goi Pleistozenoko-Behe Holozenoko Antoliñako Koba aztarnategiaren mikroornodunen ikerketa (Arteaga, Bizkaia). Arkeztutako Tesis de Licenciatura, Universidad del País Vasco, Leioa, 1-130 (inédita).
Manuscrito recibido: 8 de Mayo, 2007 Manuscrito aceptado: 4 de Marzo, 2008 


\section{REVISTA ESPAÑOLA DE PALEONTOLOGÍA}

\section{NÚMERO EXTRAORDINARIO X}

(XIX Jornadas de Paleontología, Morella, 16-18 de octubre de 2003)

J. V. SANTAFÉ LLOPIS. Presentación

J. L. SANZ. Aproximación histórica al género Iguanodon. [Historical approach at genus Iguanodon.].

X. PEREDA SUBERBIOLA \& J.I. RUIZ-OMEÑACA. Los primeros descubrimientos de dinosaurios en España. [The first dinosaur discoveries in Spain.]

J.M. GASULLA ASENSIO. Los dinosaurios de Morella (Castellón, España): historia de su investigacion. [The dinosaurs of Morella (Castellón, Spain): History of their investigation.]

O. FERRER \& J. M. DE GIBERT. Presencia de Teredolites en la Formación Arcillas de Morella (Cretácico Inferior, Castellón). [Presence of Teredolites in the Morella Mudstone Formation (Lower Cretaceous, Castellón).]

A.M. BRAVO, B. VILA, A. GALOBART \& O. OMS. Restos de huevos de dinosaurio en el Cretácico Superior del sinclina de Vallcebre (Berguedà, provincia de Barcelona). [Dinosaur egg remains from the Upper Cretaceous of Vallcebre Syncline (Berguedà, Barcelona Province).]

J.L. BARCO, J. I. CANUDO, J. I. RUIZ-OMEÑACA \& J.L. RUBIO. Evidencia icnológica de un dinosaurio terópodo gigante en el Berriasiense (Cretácico Inferior) de Laurasia (Las Villasecas, Soria, España). [Ichnological evidence of a giant theropod dinosaur in Berriasian (Lower Cretaceous) of Laurasia (Las Villasecas, Soria, Spain).].

F. TORCIDA FERNÁNDEZ-BALDOR, J.I. RUIZ-OMEÑACA, L.A. IZQUIERDO MONTERO, D. MONTERO HUERTA, G. PÉREZ MARTÍNEZ, P. HUERTA HURTADO \& V. URIÉN MONTERO. Dientes de un enigmático dinosaurio ornitópodos en el Cretácico Inferior de Burgos (España). [Enigmatic ornithopod teeth from the Lower Cretaceous of Burgos (Spain).]

C. FUENTES VIDARTE, M. MEIJIDE CALVO, F. MEIJIDE FUENTES \& M. MEIJIDE FUENTES. Fauna de vertebrados del Cretácico Inferior del Yacimiento de "Zorralbo" en Golmayo (Soria, España). [Vertebrate fauna (Lower Cretaceous) of the site "Zorralbo" a Golmayo (Soria, Spain).]

M. SUÑER, C. DE SANTISTEBAN \& A. GALOBART. Nuevos restos de Theropoda del Jurásico Superior - Cretácico Inferior de la Comarca de los Serranos (Valencia). [ New Upper Jurassic - Lower Cretaceous Theropoda remains from 'Los Serranos' region (Valencia).]

F.J. RUIZ-SÁNCHEZ, C. DE SANTISTEBAN \& J.I. LACOMBA. Cazuma 1, nueva localidad de micromamíferos (Mammalia, Rodentia) del Aragoniense Superior en la cuenca de Quesa - Bicrop (prov. Valencia). [Cazuma 1, new micromammal locality (Mammalia, Rodentia) of Late Aragonian of the Quesa - Bicorp basin (Valencia, Spain).].

M.A. SALINAS JAQUES. Las hipótesis de Eduardo Boscá sobre la alimentación del megaterio y el montaje del ejemplar de la Colección Rodrigo Botet (1902-1928). [The Eduardo Bosca's hypothesis about the megatherium's feeding and the assembly of the Rodrigo Botet Collection's specimen (1902-1928).].

F.J. RUIZ-SÁNCHEZ. La legislación de medio ambiente y la protección del patrimonio paleontológico en la Comunidad Valenciana (España). [The environmental legislation and paleontological heritage protection in the Valencian Community (Spain).] 
Apellidos

Last name

Título/Title

(dirección/address)

C.P.

Zip Code

Ciudad

City/State
País

Country

(temas; edades; área geográfica / fields; ages; geographic area

Solicita ser admitido en la Sociedad Española de Paleontología como:

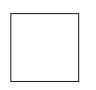

Socio ordinario
Ordinary membership

Socio estudiante (menores de 27 años)

Student membership (under 27 years old)

Cuota 2008
2008 Dues $\{50$ euros

Cuota 2008
2008 Dues $\left\{\begin{array}{l}20 \text { euros } \\ \text {. }\end{array}\right.$

Fecha de nacimiento

Birth date

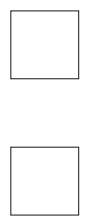

Socio corporativo

Cuota 2008

Institutional membership

2008 Dues

Nombre

First name

Tlfno: :

\section{(nombre del Centro / Institution name)}

Presentado por/Presented by

(dos socios/two members)

Certificación de la condición de estudiante (sólo para socios estudiantes)

Certification of student status (for student members only)

Certifico que el solicitante es

estudiante/doctorando en el

Dpto. de

de la

(institución)
I certify that the above-named is a full-time undergraduate/postgraduate student in the

Dept. of

at

Fecha y firma/Date and signature

(nombre y título / full name and title)

Enviar una copia a: Send a copy to:
Secretaría de la Sociedad Española de Paleontología

Museo Nacional de Ciencias Naturales

C/. José Gutiérrez Abascal, 2

E-28006 MADRID

ESPAÑA/SPAIN 